\title{
Participatory planning for local sustainability guided by the Sustainable Development Goals
}

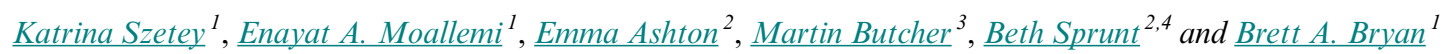

\begin{abstract}
To achieve the United Nations Sustainable Development Goals (SDGs), actions are required at all global, national, and local scales. To ensure coordination between scales, local actions need to be carefully planned to be aligned with global and national priorities. Local planning for sustainability must be adaptive and heterogeneous but also consistent and driven by the community. We describe an approach to co-create a local sustainability plan using the SDGs for a rural community in southeastern Australia using participatory techniques for co-creation, data collection, and review. The community placed a high priority on infrastructure for achieving sustainable growth and social equity while preserving their unique environment. By articulating their priorities in this community-led plan, the community is empowered to advocate for the sustainable development of their town with decision makers and funding bodies. If local communities create sustainability plans using the SDGs, then such planning will be consistent between and across geographic scales, and aligned with the global goals. This will also aid in achievement of the SDGs at national and global scales, as advocated by the United Nations in the 2030 Agenda for Sustainable Development.
\end{abstract}

Key Words: community; local; participatory; planning; sustainability; Sustainable Development Goals

\section{INTRODUCTION}

As the world adapts to the climate and COVID-19 crises, longterm, adaptive, and inclusive planning to achieve ambitious goals for humanity's future is vital (Walker et al. 2020). Sustainable development and plans for how to achieve it is needed worldwide and across all types of settlements in order to meet the challenges of climate change and other uncertain futures (United Nations 2015). Sustainability planning entails not only the principles of sustainable development, that is, ensuring that humanity's present use of resources does not compromise the requirements of future generations (World Commission on Environment and Development 1987), but must also take into account local contexts and their intersection with the pillars of sustainability, i.e., society, economy, and environment (Hallström et al. 2017). Sustainability planning in local contexts requires an integrated approach that connects place making, community building, and downscaled sustainability priorities (Frank and Reiss 2014). The United Nations Sustainable Development Goals (SDGs) are an ambitious global agenda for sustainability that has been adopted by all UN member states, and the UN have advocated for both government-led and community-led, i.e., local, implementation (United Nations 2015). The SDGs offer a foundation upon which sustainability plans can be built.

Sustainability planning at the local scale requires participation from the community, driven by the community (what is known as a bottom-up approach) to increase the chances of a successful outcome (Brody et al. 2003, Burby 2003, Bagheri and Hjorth 2007 , Mistry et al. 2016, Hallström et al. 2019, Moallemi et al. 2021). There are two main reasons for this requirement: first, only local actors possess the intimate connection to place and local knowledge needed to develop place-based solutions (Manzo and Perkins 2006); and second, local areas have been subjected to repeated transitions in governance and economies, over many years and often imposed from above, and this has engendered a skepticism in populations of top-down planning and change (Frank and Reiss 2014). This second issue is part of the backlash against top-down planning that occurred as a result of the sidelining of local knowledge and actors, and because of the greater impact of local planning (Morrison et al. 2015).

Another multifaceted issue is a lack of consistency in planning approaches for local sustainability. Morrison (2006) expressed that this may be due to a haphazard integration of sustainability into local planning during its early phases. In their search for a theory of rural planning (a subset of local planning), Hibbard and Frank (2019) suggested that the purpose of rural planning is guided by the relationship between the rural and the rest of society, a relationship that has become ambiguous over the last 70 years. This ambiguity has led to an inconsistency in planning approaches in rural areas, however it is not limited to the rural. McLean and Borén (2015) discussed how the concept of policy transfer, where policies and knowledge are shared across scales (i.e., from state to local) in both rural and urban areas, becomes policy immobility at the local scale as sharing no longer occurs between different local areas. If knowledge transfer does not occur between jurisdictions at the local scale, then consistency cannot be achieved. Power imbalances between levels of government can also inhibit progress. Within an Australian context, local government (already much less powerful than its international equivalents) can be perceived as a political threat at higher levels of government so there is less incentive to be consistent (Henderson 2019).

Čiegis and Gineitiené (2008) described their experiences of participatory strategic sustainable development planning in the newly independent nation of Lithuania using the principles of Local Agenda 21 (Coenen 2009). They found that a bottom-up planning approach was more successful because development strategies prior to this had been prepared by non-local experts

${ }^{1}$ Centre for Integrative Ecology, School of Life and Environmental Sciences, Deakin University, Melbourne, Australia, ${ }^{2}$ Forrest Gateway Project, Forrest, Victoria, Australia, ${ }^{3}$ Forest, Fire and Regions, Department of Environment, Land, Water and Planning, Geelong, Victoria, Australia, ${ }^{4}$ Nossal Institute for Global Health, University of Melbourne, Melbourne, Australia 
and were impossible to implement because they had lacked understanding of the local context. Their method was applied to eight diverse local communities, urban and rural, and they listed the importance of the direct involvement of the community among their conclusions. They also noted the need for a flexible but consistent planning process. An opportunity exists to build on the work of Čiegis and Gineitiené (2008) and advance local sustainability planning using the SDGs. We propose an approach for co-developing local sustainability plans using the SDGs, which will ensure consistency between local communities and across different spatial scales, e.g., local, national, global. A full implementation of the SDGs is likely not appropriate at the local scale, so the SDGs should be localized to maintain local diversity and sense of place (Moallemi et al. 2019, 2020). ElMassah and Mohieldin (2020) found that when SDGs are localized, governance is more robust and provides a more realistic way to achieve the SDGs, because localization incorporates the advantages of centralization, i.e., national strategies, and decentralization, i.e., local strategies. They also conclude that localization distributes ownership of the SDGs across all levels of society, providing a more inclusive outcome. One study developed a rural revitalization strategy guided by the SDGs, and also identified the research gap in using participatory methods for SDG planning at the local scale (Diaz-Sarachaga 2020). Localization of the SDGs involves identifying locally relevant sustainability ambitions through the use of participatory methods (Szetey et al. 2021) and aligns the needs of local actors with national and global priorities (Moallemi et al. 2020). Using the SDGs to guide sustainability planning at the local scale will facilitate the consistency that we identified as lacking, and using participatory processes to localize them ensures the bottom-up, community-driven approach that is necessary for success.

Here we present an approach for co-creating a local community sustainability plan framed by localized SDGs using participatory methods applied to a case study of the township of Forrest in southwestern Victoria, Australia. We collected data on the sustainability ambitions of a local community using a range of participatory techniques. We used this information along with a synthesis of several previous community engagements to develop tailored community goals mapped to SDG targets. We engaged with the community for review and validation of the plan, and co-developed local priorities based upon their ability to achieve the community goals. Local planning guided by the SDGs affords a foundation that is consistent across scales, allowing for the alignment of sustainability policy and outcomes at different levels.

\section{METHODS}

\section{Background}

\section{Study area and context}

Our case study community of Forrest is located in Victoria, Australia (Fig. 1). It lies within a region of temperate rain forest that has been part of a National Park since 2005, and prior to that was heavily logged for timber. Logging was prohibited in 2008 and concurrently there was a decline of agricultural industries. Since around 2010, tourism and tourism-supporting activities have become dominant in its economy, giving it a designation of a community-in-transition (Morzillo et al. 2015). The local environment is at risk of wildfire impact and vulnerable to the effects of climate change. Community members in Forrest are concerned about their future in the face of climate change and are highly engaged with their town's development. The Eastern Maar are the Traditional Owners of south-western Victoria and custodians of the land.

Fig. 1. Location map of the case study area (Forrest).

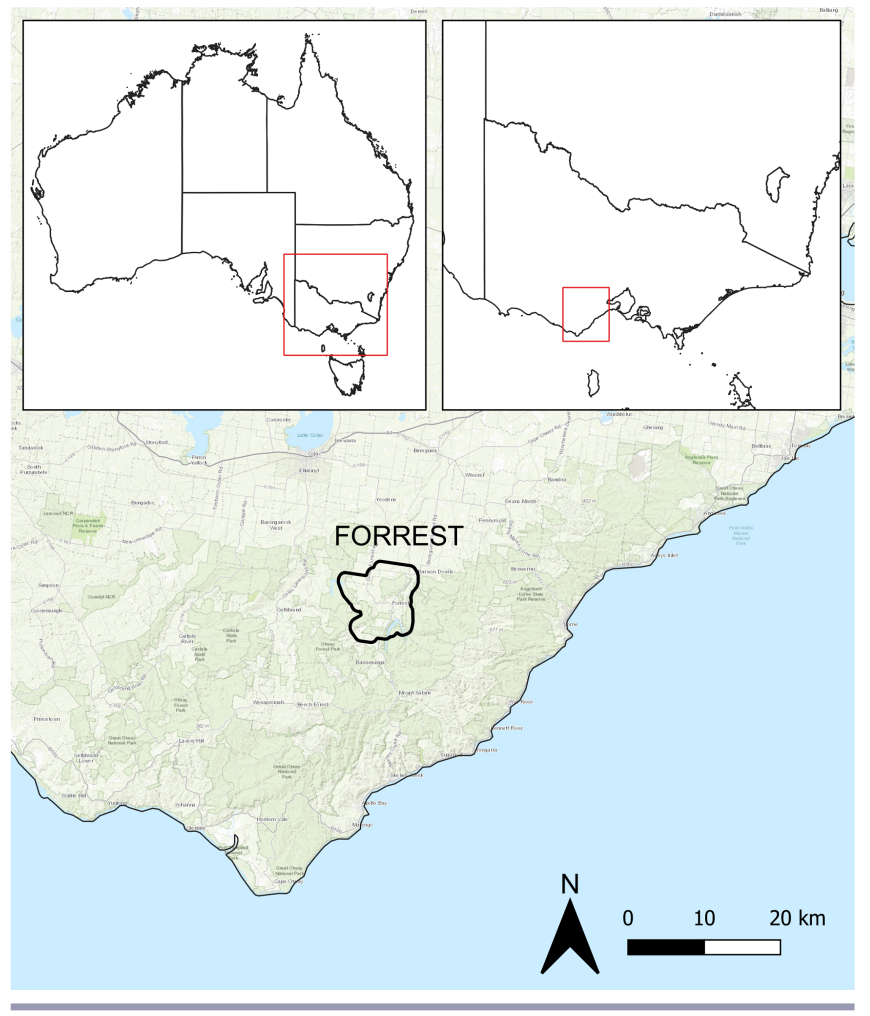

The population of Forrest and the local surrounding district is approximately 470 people. Forrest is a desirable location to live and there has been significant increase in housing prices caused in part by pressure on the housing supply: the infrastructure to support housing development does not exist (e.g., adequate wastewater facilities), while at the same time a repurposing of residential housing for use as tourism accommodation is taking place. Thus, housing supply is constraining the growth of the local population.

Although we have described the study area as the township of Forrest, the plan is called The Forrest and District Plan (Szetey et al. 2020), and was written to include the neighboring district townships of Gerangamete, Barwon Downs, and Barramunga. This is because Forrest is a central hub of the district, where most of the local services exist, e.g., the post office, local general store, hospitality venues, and various social and community groups. The future of Forrest's services will have a significant impact on the district townships.

The local Council of the region in which Forrest is located, ColacOtway Shire, traditionally engages consultants to write strategic plans for townships. The Forrest and District Community Group consulted with Colac-Otway Shire and were granted permission to develop a community plan independently, which would then 
be endorsed by Council. The Forrest and District Community Group is a volunteer group of six local residents (three women, three men) who promote the community and administer community-driven initiatives. The group comprises local business owners, health workers, and other professionals. The Forrest and District Community Group intended to use extensive community engagement data collected between 2015 and 2020 to develop the content of the plan, and co-wrote the plan with university researchers already performing research in Forrest.

\section{Planning approach}

Emerging wisdom in sustainability planning suggests a process approach is preferable to a fixed-goal approach, that is, using a vision to guide outcomes rather than optimizing to achieve a set of fixed goals (Bagheri and Hjorth 2007, Hallström et al. 2019). The goal-based approach seeks to predict the future to prepare for potential change, whereas the process-based approach can learn and adapt, and thus manage uncertainty more effectively (Bagheri and Hjorth 2007). Here we followed a four-step process with two-way information flow (learning) between the community and researchers at each step, and significant iterative revision (adaptation) occurring at step 4 (Fig. 2):

\section{Localizing SDGs}

2. Data synthesis

3. Analyzing possible futures

4. Community engagement, objectives, and validation

Fig. 2. The process of plan development. The diagram should be read from the bottom up, implying that the Sustainable Development Goals (SDGs) are at the root of the process; the step "Analyze possible futures" is in the branches of the tree, representing the different futures that may emerge; the engagement and revision steps are in the canopy of the tree, where iteration occurs. The arrows indicate information flow, the black text represents the stages in the process, and the brown text are inputs and outputs.

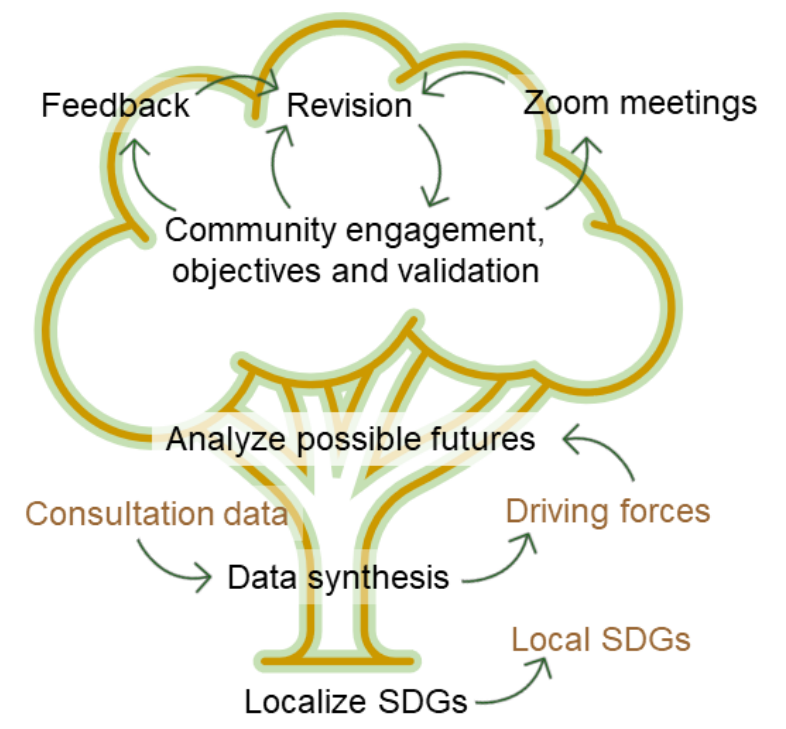

These steps will be described in detail in the next section of the manuscript.

We used the principles of community-based participatory research, in which the community is actively involved in research intended to facilitate change (Israel et al. 2001, Shalowitz et al. 2009), being that it (1) is participatory; (2) is cooperative, with a collaborative and equitable partnership between researchers and community; (3) is a co-learning process with a shared exchange of knowledge; (4) builds on the strengths of the community; (5) empowers all participants with equal knowledge dissemination; (6) intends that there will be action based on research outcomes; (7) identifies the community as an entity rather than a location; and (8) is a long-term commitment by all participants. Community-based participatory research is appropriate for sustainability applications at the local level (Cutts et al. 2020), and is suitable for the shift to online participatory methods necessitated by the COVID-19 pandemic (Valdez and Gubrium 2020). Alongside these principles, we also characterized the community participation at the levels of consultation, discussion, and co-design on the modified ladder of participation developed by Basco-Carrera et al. (2017), based on Arnstein's (1969) original work. We designed our participatory activities with all of this in mind; additionally, the plan was co-written with two members of the community as authors and other members who were consulted heavily.

Once the first draft of the plan was complete, the fourth stage was to subject it to two rounds of community and one round of noncommunity stakeholder review (Fig. 2). At the end of each of these rounds, we revised the plan based on reviewer comments. The community review served to validate the contents of the plan and ensured that it was an accurate representation of the community's aspirations. The first draft took two months to complete, the revision was completed six weeks after the first review period closed, and each round of community comment was open for two weeks. The final published version incorporating non-community stakeholder review was released six months after the commencement of the project.

\section{Plan development}

Localizing SDGS

We undertook community engagement activities to localize the SDGs, i.e., identify the locally relevant SDGs, in Forrest using multiple techniques. The community members were, in general, not familiar with the SDGs before our engagement activities. They were, however, concerned about the development of Forrest viewed with environmental, economic, and social lenses, especially in the light of climate change. From this we concluded they would be receptive to the concepts of sustainable development.

The first engagement activity was a Listening Post (Szetey et al. 2021), where we set up a table outside the township general store at times of high traffic, and polled local residents on which SDGs they believed were most important for the future of Forrest. This activity was open to any person who wished to participate, and there were 55 responses to the poll. The second activity was a facilitated Kitchen Table Discussion (van Hees et al. 2020, Szetey et al. 2021) with representative members of the community, covering topics such as what the participants liked about Forrest 
and why they remained there, and what challenges and threats Forrest faced. At the conclusion of the discussion, the attendees jointly ranked the SDGs. The facilitator motivated the ranking by asking participants, primed from the earlier discussion, to prioritize what was most important for Forrest. The eight participants were selected by a community-based collaborator to represent different stakeholder groups within the community, and included a school administrator, a local tourism business owner, a government employee, and a farmer, among others.

To support these participatory activities, we performed a contextual analysis of locally relevant documents (including many of the consultation processes that form the basis of the plan). This contextual analysis was a comprehensive desktop review of 19 locally relevant documents identified through a snowball process with guidance from local stakeholders, from which we ascertained the priorities of the community, and developed a shortlist of locally important SDGs (Szetey et al. 2021). From these three activities, we had three independently sourced shortlists of SDGs that we combined into one final list of locally relevant SDGs for Forrest. These local SDGs were the following: 3 - Good Health and Well-being; 6 - Clean Water and Sanitation; 8 - Decent Work and Economic Growth; 11 Sustainable Cities and Communities; 13 - Climate Action; and 15 - Life on Land. These community engagement activities and the contextual analysis are described in detail in Szetey et al. (2021) as they formed the basis of an earlier phase of our research. A decision was made to consolidate the local SDGs and rename them to be more specific to Forrest for the purposes of the plan; however the community goals as defined in the plan can be considered to be synonymous with these local SDGs. We mapped these community goals to specific SDG targets.

\section{Data synthesis}

In the period from 2015 to 2020 , the community engaged in at least seven different consultation processes for various community projects. These included new wastewater infrastructure; mountain bike trail redevelopment; redevelopment of a parcel of land known as the Forrest Common; a process for the community to take ownership of unused government land; and the SDG localization project from which this research emerged (see Szetey et al. 2021). A considerable amount of qualitative data were generated from these engagement activities about the goals and aspirations of the community for their future. We identified major themes from this data from qualitative analysis; the method for identifying these themes was a simple categorization based on close reading and familiarization with the data.

Additional data beyond the community engagement results were collated to understand the local context: historical, demographic, topographic, and ecological. This data was found, for example, by searching the Australian Bureau of Statistics census data for the community (Australian Bureau of Statistics 2017).

\section{Analyzing possible futures}

In synthesizing the community engagement data, we identified a list of driving forces that were likely to have significant influence on the future development of the community. We analyzed the current status of these driving forces in Forrest based on information collected through the community engagement activities described here and additional activities as described in
Szetey et al. (2021), and through the contextual analysis. We analyzed this by noting the trend of that driving force, i.e., the expected behavior into the future based on its current trajectory, and potential opportunities and challenges for Forrest in respect of that trend (Table A1.1). We then synthesized that information into a paragraph for each driving force. The complete list of driving forces is described in the results, however we present here one example of a driving force and the influences which we had to consider: housing availability and affordability was one driving force which limits population and economic growth, but new housing cannot be built without wastewater infrastructure improvements, and current land-use zoning limits new housing development on land zoned as agricultural within the township. We identified the local SDGs and SDG targets each driving force was associated with (Table A1.3).

\section{Community engagement, objectives, and validation}

When the first draft of the plan was complete, we released it to the community to provide feedback and comment. The plan was uploaded to the community's website and publicized through social media and posters in the Forrest general store. Printed copies were also available in the general store for those without access to the internet. At the conclusion of the comment period, we conducted two separate facilitated community videoconference sessions for people to ask questions and participate in a discussion about community infrastructure with a representative from Colac Otway Shire. These sessions were conducted via videoconference because they occurred during the local lockdown period of the COVID-19 pandemic in 2020. Efforts were made to engage those without internet access or sufficient technical understanding by using a "buddy" system to pair up technologically confident people with those who were less confident. During the sessions, we presented a short video describing the five community goals (Online Resource 1), and then a list of collated community improvement ideas for people to discuss. We made use of the "breakout room" function in the videoconference platform to have meeting attendees discuss the information we presented in randomly allocated groups of three or four people, much as they would be able to in an in-person meeting, and then they could ask questions when they returned to the full meeting. Each breakout session lasted for five minutes, and there were two breakouts over the course of the one-hour meeting (see Appendix 2 for meeting agenda). Attendance at the videoconference meetings was open to all in the community. The meetings were facilitated by a noncommunity member who had been involved in multiple prior community engagements in Forrest, and was trusted by the community.

From these community meetings, and from feedback received on the draft plan, we compiled a list of community objectives suggested by residents for improvements in Forrest. These ranged from public art and signage upgrades through to an integrated water management plan. We included every suggestion received in the plan because they were all valuable ideas. Each objective was aligned with up to five community goals by categorizing the objective with the goal(s) it would help with achieving. We did not consult with the wider community about this alignment (although they had opportunities to comment during the second review) but rather discussed within the author and consultant group, which consisted principally of community members. Of this list, nine priorities were selected that would permit the 
Fig. 3. Mapping Sustainable Development Goals (SDGs) to community goals and driving forces. See Appendix 1 for mapping to SDG targets.

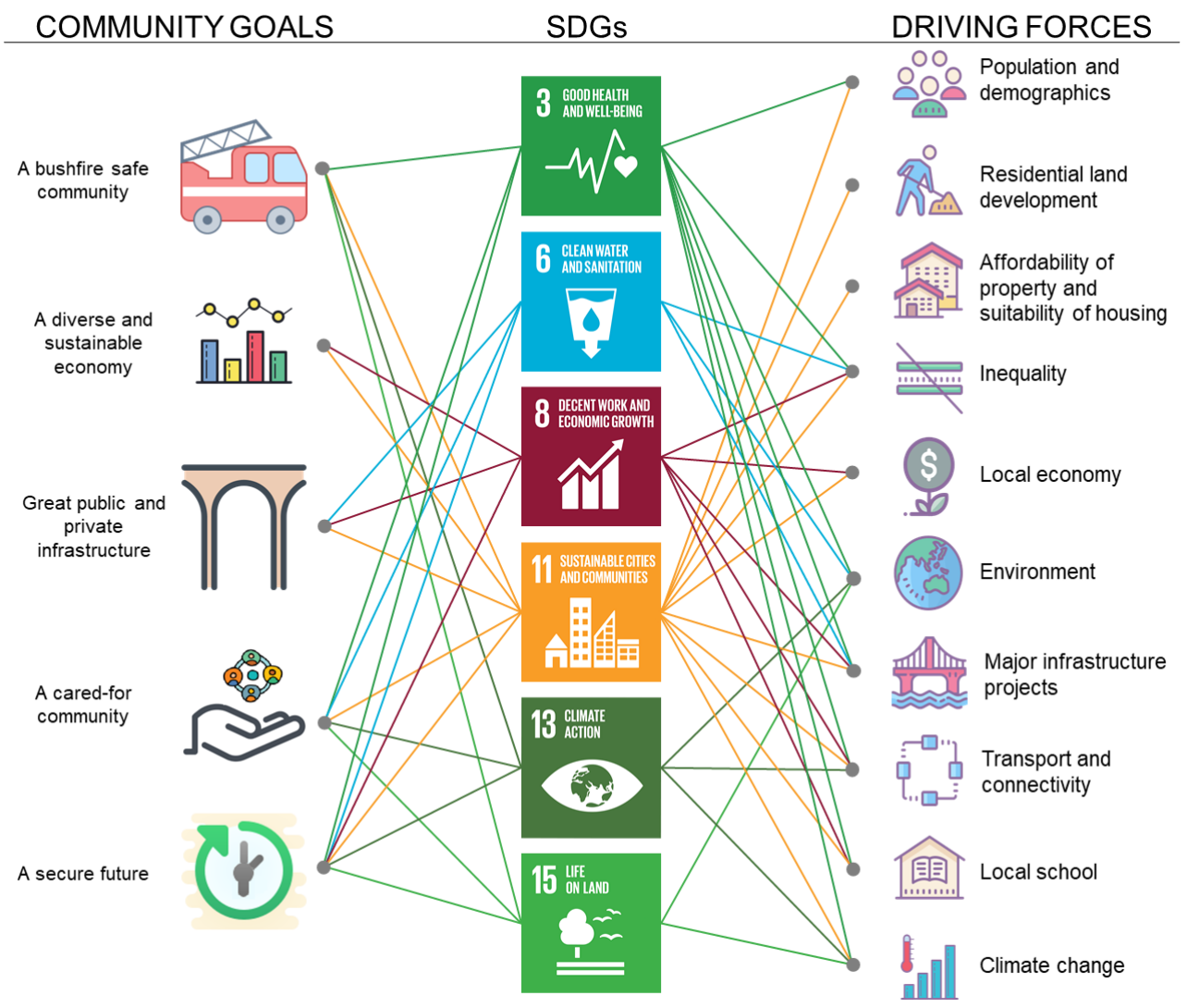

community to develop sustainably. These priorities were selected based on the relative urgency of the driving forces identified above and the number of community goals each would help achieve, with consideration given to projects already in progress and potential for synergistic effects with other objectives.

Once we had received all the community feedback on the first draft of the plan, we revised the plan. This completed draft then went through a second round of community comment, with the same revision process. At the conclusion of community review, the document was sent to government and agency stakeholders (for example, local and state government, the local water authority, and the philanthropic organization which funded the research project). Minor revisions were made at this point and the final plan was launched in October 2020.

\section{RESULTS}

\section{Localizing SDGs}

The local SDGs identified from community engagement activities form the foundation of the plan. To enhance the relevance of the local SDGs and facilitate community understanding, we consolidated the six local SDGs into five community goals that are more representative of local circumstances (Fig. 3), and then mapped these community goals to SDG targets. For example, "A bushfire safe community" is mapped to SDG 3 Good Health and
Well-being to meet target 3.9 regarding air and water pollution; to SDG 11 Sustainable Cities and Communities to meet targets 11.4 regarding protecting natural heritage, and 11.5 regarding reducing deaths, people affected, and loss from disasters; to SDG 13 Climate Action to meet target 13.1 regarding resilience against climate-related disasters; and to SDG 15 Life on Land to meet targets 15.1 regarding conservation of inland freshwater ecosystems, and 15.5 regarding action to reduce degradation of natural habitats and prevent extinction of threatened species. The complete mapping of SDG targets to community goals is in the appendices (Table A1.2).

\section{Data synthesis}

We identified six major themes within the community engagement data, which encompass the SDGs that had previously been selected (Appendix 3:36-37). These were the six themes:

- Nature: beautiful landscapes; Otways and Great Ocean Road; connection to country

- Community: supportive and connected; small-town charm; includes young and old

- Infrastructure: inadequate wastewater system; mountain bike trail development; key assets reflect town character

- Recreation: tourism, mountain biking, sport, camping, horse-riding, arts; infrastructure 
Fig. 4. The infographic used to promote the plan and community review.

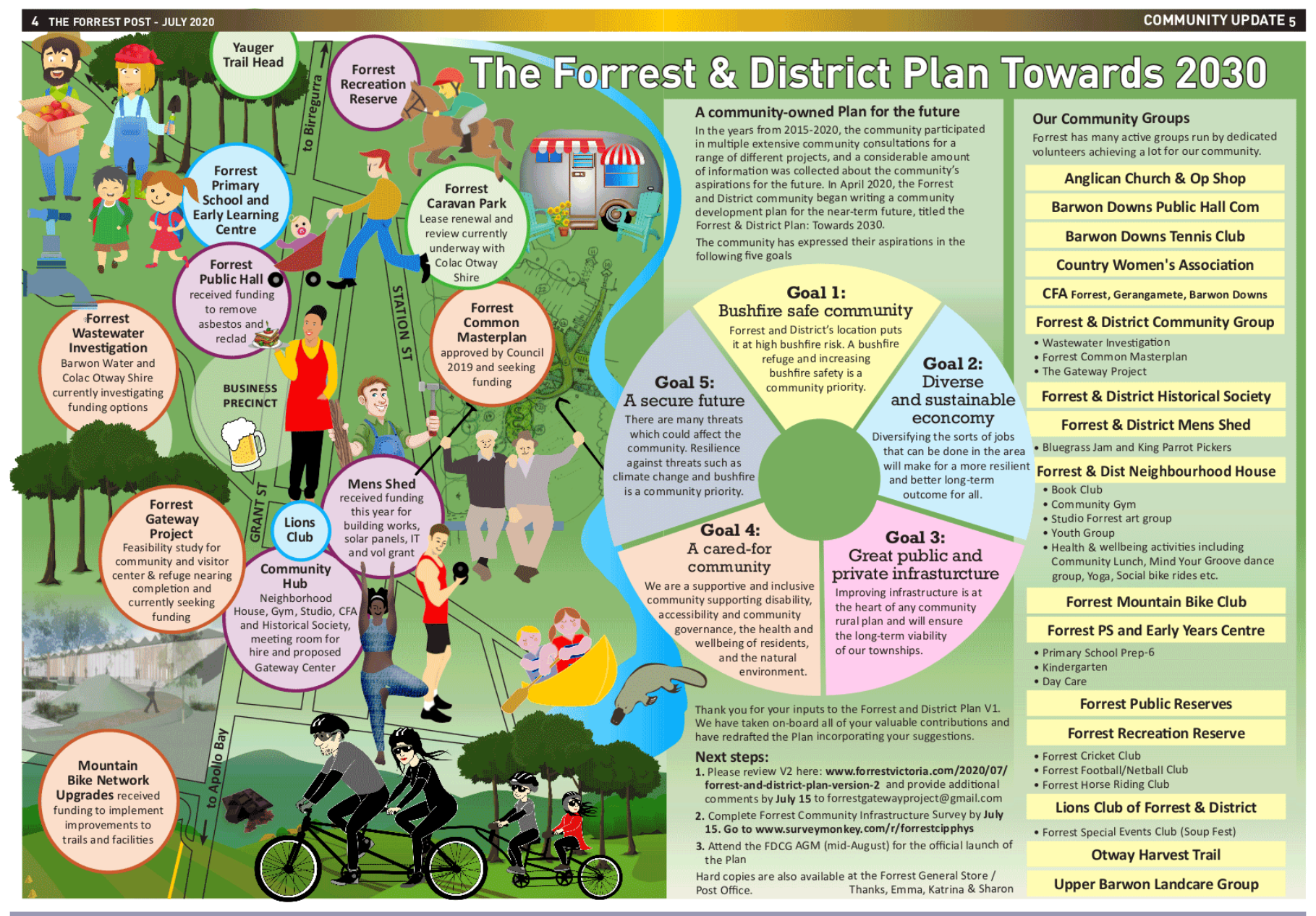

- Challenges: bushfire vulnerable; climate change; agricultural adaptation

- The Future: sustainability aspirations; food systems and sharing; energy independence

We also identified the community strengths, such as being a community hub for the surrounding townships; access to a pristine local environment; proximity to the coast and a national park; and the local learning and childcare center.

\section{Analyzing possible futures}

The driving forces that we identified were population and demographics; residential land development; affordability of property and suitability of housing; inequality; local economy; environment; major infrastructure projects; transport and connectivity; local school; and climate change (Appendix 3:50-54). Each of these driving forces was associated with the local SDGs (Fig. 3) and mapped to the SDG targets (Table A1.3). Here is an example of the potential futures which we described, with respect to climate change:

Encroaching sea level rise is already affecting communities along the Great Ocean Road, with landslips creating dangerous road conditions and impacting coastal properties. This could have positive or negative effects on visitor numbers to Forrest: dangerous and unsightly conditions may drive people away from the region, or encourage them to visit areas further inland. Decreasing amenity along the Great Ocean Road could also push residents to move further inland, potentially into Forrest and District. This, coupled with the increasing cost of farmland as agriculture shifts south, away from drying and drought-affected northern Victoria, could make living in Forrest and District even less affordable than it currently is.

\section{Community engagement, objectives, and validation}

We promoted the plan and request for community review in the local newspaper, The Forrest Post, and we engaged a local graphic designer to develop an infographic to communicate the main points to the community (Fig. 4).

There were 16 responses to the first version of the draft plan. One criticism received was the absence of information on the local Indigenous people of the region from before European colonization, so we invited the regional Indigenous corporation to provide those voices. The second version of the draft plan received 13 responses, including from an Indigenous representative. In the 
videoconference meetings, we had 10 attendees at the first session, and eight attendees at the second session.

The feedback received fell into three main categories: suggestions for community improvements, which we added to the list of community objectives; omissions or corrections, for example, missing community groups or incorrect dates; and recommendations for content reframing, such as emphasizing the healthy environment away from a tourism context. In general, the feedback suggested a greater emphasis on the sustainability dimensions of society and environment over economy, more discussion of diversifying the economy beyond tourism, and a desire for a stronger community voice. These suggestions reflected the community goals and the driving forces as the economy was only one of many aspects of the community's ambitions, with its diversification being specifically identified (Fig. 3). Alongside this, only one of the nine priorities has a tourism, i.e., economy, focus: the Mountain Bike Trails Design Project. The remaining seven priorities share both social and environmental focuses. The complete list of feedback received is contained in the appendices (Table A4.1). The complete list of community objectives (Appendix 3:48-49, Table A5.1) and the nine community priorities (Appendix 3:7, Appendix 5) are contained in the appendices.

There was one final review of the plan by non-resident stakeholders, including local government, the local water authority, and the research funding body. The only substantive feedback we received was from the local water authority concerning the representation of the local wastewater project, and a contentious environmental issue caused by groundwater extraction. Their comments and our response can be found in the appendices (Appendix 4). The final published plan document, which was designed with the assistance of a local graphic designer, is available in the appendices (Appendix 3).

\section{DISCUSSION}

\section{Participatory planning for local sustainability}

We have presented our work with the community in Forrest and District to co-create a local community plan based upon the SDGs. We identified the local SDGs for the community using participatory techniques, and consolidated them to form five community-specific goals (Fig. 3). These five goals formed the backbone of the final priorities of the plan. Drafts of the plan were sent twice for community evaluation and validation, and the plan was revised to take into account feedback received. We also conducted two facilitated discussions via videoconference so that community members could ask questions and submit further ideas for inclusion in the plan. We found that the community were concerned about their future opportunities for growth of their town while their infrastructure remained insufficient for their current needs, and were glad to have an opportunity to articulate their ambitions for the future independently of the organizations who were key to providing funding for their needed infrastructure. The list of nine priorities (Appendix 3:7, Appendix 5) set forth an agenda and empowered the community to negotiate with decision makers about projects and improvements for their town. Although this plan is not currently legally binding, it is the community's intention to submit the Forrest and District Plan for endorsement to the local government (Colac Otway Shire) as their formal plan. Beyond this, having a formal document with carefully articulated goals and priorities gives the community a strong foundation to advocate for community building, particularly in respect of funding from bodies separate to local government.

We wrote this plan with the local SDGs at the base of our planning process, and all the community objectives and priorities that emerged from our data synthesis and analysis of the possible futures were aligned with the community goals (and thus the local SDGs). This gave the plan a foundation in sustainability, with continual reference back to the community goals. Our process required genuine engagement, contribution, and repeated evaluation by the community, ensuring the final plan was a collaboratively written and validated document. Additionally, as Hallström et al. (2019) state, sustainability planning by its very nature needs to be adaptive and participatory to be achievable, so we sought to meet both those requirements with our process. We believe that our work, based upon the principles of community-based participatory research, fostered a collaborative exchange of knowledge: the community provided us with information about their desires and ambitions for Forrest, while we used that information and categorized it, aligned it with goals, and shared that back with the community. Further, we prioritized actions that will enable Forrest to achieve those goals and ambitions and become a more sustainable community. Working through this process of planning with the community has, in return, afforded the researchers a deeper understanding of the needs and requirements of the community, which will better inform future research. This final point is a fulfillment of another of the principles of community-based participatory research: the co-learning process with an equal exchange of knowledge in both directions.

\section{Why localization is important}

The local scale requires a different approach to planning because local areas are much less homogenized and encompass greater diversity across a smaller population compared to national or global scales (Moallemi et al. 2020). Using localized SDGs provides a way to manifest that diversity while at the same time remaining aligned to a common sustainability agenda. Additionally, planning for local sustainability using the SDGs contributes to global SDG achievement: Sterling et al. (2020) explored how place-based planning to achieve the SDGs aligns with global transformation, and our work also aims to realize this. Empowering local communities to take ownership of their local sustainability priorities has the dual outcomes of facilitating local sustainability achievement, and aiding achievement at larger scales. For example, local community renewable energy projects contribute to reducing state or national carbon emissions. A widespread application of this approach of using the SDGs to guide local sustainability planning would lead to consistent and therefore comparable planning and outcomes at the local scale. Empowering communities to advocate for their own progress is itself an achievement of SDG 16, Target 7: "Ensure responsive, inclusive, participatory and representative decision-making at all levels."

\section{Implications}

There is an alignment of governance and infrastructure outcomes in the SDG literature. Gbadegesin et al. (2020) discussed the need to plan for sustainability with reference to Nigerian communities, 
finding that infrastructure development driven by the community and supported by government results in a positive outcome for governance, because the communities feel empowered to create lasting change and engage with stakeholders. Because the Forrest community has specific infrastructure goals, this has direct relevance for our case study. Additionally, investment in and development of infrastructure was found to work synergistically with SDG achievement because over $70 \%$ of SDG targets can be influenced by infrastructure provision (Adshead et al. 2019, Thacker et al. 2019). These findings support Forrest's priorities for infrastructure development to fulfill sustainability objectives.

Aligning community planning with the SDGs also allows access to a range of monitoring and evaluation processes tied to the SDGs, such as the composite index designed by Campagnolo et al. (2018), the evaluation framework proposed by Yonehara et al. (2017), or any number of alternatives. It is our intention with future research to design modeling and evaluation for this case study, which is now well grounded in sustainability ambitions. The suite of existing SDG indicators provides an additional benefit to using the SDGs for planning as they can be employed to measure progress at the modeling and implementation stages.

\section{Contribution}

This work makes two main contributions. First, we provide a practical example showing that the use of localized SDGs as a basis for local community planning can provide a consistent and comparative planning approach for local areas, building upon the work of Čiegis and Gineitiené (2008) and Local Agenda 21 (Coenen 2009). The second contribution is the participatory methods used to co-develop the plan. Our methods advance the techniques used in Bodorkós and Pataki (2009) with multiple waves of community engagement activities within the community culminating with the writing of a local development plan, but with a translation of the second stage of plan development to a remote, online process. Our co-design and evaluation process was successful thanks to significant preparatory work undertaken during the localizing SDGs step, more fully described in Szetey et al. (2021). Much of the literature on participatory processes focuses on information gathering methods such as workshops and visioning exercises. We had already engaged with the community using these types of methods but there appears to be less research investigating the results of engagements, for example what happens once the information has been compiled into a plan. Evaluation does take place but it is more often a type of "metaevaluation," where the participants are asked to evaluate the process rather than the results (e.g., Kok et al. 2011, CradockHenry et al. 2017, Ulibarri 2019). Our method effectively repurposed the scientific peer review process by casting the community and external stakeholders as the expert reviewers. Additionally, our methods extended the work of Valdez and Gubrium (2020) in using virtual community-based participatory research methods: our online engagement process was particularly relevant in this time of global pandemic but is also applicable to researchers and planners who may be located at some distance from the community they are engaging.

\section{CONCLUSION}

The SDGs are a global sustainability agenda intended to be implemented at global, national, and local scales. Local planners developing sustainability plans should make use of the SDGs to have a consistent and comparable set of goals and targets. We have demonstrated a method using a bottom-up, participatory approach to develop a local sustainability plan guided by the SDGs. This approach aligns bottom-up local needs with topdown global goals. We suggest that a broad adoption of our method would ensure consistency in local planning as well as allowing for comparison at the local scale, as well as with national and global scales. We believe that if the SDGs are implemented at the local level it will greatly aid their achievement at national and global level, and developing local sustainability plans is a positive first step to accomplishing that.

Responses to this article can be read online at: https://www.ecologyandsociety.org/issues/responses. $\mathrm{php} / 12566$

\section{Acknowledgments:}

We acknowledge the contributions of our community engagement collaborators: George O'Dwyer and David Rourke from the Department of Environment, Land, Water and Planning of Victoria (Australia); the Forrest General Store; the members of the Forrest Gateway Project Steering Committee; and Dianty Ningrum from Monash University. We would like to thank the Forrest community for reviewing the plan and providing feedback. Ebony Hickey of the Wathaurong Aboriginal Co-operative provided an Indigenous perspective for the plan's contents, and Gillian Brew provided graphic design services for the final publication. The coordination and writing of the plan was made possible through the Forrest Gateway Project, funded by the Victorian State Government's Virtual Centre for Climate Change Innovation (Emma Ashton), and the Ian Potter Foundation (Katrina Szetey). Sharon Bradshaw, in her role as secretary of the Forrest and District Community Group, volunteered her time to consult on the writing of the plan.

\section{Data Availability:}

The data that support the findings of this study are available on request from the corresponding author, KS. None of the data are publicly available because it would violate the conditions of our ethics approval. Ethical approval for this research study was granted by Deakin University, reference 2019-249.

\section{LITERATURE CITED}

Adshead, D., S. Thacker, L. I. Fuldauer, and J. W. Hall. 2019. Delivering on the Sustainable Development Goals through longterm infrastructure planning. Global Environmental Change 59:101975. https://doi.org/10.1016/j.gloenvcha.2019.101975

Arnstein, S. R. 1969. A ladder of citizen participation. Journal of the American Institute of Planners 35(4):216-224. https://doi. org/10.1080/01944366908977225

Australian Bureau of Statistics. 2017. 2016 Census QuickStats: Forrest (Vic.). Australian Bureau of Statistics, Canberra, 
Australia. [online] URL: https://quickstats.censusdata.abs.gov. au/census_services/getproduct/census/2016/quickstat/SSC20933

Bagheri, A., and P. Hjorth. 2007. Planning for sustainable development: a paradigm shift towards a process-based approach. Sustainable Development 15(2):83-96. https://doi.org/10.1002/ $\underline{\text { sd. } 310}$

Basco-Carrera, L., A. Warren, E. van Beek, A. Jonoski, and A. Giardino. 2017. Collaborative modelling or participatory modelling? A framework for water resources management. Environmental Modelling and Software 91:95-110. https://doi. org/10.1016/j.envsoft.2017.01.014

Bodorkós, B., and G. Pataki. 2009. Local communities empowered to plan? Applying PAR to establish democratic communicative spaces for sustainable rural development. Action Research 7(3):313-334. https://doi.org/10.1177/1476750309336720

Brody, S. D., D. R. Godschalk, and R. J. Burby. 2003. Mandating citizen participation in plan making: six strategic planning choices. Journal of the American Planning Association 69 (3):245-264. https://doi.org/10.1080/01944360308978018

Burby, R. J. 2003. Making plans that matter: citizen involvement and government action. Journal of the American Planning Association 69(1):33-49. https://doi.org/10.1080/01944360308976292

Campagnolo, L., C. Carraro, F. Eboli, L. Farnia, R. Parrado, and R. Pierfederici. 2018. The ex-ante evaluation of achieving Sustainable Development Goals. Social Indicators Research 136 (1):73-116. https://doi.org/10.1007/s11205-017-1572-X

Čiegis, R., and D. Gineitiené. 2008. Participatory aspects of strategic sustainable development planning in local communities: experience of Lithuania. Technological and Economic Development of Economy 14(2):107-117. https://doi. org/10.3846/1392-8619.2008.14.107-117

Coenen, F. 2009. Local agenda 21: 'Meaningful and effective' participation? Pages 165-182 in F. Coenen, editor. Public participation and better environmental decisions: the promise and limits of participatory processes for the quality of environmentally related decision-making. Springer, Dordrecht, The Netherlands. https://doi.org/10.1007/978-1-4020-9325-8_10

Cradock-Henry, N. A., S. Greenhalgh, P. Brown, and J. Sinner. 2017. Factors influencing successful collaboration for freshwater management in Aotearoa, New Zealand. Ecology and Society 22 (2):14. https://doi.org/10.5751/ES-09126-220214

Cutts, B. B., A. J. Greenlee, K. Hornik, and C. A. Nigrelli. 2020. Hyperlocal sustainabilities: theorizing action research for sustainability in the digital age. Sustainability Science 15 (1):315-331. https://doi.org/10.1007/s11625-019-00694-9

Diaz-Sarachaga, J. M. 2020. Combining participatory processes and Sustainable Development Goals to revitalize a rural area in Cantabria (Spain). Land 9(11):412. https://doi.org/10.3390/ land9110412

ElMassah, S., and M. Mohieldin. 2020. Digital transformation and localizing the Sustainable Development Goals (SDGs). Ecological Economics 169:106490. https://doi.org/10.1016/j. ecolecon.2019.106490
Frank, K. I., and S. A. Reiss. 2014. The rural planning perspective at an opportune time. Journal of Planning Literature 29 (4):386-402. https://doi.org/10.1177/0885412214542050

Gbadegesin, J. T., S. Ojekalu, T. F. Gbadegesin, and M. O. Komolafe. 2020. Sustaining community infrastructure through community-based governance (the social practice of collective design policy). Smart and Sustainable Built Environment. https:// doi.org/10.1108/SASBE-10-2019-0142

Hallström, L. K., G. Hvenegaard, and N. J. Dipa. 2019. Citizen engagement in sustainability planning: patterns and barriers from Hinton and Wood Buffalo, Alberta, Canada. Journal of Rural and Community Development 14(2):42-65. https://doi. org/10.7939/r3-7tt0-sy41

Hallström, L. K., G. T. Hvenegaard, J. L. Stonechild, and N. J. Dipa. 2017. Rural sustainability plans in Canada: An analysis of structure, content and influence. Journal of Rural Studies 56:132-142. https://doi.org/10.7939/r3-hrpm-fj05

Henderson, S. R. 2019. Framing regional scalecraft: insights into local government advocacy. Territory, Politics, Governance 7 (3):365-385. https://doi.org/10.1080/21622671.2017.1389660

Hibbard, M., and K. I. Frank. 2019. Notes for a substantive theory of rural planning: evidence from the US experience. Planning Theory and Practice 20(3):339-357. https://doi. org/10.1080/14649357.2019.1627572

Israel, B. A., A. J. Schulz, E. P. Parker, and A. B. Becker. 2001. Community-based participatory research: policy recommendations for promoting a partnership approach in health research. Education for Health: Change in Learning \& Practice 14 (2):182-197. https://doi.org/10.1080/13576280110051055

Kok, K., M. van Vliet, I. Bärlund, A. Dubel, and J. Sendzimir. 2011. Combining participative backcasting and exploratory scenario development: experiences from the SCENES project. Technological Forecasting and Social Change 78(5):835-851. https://doi.org/10.1016/j.techfore.2011.01.004

Manzo, L. C., and D. D. Perkins. 2006. Finding common ground: the importance of place attachment to community participation and planning. Journal of Planning Literature 20(4):335-350. https://doi.org/10.1177/0885412205286160

McLean, B. L., and T. Borén. 2015. Barriers to implementing sustainability locally: a case study of policy immobilities. Local Environment 20(12):1489-1506. https://doi.org/10.1080/135498$\underline{39.2014 .909798}$

Mistry, J., A. Berardi, C. Tschirhart, E. Bignante, L. Haynes, R. Benjamin, G. Albert, R. Xavier, B. Robertson, O. Davis, D. Jafferally, and G. de Ville. 2016. Community owned solutions: identifying local best practices for social-ecological sustainability. Ecology and Society 21(2):42. https://doi.org/10.5751/ES-08496-210242

Moallemi, E. A., F. J. de Haan, M. Hadjikakou, S. Khatami, S. Malekpour, A. Smajgl, M. S. Smith, A. Voinov, R. Bandari, P. Lamichhane, K. K. Miller, E. Nicholson, W. Novalia, E. G. Ritchie, A. M. Rojas, M. A. Shaikh, K. Szetey, and B. A. Bryan. 2021. Evaluating participatory modeling methods for co-creating pathways to sustainability. Earth's Future 9(3):e2020EF001843. https://doi.org/10.1029/2020EF001843 
Moallemi, E. A., S. Malekpour, M. Hadjikakou, R. Raven, K. Szetey, M. M. Moghadam, R. Bandari, R. Lester, and B. A. Bryan. 2019. Local Agenda 2030 for sustainable development. Lancet Planetary Health 3(6):e240-e241. https://doi.org/10.1016/ $\underline{\text { s2542-5196(19)30087-7 }}$

Moallemi, E. A., S. Malekpour, M. Hadjikakou, R. Raven, K. Szetey, D. Ningrum, A. Dhiaylhaq, and B. A. Bryan. 2020. Achieving the Sustainable Development Goals requires transdisciplinary innovation at the local scale. One Earth 3 (3):300-313. https://doi.org/10.1016/j.oneear.2020.08.006

Morrison, T. H. 2006. Pursuing rural sustainability at the regional level: key lessons from the literature on institutions, integration, and the environment. Journal of Planning Literature 21 (2):143-152. https://doi.org/10.1177/0885412206292261

Morrison, T. H., M. B. Lane, and M. Hibbard. 2015. Planning, governance and rural futures in Australia and the USA: revisiting the case for rural regional planning. Journal of Environmental Planning and Management 58(9):1601-1616. https://doi. org/10.1080/09640568.2014.940514

Morzillo, A. T., C. R. Colocousis, D. K. Munroe, K. P. Bell, S. Martinuzzi, D. B. Van Berkel, M. J. Lechowicz, B. Rayfield, and B. McGill. 2015. "Communities in the middle": interactions between drivers of change and place-based characteristics in rural forest-based communities. Journal of Rural Studies 42:79-90. https://doi.org/10.1016/j.jrurstud.2015.09.007

Shalowitz, M. U., A. Isacco, N. Barquin, E. Clark-Kauffman, P. Delger, D. Nelson, A. Quinn, and K. A. Wagenaar. 2009. Community-based participatory research: a review of the literature with strategies for community engagement. Journal of Developmental and Behavioral Pediatrics 30(4):350-361. https:// doi.org/10.1097/DBP.0b013e3181b0ef14

Sterling, E. J., P. Pascua, A. Sigouin, N. Gazit, L. Mandle, E. Betley, J. Aini, S. Albert, S. Caillon, J. E. Caselle, S. H. Cheng, J. Claudet, R. Dacks, E. S. Darling, C. Filardi, S. D. Jupiter, A. Mawyer, M. Mejia, K. Morishige, W. Nainoca, J. Parks, J. Tanguay, T. Ticktin, R. Vave, V. Wase, S. Wongbusarakum, and J. McCarter. 2020. Creating a space for place and multidimensional well-being: lessons learned from localizing the SDGs. Sustainability Science 15(4):1129-1147. https://doi. org/10.1007/s11625-020-00822-W

Szetey, K., E. Ashton, and S. Bradshaw. 2020. The Forrest and District Plan: Towards 2030. Forrest and District Community Group, Forrest, Australia. [online] URL: https://www.localsdgs. org/recently-published/forrest-amp-district-plan-gtgt-towards-2030-36yc3

Szetey, K., E. A. Moallemi, E. Ashton, M. Butcher, B. Sprunt, and B. A. Bryan. 2021. Co-creating local socioeconomic pathways for achieving the Sustainable Development Goals. Sustainability Science 16:1251-1268. https://doi.org/10.1007/s11625-021-00921-2

Thacker, S., D. Adshead, M. Fay, S. Hallegatte, M. Harvey, H. Meller, N. O’Regan, J. Rozenberg, G. Watkins, and J. W. Hall. 2019. Infrastructure for sustainable development. Nature Sustainability 2(4):324-331. https://doi.org/10.1038/s41893-019-0256-8
Ulibarri, N. 2019. Collaborative governance: a tool to manage scientific, administrative, and strategic uncertainties in environmental management? Ecology and Society 24(2):15. https://doi.org/10.5751/ES-10962-240215

United Nations. 2015. Transforming our world: the 2030 agenda for sustainable development. United Nations General Assembly, New York, New York, USA. [online] URL: https:// sustainabledevelopment.un.org/post2015/transformingourworld/ publication

Valdez, E. S., and A. Gubrium. 2020. Shifting to virtual CBPR protocols in the time of Corona Virus/COVID-19. International Journal of Qualitative Methods 19. https://doi.org/10.1177/1609406920977315

van Hees, S., K. Horstman, M. Jansen, and D. Ruwaard. 2020. How does an ageing policy translate into professional practices? An analysis of kitchen table conversations in the Netherlands. European Journal of Social Work 23(2):215-226. https://doi. org/10.1080/13691457.2018.1499610

Walker, B., S. R. Carpenter, C. Folke, L. Gunderson, G. D. Peterson, M. Scheffer, M. Schoon, and F. R. Westley. 2020. Navigating the chaos of an unfolding global cycle. Ecology and Society 25(4):23. https://doi.org/10.5751/ES-12072-250423

World Commission on Environment and Development. 1987. Our common future. Oxford University Press, Oxford, UK.

Yonehara, A., O. Saito, K. Hayashi, M. Nagao, R. Yanagisawa, and K. Matsuyama. 2017. The role of evaluation in achieving the SDGs. Sustainability Science 12(6):969-973. https://doi. org/10.1007/s11625-017-0479-4 


\section{Appendix \#1}

Table A1.1: The analysis of the driving forces

\begin{tabular}{|c|c|}
\hline Driving force & Trend \\
\hline $\begin{array}{l}\text { Population } \\
\text { and } \\
\text { demographics }\end{array}$ & $\begin{array}{l}\text { Population has been increasing over time, as } \\
\text { a result of in-migration. The fertility rate is } \\
\text { below replacement. There is an ageing } \\
\text { population and the mortality rate for the } \\
\text { region is slightly higher than the state rate. } \\
\text { Typically, young people migrate away from } \\
\text { Forrest for university or work. }\end{array}$ \\
\hline
\end{tabular}

Opportunities

Forrest's advantages could encourage more full-time residents. More women are empowered to enter the workforce if they aren't acting as the primary caregiver for young children. An ageing population is generally retired; retirees often have more time for volunteering and contributing to the community

\begin{tabular}{ll}
\hline Residential & Colac Otway Shire have designated Forrest a \\
$\begin{array}{l}\text { land } \\
\text { development }\end{array}$ & $\begin{array}{l}\text { low-growth community. Land development } \\
\text { has been below the expected level of } 3.5\end{array}$ \\
& $\begin{array}{l}\text { permits per year, only one has been issued } \\
\text { per year since 2011. }\end{array}$
\end{tabular}
per year since 2011
Land exists in town to be built upon, and there is capacity in the number of building permits from Council. If Council permitted more than one residential property to be built upon Farming Zone land, this would allow additional residential housing and potentially alleviate the limits imposed by wastewater requirements.

\begin{tabular}{lll}
\hline $\begin{array}{l}\text { Affordability } \\
\text { of property }\end{array}$ & Median house prices have increased by $188 \%$ & Those selling houses in Forrest today \\
since 2009, median rents by $30 \%$. There are & would make a significant profit.
\end{tabular}
140 dwellings in Forrest.

\section{Challenges}

Forrest has limited space for expansion; any population growth would be subject to the limiting factor of housing availability. The population of the town is ageing as most growth occurs through migration. Children often move away when they turn 18 as there aren't opportunities for tertiary study or work nearby. When young people move away, it leaves a vacuum of young, able-bodied people in town. Limited space for housing means that low mortality could tie up available housing. While there is available land to build on, there is no capacity for additional sewerage. Septic systems within town are already at or beyond safe limits, so the lack of suitable wastewater infrastructure is the real brake on development.

Tourism businesses have been purchasing houses and removing them from the pool of available residential housing. With the 
and suitability

of housing

Inequality

In 2016, Forrest had a SEIFA score of 968. This is in the third quintile of the country, and the second quintile of the state. This would put it as a medium-low equity community.

Forrest has $20 \%$ single parent families (100\% of single parents are women). The median family income in Forrest is $35 \%$ lower than for the rest of Victoria.

Local Forrest experienced a major shift in local

economy industry with the cessation of logging in 2008 and the decline of agricultural industries. The development of the Mountain Bike Trail system began the transition to a primarily tourism-based economy. This led to a growth of local small businesses catering to both tourists and local residents. The local community have expressed a desire for diversification of the economy so there are other options for employment growth within the town.

Environment Forrest is located in a biodiversity hotspot, and the Great Otway National Park provides protection for some of that biodiversity. This, along with the mountain bike trails, are the biggest drawcard of the
Forrest is a supportive community and provides assistance to those in need, for example through community lunches and foodsharing. limits already existing for land development, this creates genuine scarcity in the housing market, driving up prices for those who wish to buy.

All the various drivers of inequality need to be tackled together to eliminate inequality entirely and is a considerable undertaking.

\begin{abstract}
The G21 Colac Otway region profile identifies a number of economic development opportunities through the greater Colac Otway region, including dairy farming and processing; green energy; transport and logistics; tourism; and health care and social assistance. It also notes that the Forrest Common and Forrest Mountain Bike Trails Strategy projects are likely to have positive impact on future economic growth in the Shire.

The expansion of the tourism industry is obstructed by limited housing supply for both accommodation and employees, and by ageing and failing infrastructure. Additional businesses are prevented from being created due to lack of housing and office space (e.g. having service businesses move into the area accountants, hairdressers, tradespeople etc) and poor connectivity (internet and transport).
\end{abstract}

Forrest and District is a growing hub for regenerative agriculture - where the land is improved as a result of agriculture and carbon is stored in biologically active soil. This limits the use of fertilisers, which
Climate change and potential bushfire impact are both threats to the local environment. There needs to be a pathway out of industry for those who 
local tourism industry. The local residents are proud of their pristine surroundings and dedicated to ensuring they remain so.

Major Forrest has four major infrastructure projects

infrastructure currently in train: The Forrest Gateway

projects (funding is being funding); Wastewater

(funding is being sought); upgrades to the Mountain Bike Trails (funding achieved); and the Forrest Common (funding is being sought). reduces agricultural runoff into

waterways, improving local water quality and the environment generally

Upgrades to local infrastructure will enable many things which are currently being obstructed: wastewater will have positive effects on housing, health, the economy and the environment. The Mountain Bike Trails will boost tourism, and provide improved trails for locals to use. The Gateway Project will provide both a safer location in case of bushfire as well as a community hub and potential venue for hire. The Forrest Common will provide public space for locals, their children and tourists.

Transport and State government are currently upgrading connectivity
State government are currently upgrading
some portions of the Forrest-Apollo Bay

Road, and are planning to undertake surfacing work on the Birregurra-Forrest Road near Seven Bridges Road.

There is one bus line that runs through Forrest, which runs only on Wednesdays and only once in each direction. During summer months, a more frequent bus service is offered for tourists.

NBN Fixed Wireless is known to suffer from congestion issues, and the distance to the
Recent upgrades to the channel routes to

Forrest make it easier for tourists to visit

the area, and safer for residents to drive. Regular public transport links would allow residents to travel to Colac or Birregurra without the use of a car, decreasing carbon emissions.

Improved internet access (fixed and mobile) would encourage new businesses which rely on connectivity, and better support the existing residents and businesses. currently work in environmentally

degrading industries.

Not fulfilling the infrastructure needs of the community will impede growth in the economy and the population, and have negative effects on housing, health and the environment.
Poor road quality may increase the incidence of road deaths.

The lack of regular and frequent public transport puts a severe limit on residents who may want to avoid driving, and for tourists who wish to visit that do not drive.

Poor mobile reception and internet is a potential safety issue in case of disaster (e.g. bushfire), and also discourages new businesses. 
tower affects internet speeds. The nearest tower to Forrest is in Barwon Downs.

Local school Forrest Primary School as the only primary school in the district and contains the Forrest Pre-School in addition to long daycare and out of school hours care, assisting parents who need to travel longer distances for work outside of Forrest.
The school is a significant employer with three full-time and eight part-time staff,

Climate Climate change is a global problem but will

change also affect Forrest at a community level. Such effects include increasing temperatures, drying climates, increased frequency and severity of bushfires, droughts and extreme weather.

Encroaching sea level rise is already affecting communities along the Great Ocean Road, with landslips creating dangerous road conditions and impacting coastal properties.

To remain safe and stay resilient in the face of climate change, Forrest must anticipate more frequent bushfires, flooding and drought, and develop plans for sustainable recovery. and one trainee. The school has offered traineeships to local residents for over 20 years. The school creates traffic for local businesses in town as parents from outside Forrest will visit daily. It also works with many of the community groups in Forrest.

\section{If Forrest were to lose its primary} school, there would be many negative knock-on effects causing harm to Forrest's future, from decreased business patronage to young families moving away to access closer schools.

Dangerous and unsightly conditions along
the Great Ocean Road may encourage people to visit further inland.
The effect of climate change on biodiversity is a serious threat by itself, but may also affect Forrest's ecotourism economy. Forrest is likely to be impacted by bushfire simply through the balance of probabilities, and climate change means that it will likely be harsher and stronger. Bushfire elsewhere in Victoria will affect Forrest's visitor numbers because of bushfire smoke.

Decreasing amenity along the Great Ocean Road could push residents to move further inland, potentially into Forrest and District. This plus the increasing cost of farmland as agriculture shifts south, could further affect Forrest's housing affordability. 
Table A1.2: The mapping of SDG targets to the community goals

\begin{tabular}{|c|c|}
\hline Community goal & SDG Targets \\
\hline \multirow[t]{6}{*}{ A bushfire safe cc } & $\begin{array}{l}3.9 \text { By } 2030 \text {, substantially reduce the number of deaths and } \\
\text { illnesses from hazardous chemicals and air, water and soil } \\
\text { pollution and contamination }\end{array}$ \\
\hline & $\begin{array}{l}\text { 11.4 Strengthen efforts to protect and safeguard the world's } \\
\text { cultural and natural heritage }\end{array}$ \\
\hline & $\begin{array}{l}11.5 \text { By } 2030 \text {, significantly reduce the number of deaths and the } \\
\text { number of people affected and substantially decrease the direct } \\
\text { economic losses relative to global gross domestic product caused } \\
\text { by disasters, including water-related disasters, with a focus on } \\
\text { protecting the poor and people in vulnerable situations }\end{array}$ \\
\hline & $\begin{array}{l}\text { 13.1 Strengthen resilience and adaptive capacity to climate- } \\
\text { related hazards and natural disasters in all countries }\end{array}$ \\
\hline & $\begin{array}{l}15.1 \text { By } 2020 \text {, ensure the conservation, restoration and } \\
\text { sustainable use of terrestrial and inland freshwater ecosystems } \\
\text { and their services, in particular forests, wetlands, mountains and } \\
\text { drylands, in line with obligations under international agreements }\end{array}$ \\
\hline & $\begin{array}{l}15.5 \text { Take urgent and significant action to reduce the } \\
\text { degradation of natural habitats, halt the loss of biodiversity and, } \\
\text { by } 2020 \text {, protect and prevent the extinction of threatened } \\
\text { species }\end{array}$ \\
\hline \multirow[t]{4}{*}{$\begin{array}{l}\text { A diverse and sustainable } \\
\text { economy }\end{array}$} & $\begin{array}{l}\text { 8.3 Promote development-oriented policies that support } \\
\text { productive activities, decent job creation, entrepreneurship, } \\
\text { creativity and innovation, and encourage the formalization and } \\
\text { growth of micro-, small- and medium-sized enterprises, including } \\
\text { through access to financial services }\end{array}$ \\
\hline & $\begin{array}{l}8.5 \text { By } 2030 \text {, achieve full and productive employment and decent } \\
\text { work for all women and men, including for young people and } \\
\text { persons with disabilities, and equal pay for work of equal value }\end{array}$ \\
\hline & $\begin{array}{l}8.9 \text { By } 2030 \text {, devise and implement policies to promote } \\
\text { sustainable tourism that creates jobs and promotes local culture } \\
\text { and products }\end{array}$ \\
\hline & $\begin{array}{l}\text { 11a Support positive economic, social and environmental links } \\
\text { between urban, peri-urban and rural areas by strengthening } \\
\text { national and regional development planning }\end{array}$ \\
\hline \multirow[t]{5}{*}{$\begin{array}{l}\text { Great private and public } \\
\text { infrastructure }\end{array}$} & $\begin{array}{l}6.2 \text { By } 2030 \text {, achieve access to adequate and equitable sanitation } \\
\text { and hygiene for all and end open defecation, paying special }\end{array}$ \\
\hline & $\begin{array}{l}\text { attention to the needs of women and girls and those in } \\
\text { vulnerable situations }\end{array}$ \\
\hline & $\begin{array}{l}6.5 \text { By } 2030 \text {, implement integrated water resources } \\
\text { management at all levels, including through transboundary } \\
\text { cooperation as appropriate }\end{array}$ \\
\hline & $\begin{array}{l}\text { 6b Support and strengthen the participation of local } \\
\text { communities in improving water and sanitation management }\end{array}$ \\
\hline & $\begin{array}{l}\text { 8.3 Promote development-oriented policies that support } \\
\text { productive activities, decent job creation, entrepreneurship, }\end{array}$ \\
\hline
\end{tabular}


creativity and innovation, and encourage the formalization and growth of micro-, small- and medium-sized enterprises, including through access to financial services

8.4 Improve progressively, through 2030 , global resource efficiency in consumption and production and endeavour to decouple economic growth from environmental degradation, in accordance with the 10-Year Framework of Programmes on Sustainable Consumption and Production, with developed countries taking the lead

11.1 By 2030 , ensure access for all to adequate, safe and affordable housing and basic services and upgrade slums

11.2 By 2030, provide access to safe, affordable, accessible and sustainable transport systems for all, improving road safety, notably by expanding public transport, with special attention to the needs of those in vulnerable situations, women, children, persons with disabilities and older persons

11.7 By 2030, provide universal access to safe, inclusive and accessible, green and public spaces, in particular for women and children, older persons and persons with disabilities 3.4 By 2030, reduce by one third premature mortality from noncommunicable diseases through prevention and treatment and

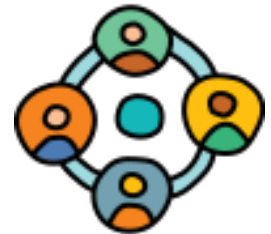
promote mental health and well-being

3.5 Strengthen the prevention and treatment of substance abuse, including narcotic drug abuse and harmful use of alcohol 3.6 By 2020, halve the number of global deaths and injuries from road traffic accidents

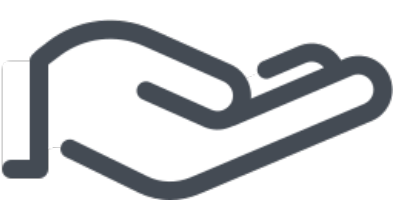

3.8 Achieve universal health coverage, including financial risk protection, access to quality essential health-care services and access to safe, effective, quality and affordable essential medicines and vaccines for all

6.5 By 2030, implement integrated water resources management at all levels, including through transboundary cooperation as appropriate

6.6 By 2020, protect and restore water-related ecosystems, including mountains, forests, wetlands, rivers, aquifers and lakes

11.1 By 2030, ensure access for all to adequate, safe and affordable housing and basic services and upgrade slums

11.2 By 2030, provide access to safe, affordable, accessible and sustainable transport systems for all, improving road safety, notably by expanding public transport, with special attention to the needs of those in vulnerable situations, women, children, persons with disabilities and older persons

11.5 By 2030, significantly reduce the number of deaths and the number of people affected and substantially decrease the direct economic losses relative to global gross domestic product caused by disasters, including water-related disasters, with a focus on protecting the poor and people in vulnerable situations 
11a Support positive economic, social and environmental links between urban, peri-urban and rural areas by strengthening national and regional development planning

13.1 Strengthen resilience and adaptive capacity to climaterelated hazards and natural disasters in all countries

13.3 Improve education, awareness-raising and human and institutional capacity on climate change mitigation, adaptation, impact reduction and early warning

15.1 By 2020, ensure the conservation, restoration and sustainable use of terrestrial and inland freshwater ecosystems and their services, in particular forests, wetlands, mountains and drylands, in line with obligations under international agreements 15.5 Take urgent and significant action to reduce the degradation of natural habitats, halt the loss of biodiversity and, by 2020 , protect and prevent the extinction of threatened species

15.9 By 2020 , integrate ecosystem and biodiversity values into national and local planning, development processes, poverty reduction strategies and accounts

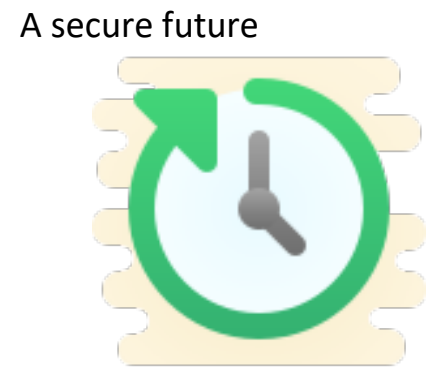
3.4 By 2030, reduce by one third premature mortality from noncommunicable diseases through prevention and treatment and promote mental health and well-being

3.6 By 2020, halve the number of global deaths and injuries from road traffic accidents

3.8 Achieve universal health coverage, including financial risk protection, access to quality essential health-care services and access to safe, effective, quality and affordable essential medicines and vaccines for all

6.4 By 2030, substantially increase water-use efficiency across all sectors and ensure sustainable withdrawals and supply of freshwater to address water scarcity and substantially reduce the number of people suffering from water scarcity

6.5 By 2030, implement integrated water resources management at all levels, including through transboundary cooperation as appropriate

6.6 By 2020 , protect and restore water-related ecosystems, including mountains, forests, wetlands, rivers, aquifers and lakes

8.3 Promote development-oriented policies that support productive activities, decent job creation, entrepreneurship, creativity and innovation, and encourage the formalization and growth of micro-, small- and medium-sized enterprises, including through access to financial services

8.5 By 2030 , achieve full and productive employment and decent work for all women and men, including for young people and persons with disabilities, and equal pay for work of equal value 8.9 By 2030 , devise and implement policies to promote sustainable tourism that creates jobs and promotes local culture and products 
11.1 By 2030, ensure access for all to adequate, safe and affordable housing and basic services and upgrade slums

11.2 By 2030, provide access to safe, affordable, accessible and sustainable transport systems for all, improving road safety, notably by expanding public transport, with special attention to the needs of those in vulnerable situations, women, children, persons with disabilities and older persons

11.4 Strengthen efforts to protect and safeguard the world's cultural and natural heritage

11.5 By 2030 , significantly reduce the number of deaths and the number of people affected and substantially decrease the direct economic losses relative to global gross domestic product caused by disasters, including water-related disasters, with a focus on protecting the poor and people in vulnerable situations 11a Support positive economic, social and environmental links between urban, peri-urban and rural areas by strengthening national and regional development planning

13.1 Strengthen resilience and adaptive capacity to climaterelated hazards and natural disasters in all countries

13.2 Integrate climate change measures into national policies, strategies and planning

15.1 By 2020, ensure the conservation, restoration and sustainable use of terrestrial and inland freshwater ecosystems and their services, in particular forests, wetlands, mountains and drylands, in line with obligations under international agreements 15.5 Take urgent and significant action to reduce the degradation of natural habitats, halt the loss of biodiversity and, by 2020 , protect and prevent the extinction of threatened species

15.9 By 2020, integrate ecosystem and biodiversity values into national and local planning, development processes, poverty reduction strategies and accounts

Table A1.3: The mapping of the SDG targets to the community goals

\begin{tabular}{l|l}
\hline \hline Driving forces & SDG targets \\
\hline Population and demographics & $\begin{array}{l}\text { 3.4 By 2030, reduce by one third premature mortality from non- } \\
\text { communicable diseases through prevention and treatment and } \\
\text { promote mental health and well-being }\end{array}$ \\
& $\begin{array}{l}\text { 3.5 Strengthen the prevention and treatment of substance } \\
\text { abuse, including narcotic drug abuse and harmful use of alcohol }\end{array}$ \\
& $\begin{array}{l}\text { 3.6 By 2020, halve the number of global deaths and injuries from } \\
\text { road traffic accidents }\end{array}$ \\
\hline $\begin{array}{l}\text { 3.8 Achieve universal health coverage, including financial risk } \\
\text { protection, access to quality essential health-care services and } \\
\text { access to safe, effective, quality and affordable essential } \\
\text { medicines and vaccines for all }\end{array}$ \\
\hline
\end{tabular}


11.1 By 2030, ensure access for all to adequate, safe and affordable housing and basic services and upgrade slums

11.2 By 2030, provide access to safe, affordable, accessible and sustainable transport systems for all, improving road safety, notably by expanding public transport, with special attention to the needs of those in vulnerable situations, women, children, persons with disabilities and older persons

11.5 By 2030 , significantly reduce the number of deaths and the number of people affected and substantially decrease the direct economic losses relative to global gross domestic product caused by disasters, including water-related disasters, with a focus on protecting the poor and people in vulnerable situations 11a Support positive economic, social and environmental links between urban, peri-urban and rural areas by strengthening national and regional development planning

Residential land development

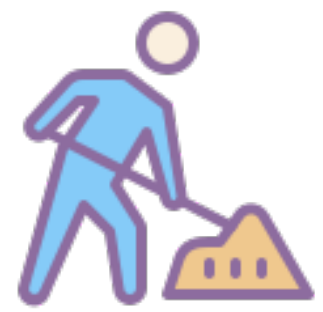

Affordability of property and suitability of housing

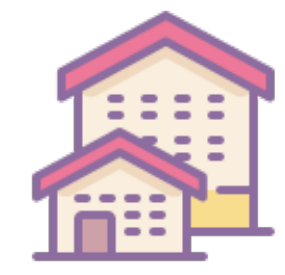

Inequality

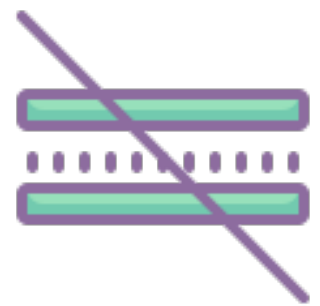

11.1 By 2030, ensure access for all to adequate, safe and affordable housing and basic services and upgrade slums 11.3 By 2030, enhance inclusive and sustainable urbanization and capacity for participatory, integrated and sustainable human settlement planning and management in all countries

11.4 Strengthen efforts to protect and safeguard the world's cultural and natural heritage

11a Support positive economic, social and environmental links between urban, peri-urban and rural areas by strengthening national and regional development planning

11.1 By 2030, ensure access for all to adequate, safe and affordable housing and basic services and upgrade slums 11.3 By 2030 , enhance inclusive and sustainable urbanization and capacity for participatory, integrated and sustainable human settlement planning and management in all countries

11a Support positive economic, social and environmental links between urban, peri-urban and rural areas by strengthening national and regional development planning

3.4 By 2030, reduce by one third premature mortality from noncommunicable diseases through prevention and treatment and promote mental health and well-being

3.5 Strengthen the prevention and treatment of substance abuse, including narcotic drug abuse and harmful use of alcohol 3.6 By 2020, halve the number of global deaths and injuries from road traffic accidents

3.7 By 2030, ensure universal access to sexual and reproductive health-care services, including for family planning, information and education, and the integration of reproductive health into national strategies and programmes

3.8 Achieve universal health coverage, including financial risk protection, access to quality essential health-care services and access to safe, effective, quality and affordable essential medicines and vaccines for all 
6.1 By 2030, achieve universal and equitable access to safe and affordable drinking water for all

6.2 By 2030 , achieve access to adequate and equitable sanitation and hygiene for all and end open defecation, paying special attention to the needs of women and girls and those in vulnerable situations

6.3 By 2030 , improve water quality by reducing pollution, eliminating dumping and minimizing release of hazardous chemicals and materials, halving the proportion of untreated wastewater and substantially increasing recycling and safe reuse globally 6.4 By 2030, substantially increase water-use efficiency across all sectors and ensure sustainable withdrawals and supply of freshwater to address water scarcity and substantially reduce the number of people suffering from water scarcity

8.3 Promote development-oriented policies that support productive activities, decent job creation, entrepreneurship, creativity and innovation, and encourage the formalization and growth of micro-, small- and medium-sized enterprises, including through access to financial services

8.5 By 2030, achieve full and productive employment and decent work for all women and men, including for young people and persons with disabilities, and equal pay for work of equal value 8.6 By 2020 , substantially reduce the proportion of youth not in employment, education or training

8.8 Protect labour rights and promote safe and secure working environments for all workers, including migrant workers, in particular women migrants, and those in precarious employment 8.9 By 2030 , devise and implement policies to promote sustainable tourism that creates jobs and promotes local culture and products

11.1 By 2030 , ensure access for all to adequate, safe and affordable housing and basic services and upgrade slums

11.2 By 2030, provide access to safe, affordable, accessible and sustainable transport systems for all, improving road safety, notably by expanding public transport, with special attention to the needs of those in vulnerable situations, women, children, persons with disabilities and older persons

11.5 By 2030, significantly reduce the number of deaths and the number of people affected and substantially decrease the direct economic losses relative to global gross domestic product caused by disasters, including water-related disasters, with a focus on protecting the poor and people in vulnerable situations productive activities, decent job creation, entrepreneurship, creativity and innovation, and encourage the formalization and growth of micro-, small- and medium-sized enterprises, including through access to financial services 


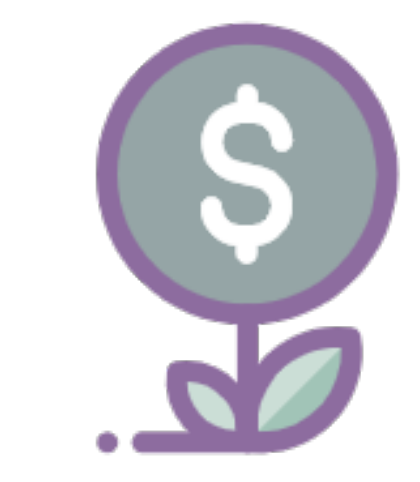

8.5 By 2030, achieve full and productive employment and decent work for all women and men, including for young people and persons with disabilities, and equal pay for work of equal value 8.6 By 2020, substantially reduce the proportion of youth not in employment, education or training

8.8 Protect labour rights and promote safe and secure working environments for all workers, including migrant workers, in particular women migrants, and those in precarious employment 8.9 By 2030 , devise and implement policies to promote sustainable tourism that creates jobs and promotes local culture and products

11.2 By 2030, provide access to safe, affordable, accessible and sustainable transport systems for all, improving road safety, notably by expanding public transport, with special attention to the needs of those in vulnerable situations, women, children, persons with disabilities and older persons

11a Support positive economic, social and environmental links between urban, peri-urban and rural areas by strengthening national and regional development planning

\section{Environment}

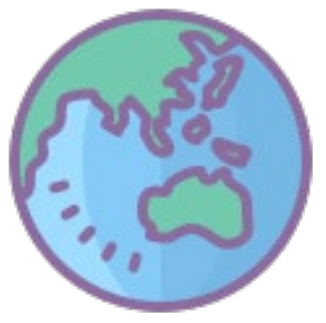

3.7 By 2030, ensure universal access to sexual and reproductive health-care services, including for family planning, information and education, and the integration of reproductive health into national strategies and programmes

3.9 By 2030 , substantially reduce the number of deaths and illnesses from hazardous chemicals and air, water and soil pollution and contamination

6.2 By 2030 , achieve access to adequate and equitable sanitation and hygiene for all and end open defecation, paying special attention to the needs of women and girls and those in vulnerable situations

6.3 By 2030 , improve water quality by reducing pollution, eliminating dumping and minimizing release of hazardous chemicals and materials, halving the proportion of untreated wastewater and substantially increasing recycling and safe reuse globally

6.4 By 2030, substantially increase water-use efficiency across all sectors and ensure sustainable withdrawals and supply of freshwater to address water scarcity and substantially reduce the number of people suffering from water scarcity

6.5 By 2030, implement integrated water resources management at all levels, including through transboundary cooperation as appropriate

6.6 By 2020, protect and restore water-related ecosystems, including mountains, forests, wetlands, rivers, aquifers and lakes

13.1 Strengthen resilience and adaptive capacity to climaterelated hazards and natural disasters in all countries

13.2 Integrate climate change measures into national policies, strategies and planning 
13.3 Improve education, awareness-raising and human and institutional capacity on climate change mitigation, adaptation, impact reduction and early warning

15.1 By 2020, ensure the conservation, restoration and sustainable use of terrestrial and inland freshwater ecosystems and their services, in particular forests, wetlands, mountains and drylands, in line with obligations under international agreements 15.2 By 2020, promote the implementation of sustainable management of all types of forests, halt deforestation, restore degraded forests and substantially increase afforestation and reforestation globally

15.4 By 2030, ensure the conservation of mountain ecosystems, including their biodiversity, in order to enhance their capacity to provide benefits that are essential for sustainable development 15.5 Take urgent and significant action to reduce the degradation of natural habitats, halt the loss of biodiversity and, by 2020 , protect and prevent the extinction of threatened species

15.8 By 2020, introduce measures to prevent the introduction and significantly reduce the impact of invasive alien species on land and water ecosystems and control or eradicate the priority species

15a Mobilize and significantly increase financial resources from all sources to conserve and sustainably use biodiversity and ecosystems

$15 \mathrm{~b}$ Mobilize significant resources from all sources and at all levels to finance sustainable forest management and provide adequate incentives to developing countries to advance such management, including for conservation and reforestation illnesses from hazardous chemicals and air, water and soil pollution and contamination

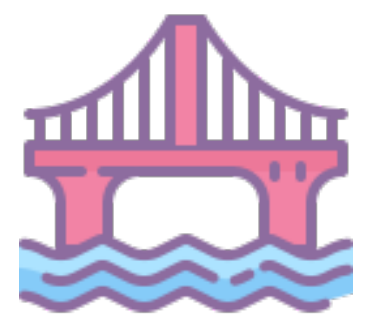

6.2 By 2030 , achieve access to adequate and equitable sanitation and hygiene for all and end open defecation, paying special attention to the needs of women and girls and those in vulnerable situations

6.3 By 2030 , improve water quality by reducing pollution, eliminating dumping and minimizing release of hazardous chemicals and materials, halving the proportion of untreated wastewater and substantially increasing recycling and safe reuse globally 6.5 By 2030, implement integrated water resources management at all levels, including through transboundary cooperation as appropriate 
8.3 Promote development-oriented policies that support productive activities, decent job creation, entrepreneurship, creativity and innovation, and encourage the formalization and growth of micro-, small- and medium-sized enterprises, including through access to financial services

8.4 Improve progressively, through 2030 , global resource efficiency in consumption and production and endeavour to decouple economic growth from environmental degradation, in accordance with the 10-Year Framework of Programmes on Sustainable Consumption and Production, with developed countries taking the lead

8.9 By 2030 , devise and implement policies to promote sustainable tourism that creates jobs and promotes local culture and products

11.1 By 2030, ensure access for all to adequate, safe and affordable housing and basic services and upgrade slums

11.3 By 2030, enhance inclusive and sustainable urbanization and capacity for participatory, integrated and sustainable human settlement planning and management in all countries

11.4 Strengthen efforts to protect and safeguard the world's cultural and natural heritage

11.5 By 2030, significantly reduce the number of deaths and the number of people affected and substantially decrease the direct economic losses relative to global gross domestic product caused by disasters, including water-related disasters, with a focus on protecting the poor and people in vulnerable situations 11.7 By 2030, provide universal access to safe, inclusive and accessible, green and public spaces, in particular for women and children, older persons and persons with disabilities

11a Support positive economic, social and environmental links between urban, peri-urban and rural areas by strengthening national and regional development planning

Transport and connectivity 3.6 By 2020 , halve the number of global deaths and injuries from road traffic accidents

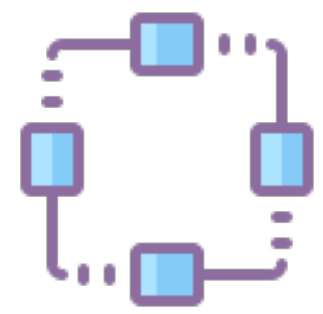

8.2 Achieve higher levels of economic productivity through diversification, technological upgrading and innovation, including through a focus on high-value added and labour-intensive sectors

8.3 Promote development-oriented policies that support productive activities, decent job creation, entrepreneurship, creativity and innovation, and encourage the formalization and growth of micro-, small- and medium-sized enterprises, including through access to financial services

8.9 By 2030, devise and implement policies to promote sustainable tourism that creates jobs and promotes local culture and products

11.1 By 2030, ensure access for all to adequate, safe and affordable housing and basic services and upgrade slums 
11.2 By 2030, provide access to safe, affordable, accessible and sustainable transport systems for all, improving road safety, notably by expanding public transport, with special attention to the needs of those in vulnerable situations, women, children, persons with disabilities and older persons

11.3 By 2030, enhance inclusive and sustainable urbanization and capacity for participatory, integrated and sustainable human settlement planning and management in all countries

13.1 Strengthen resilience and adaptive capacity to climaterelated hazards and natural disasters in all countries

13.3 Improve education, awareness-raising and human and institutional capacity on climate change mitigation, adaptation, impact reduction and early warning

3.4 By 2030, reduce by one third premature mortality from noncommunicable diseases through prevention and treatment and promote mental health and well-being

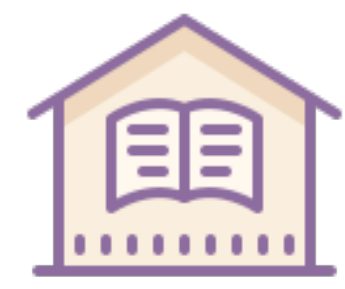

3.7 By 2030, ensure universal access to sexual and reproductive health-care services, including for family planning, information and education, and the integration of reproductive health into national strategies and programmes

8.2 Achieve higher levels of economic productivity through diversification, technological upgrading and innovation, including through a focus on high-value added and labour-intensive sectors

8.3 Promote development-oriented policies that support productive activities, decent job creation, entrepreneurship, creativity and innovation, and encourage the formalization and growth of micro-, small- and medium-sized enterprises, including through access to financial services

8.6 By 2020 , substantially reduce the proportion of youth not in employment, education or training

11.1 By 2030, ensure access for all to adequate, safe and affordable housing and basic services and upgrade slums

11.3 By 2030, enhance inclusive and sustainable urbanization and capacity for participatory, integrated and sustainable human settlement planning and management in all countries

11.7 By 2030, provide universal access to safe, inclusive and accessible, green and public spaces, in particular for women and children, older persons and persons with disabilities

11a Support positive economic, social and environmental links between urban, peri-urban and rural areas by strengthening national and regional development planning 
11.2 By 2030, provide access to safe, affordable, accessible and sustainable transport systems for all, improving road safety, notably by expanding public transport, with special attention to the needs of those in vulnerable situations, women, children, persons with disabilities and older persons

11.3 By 2030, enhance inclusive and sustainable urbanization and capacity for participatory, integrated and sustainable human settlement planning and management in all countries

11.4 Strengthen efforts to protect and safeguard the world's cultural and natural heritage

11.5 By 2030 , significantly reduce the number of deaths and the number of people affected and substantially decrease the direct economic losses relative to global gross domestic product caused by disasters, including water-related disasters, with a focus on protecting the poor and people in vulnerable situations 11a Support positive economic, social and environmental links between urban, peri-urban and rural areas by strengthening national and regional development planning

13.1 Strengthen resilience and adaptive capacity to climaterelated hazards and natural disasters in all countries

13.3 Improve education, awareness-raising and human and institutional capacity on climate change mitigation, adaptation, impact reduction and early warning

15.1 By 2020, ensure the conservation, restoration and sustainable use of terrestrial and inland freshwater ecosystems and their services, in particular forests, wetlands, mountains and drylands, in line with obligations under international agreements 15.2 By 2020 , promote the implementation of sustainable management of all types of forests, halt deforestation, restore degraded forests and substantially increase afforestation and reforestation globally

15.4 By 2030, ensure the conservation of mountain ecosystems, including their biodiversity, in order to enhance their capacity to provide benefits that are essential for sustainable development

15.5 Take urgent and significant action to reduce the degradation of natural habitats, halt the loss of biodiversity and, by 2020 , protect and prevent the extinction of threatened species

15.8 By 2020 , introduce measures to prevent the introduction and significantly reduce the impact of invasive alien species on land and water ecosystems and control or eradicate the priority species

15.9 By 2020, integrate ecosystem and biodiversity values into national and local planning, development processes, poverty reduction strategies and accounts 
15a Mobilize and significantly increase financial resources from all sources to conserve and sustainably use biodiversity and ecosystems

$15 \mathrm{~b}$ Mobilize significant resources from all sources and at all levels to finance sustainable forest management and provide adequate incentives to developing countries to advance such management, including for conservation and reforestation 


\section{Appendix \#2}

Videoconference slides and meeting agenda 


\section{Welcome}

Forrest Infrastructure Planning 


\section{Getting started}

- To get the best view, press the 'full screen' button on the top right of the zoom window

- Please also start your video, and mute your microphone. 


\section{Getting started}

- Please register by writing your name at the chat line (press this button and write at the bottom of the side bar that appears on the right)

- The chat will be used as a 'parking lot' for your questions and observations. 


\section{Overview}

- The Forrest 10yr plan Goals (5mins)

- Community convo (5mins)

- Community Infrastructure projects (5mins)

- Community convo (5mins)

- Q\&A with James ... Colac Otway Shire (20mins) 


\section{The Forrest and District Plan}

\section{Forrest and District Plan}

- Katrina and Emma presentation

\section{Community}

infrastructure

projects 


\section{Community Convo}

- Small group discussion

- click: Invited to 'join breakout session \#

- Discuss what you heard, and write down with pen and paper any Q's you might have about the emerging plan. 


\section{Questions of the plan}

- Write any Q's into the chat session.

- These will be answered later 


\section{Community Infrastructure projects}

\begin{tabular}{|c|c|c|}
\hline Wastewaster projects - needs more action & Public Toilet - needs to be improved & Community Farming \\
\hline $\begin{array}{l}\text { Integrated water management plan that takes } \\
\text { into account water supply, tanks, reuse and } \\
\text { stormwater drainage }\end{array}$ & Service Road Carparking & $\begin{array}{l}\text { Community Garden/Farming - used by school or } \\
\text { caravan park }\end{array}$ \\
\hline Waste to energy & Bus Parking & Citizen science projects \\
\hline $\begin{array}{l}\text { Housing options for local workers, including } \\
\text { encouraging more permanent housing at } \\
\text { caravan park }\end{array}$ & $\begin{array}{l}\text { Install roundabout at Brewery corner and } \\
\text { proper road crossing }\end{array}$ & Upgrade heating/airconditioning at the hall \\
\hline $\begin{array}{l}\text { Enabling housing for long term residents as } \\
\text { opposed to B\&Bs }\end{array}$ & $\begin{array}{l}\text { Better road signage }(40 \mathrm{~km} / \mathrm{h}) \text { on Turner Drive } \\
\text { (Speed humps, or restricting access) }\end{array}$ & $\begin{array}{l}\text { Upgrade hall to remove asbestos and improve } \\
\text { facility for performances }\end{array}$ \\
\hline New caravan park option at Rec Reserve & $\begin{array}{l}\text { Footpath on eastern side of the road from the } \\
\text { town to the reservoir }\end{array}$ & $\begin{array}{l}\text { Upgrade facilities at MTB hub for tourist and } \\
\text { community use }\end{array}$ \\
\hline $\begin{array}{l}\text { Increased options for short term } \\
\text { accommodation }\end{array}$ & Rail trail continuation to Birregurra & $\begin{array}{l}\text { Food venue idea- to promote touring groups to } \\
\text { visit Forrest }\end{array}$ \\
\hline Options for farms to build second dwellings & $\begin{array}{l}\text { Forrest Gateway to the Otways centre/Bushfire } \\
\text { safe place }\end{array}$ & $\begin{array}{l}\text { Investigate suitable Crop database from Dept Ag } \\
\text { to encourage farming alternatives and new } \\
\text { business }\end{array}$ \\
\hline More permanent housing options & $\begin{array}{l}\text { Remove native trees from roadsides (town } \\
\text { safety / bushfire risk reduction) }\end{array}$ & Health \& wellbeing precinct \\
\hline $\begin{array}{l}\text { Set up Bush camping/campervan overflow at } \\
\text { Rec Reserve to help with tourist congestion in } \\
\text { town }\end{array}$ & 2nd CFA truck & Arts Trail \& sculpture walk along Barwon River \\
\hline Solar farm & & $\begin{array}{l}\text { Art Gallery and Studio (perhaps at old CFA } \\
\text { building) }\end{array}$ \\
\hline Micro Grid & & Tennis courts - greater access \\
\hline
\end{tabular}




\section{Community Convo}

- Small group discussion

- click: Invited to 'join breakout session \#

- Discuss what you see and write down on paper any Q's and suggestions for and about infrastructure projects. 


\section{Questions about the infrastructure projects}

- Write any Q's and suggestions into the chat session.

- These will be answered shortly by James from COS

- James will give a 3min answer to ensure all get heard 


\section{Next Steps}

- We'll get back to you about what we heard

- COS will send out to all a Survey Monkey to rank the projects

- There will be another opportunity for this session on Friday morning - tell your friends 


\section{Appendix \#3}

The Forrest and District Plan: Towards 2030, final published version 



\section{Forrest \& District Plan $>>$ TOWARDS 2030}

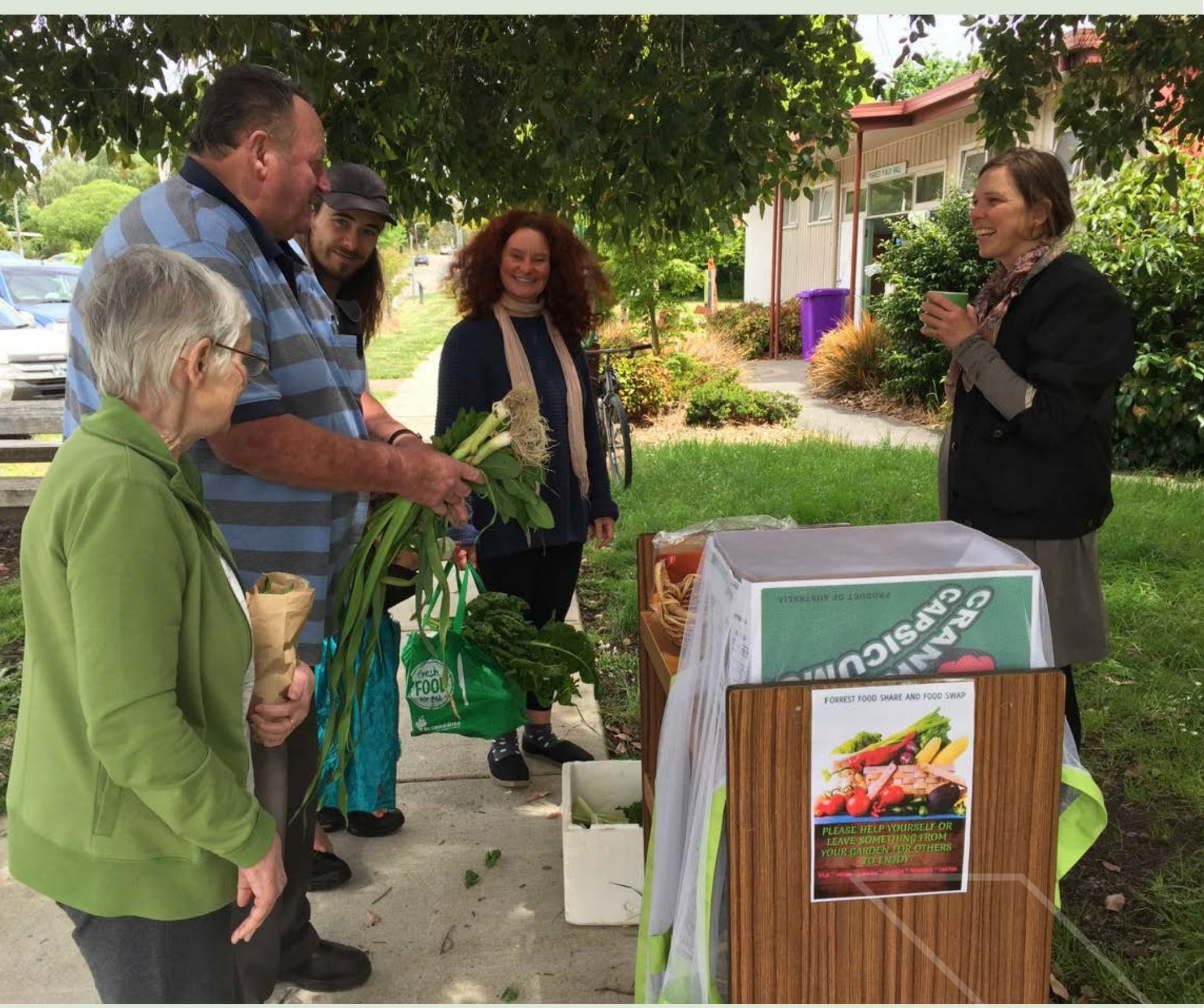

Forrest and District Community Group

Deakin University

Department of Environment, Land, Water and Planning (DELWP)

Colac Otway Shire

Authors: Szetey, K, Ashton, E, Bradshaw, S, 2020, The Forrest and District Plan: Towards 2030, Victoria, Australia.

Contributors: James Myatt, Martin Butcher

25 October, 2020 


\section{Contents}

\section{Executive Summary}

Forrest \& District Plan: Towards 2030

Forrest in 2020

Priorities

\section{INTRODUCTION}

Commitment to country

A community-owned plan for the future

\section{TOWARDS 2030}

2.1 Sustainability principles of the plan

2.2 The community's 5 goals

2.3 Plan impact

2.4 Recent projects and investigations

\section{CONTEXT}

3.1 Forrest and District's first people

International Indigenous Design Charter

3.2 Forrest and District - since 1890

3.3 Topography and landscape

3.4 Forrest historical timeline

\section{COMMUNITY ANALYSIS}

4.1 Community snapshot (Census data)

\subsection{Community strength}

Liveability and community

Economy

Services

4.3 Social, human and economic capital

Social capital

Human capital

Economic capital

\section{COMMUNITY ENGAGEMENT 2015-20 35}

5.1 Visioning and ideas workshop $\quad 35$

5.2 Key themes 36

5.3 Community surveys $\quad 38$

5.4 Community infrastructure priorities $2020 \quad 46$

5.5 Community ideas for town improvements towards 2030 48

\section{FUTURE CONSIDERATIONS 50}

6.1 Drivers of change (future scanning) 50

Population and demographics $\quad 50$

Residential land development $\quad 50$

Affordability of property and

suitability of housing 51

Inequality 51

Local economy 52

Environment 52

Major infrastructure projects 53

Transport and connectivity 53

Local school 53

Climate change 54

6.2 Current government objectives 55

7 APPENDICES $\quad 58$

Bibliography of previous strategies and reports 58 Glossary $\quad 59$

References cited in this report 59

Sustainable Development Goals $\quad 60$

Scenarios 61 
Exective Summant

\section{Forrest \& District Plan: Towards 2030}

An initiative of the Forrest

Community, the Forrest \& District

Plan: Towards 2030 is the result

of many years of community

consultation and articulates the community of Forrest and District's goals for growth and prosperity over the next ten years to 2030 .

The Plan has been written by community representatives for the community and consolidates the collected thoughts across many years of deliberations. The opportunity to

\section{A 10-YEAR VISION}

This dynamic rural community has demonstrated its capacity to be resilient and adaptive, and now looks forward to a future that uses a thoughtful and robust framework for community development.

As a gateway town to the Otway Ranges, Forrest and District offers an opportunity to connect with the natural environment and cultural landscape and maximise enrichment of the Otways experience. Not only

\section{KEY THEMES}

Six key themes were identified from community engagement.

Nature: The pristine natural environment is a major drawcard for both residents and tourists. The spectacular surrounding bushland and the proximity to the Great Ocean Road were both cited by residents as benefits of living in Forrest and District. People wanted more connection to Indigenous knowledge and practices.

Community: Forrest and District have a small-town charm. The community are highly supportive of one another and the many local community groups are indicative of the tight-knit, connected character of the local residents. produce a comprehensive document (the Plan), was a rare moment to combine all the consultations and reports into one place: a synthesis that expresses key themes, community values, concerns and aspirations.

The document aims to support future planning for the community over the next 10 years (2020-2030), acknowledging key characteristics and driving forces to encourage sustainable development. The Plan will give clarity to government and

does the community cherish the rich landscape of the Gadubanud country in the Otways, but they share it with the wider populations of Victoria and Australia, through tourism and its supporting activities, land managers both government and private, and research projects.

The Plan was written during the 2020 COVID-19 pandemic, and this context is important to keep in mind

Infrastructure: In order for Forrest and District to progress and prosper, investment in infrastructure is needed. The current situation sees failing wastewater infrastructure, inadequate communications infrastructure, insufficient housing, and a community vulnerable to bushfire without a local bushfire place of last resort. Additional improvements to local bike/horseriding/walking trails and a view to sustainability (e.g. integrated water management, microgrids, solar panels) were expressed by the community.

Recreation: Infrastructure focused around recreation was noted by many - including tourism, mountain biking, sport, horse-riding, camping agencies about the sort of community Forrest and District aspires to be.

The Plan identifies the community's five key goals. These goals reflect place-based planning and priorities across the themes of nature, community, infrastructure, recreation, challenges and the future that can enhance the delivery of government services, with the focus on the community rather than the individual services. They help determine the community's aspirations and the issues that need to be addressed.

as its impact across society and the economy are likely to have informed the considerations of the authors and community contributors. The pandemic will affect government decision-making for years to come. While its impact on the region over the long term is uncertain, assessment of the Plan against this new reality reinforces and strengthens the need for the goals and priorities identified.

and art. The interplay between tourist needs and local resident needs was highlighted.

Challenges: Vulnerability to bushfire and climate change are key concerns of the community. The future of local agriculture is also a concern.

The Future: The local community are positive about their sustainability aspirations. They have ideas for energy independence, food systems and food sharing, progressive farming techniques, and what the future economy of Forrest and District might look like.

Based on these themes, five goals were developed for the future of Forrest and District. 


\section{CORE RECOMMENDATION}

That investments and project decisions in Forrest and District should be made in line with the goals, values and priorities identified in this Plan, and with respect to the outcomes of extensive consultation over the past five years that have informed this Plan.

\section{FORREST AND DISTRICT'S FIVE GOALS}

A BUSHFIRE-SAFE COMMUNITY which encourages resilience to live safely in the Otways environment

2. A DIVERSE AND SUSTAINABLE ECONOMY including sustainable tourism and diversifying to open opportunities in other sectors

3 GREAT PUBLIC AND PRIVATE INFRASTRUCTURE to ensure long-term viability to support liveability, amenity, the environment, and growth opportunities

4 A CARED-FOR COMMUNITY that is supportive and inclusive with a focus on the wellbeing of residents

5 A SECURE FUTURE that considers the many threats such as climate change, public health risks, and bushfire

\section{STRATEGIC DIRECTION}

The community partnered with researchers from Deakin University's Local SDGs program to develop ways to adapt the United Nations Sustainable Development Goals in local communities. The Plan was developed using this framework underpinned by the principles of sustainability: Environment, Society and Economy. The SDGs are core to many government decision-making processes.

The community in Forrest and District expressed a desire for a future that is proactive with ideas to support environmental sustainability and self-sufficiency (e.g. solar microgrids, community farming/gardening projects, regenerative agriculture, and traditional burning). It has been empowered by taking opportunities to protect its built assets (DELWP sites hand-over in 2019) and create a community centre that will support bushfire safety.

\section{PROCESS}

The key consultation processes which informed this Plan were:

1. Forrest and District Community Group survey (2015)

2. Forrest Futures (leading to community management of the former DELWP sites 2017)

3. Forrest Wastewater Investigation (2017)

4. Forrest Common Masterplan (2018)

5. Forrest Gateway Project feasibility (2019)

6. Forrest Mountain Bike Trails redevelopment (2019)

7. Forrest Futures II (Deakin University SDG research (2020)

The Plan was drafted iteratively with two rounds of community comment, and revision made based upon the feedback received. This process served to validate the contents and conclusions of the Plan. The community had further options to participate, with two video conferencing meetings and a survey to rank infrastructure priorities. The Version 3 draft was sent to non-resident stakeholders, such as government and agencies, and this final version incorporates this feedback.

\section{ACKNOWLEDGEMENTS}

We would like to thank Deakin University's Local SDGs program team, and DELWP for providing their time and expertise in writing this Plan and assisting with community engagement. Ebony Hickey of the Wathaurong Aboriginal Co-operative provided an Indigenous perspective for the Plan's contents, and Gillian Brew provided graphic design services for the final publication.

The coordination and writing of this Plan was made possible through the Forrest Gateway Project, funded by the State Government's Virtual Centre for Climate Change Innovation (Emma Ashton), and the lan Potter Foundation (Katrina Szetey). Sharon Bradshaw, in her role as secretary of the Forrest and District Community Group, volunteered her time to consult on the writing of this Plan. 


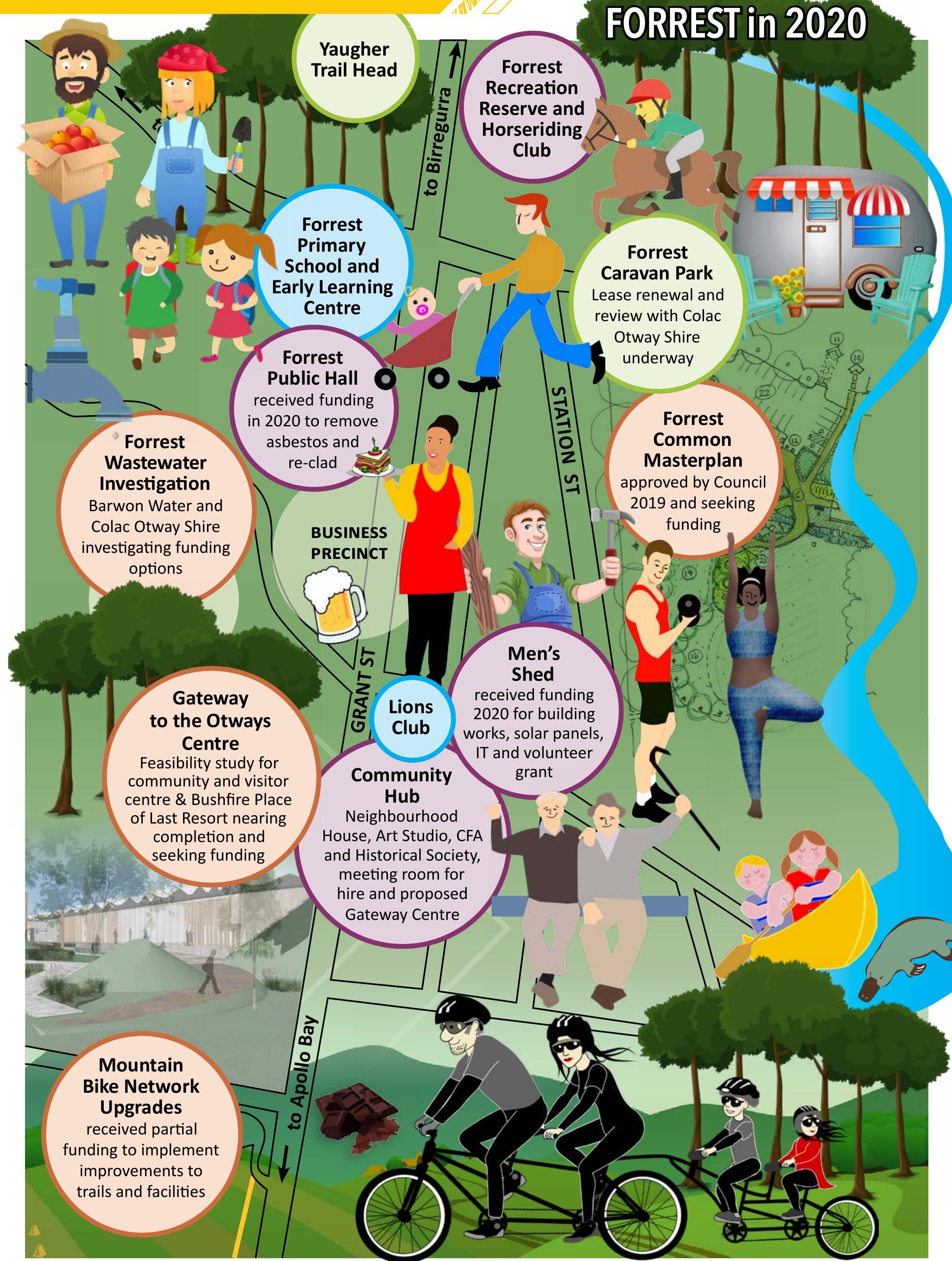




\section{Priorities}

To help achieve the five goals, a number of priorities have been identified by the community. Some are the responsibility of government and council, public or private enterprises and organisations, and others may be priorities the community can take on. Many priorities are in progress and completion could pave the way for further ideas. Investments and project decisions should be made in line with the goals, values and priorities and with respect to the outcomes of extensive consultations that have informed this Plan. The impact of the Plan and meeting these goals will reach far beyond the population of Forrest \& District.

Gateway to the Otways Centre The Gateway to the Otways Centre is a community-led initiative for driving climate and economic adaptation, resilience and recovery, while celebrating the unique and accessible beauty of the Otway Ranges. The project involves constructing a best-practice, fire-adapted building which will have everyday use as a community and visitor hub, a research and learning centre and a co-located CFA fire station. The design enables the Centre to operate as a Bushfire Place of Last Resort and will help achieve all five community goals (see section 2.4 for details).

Integrated Water Management Plan incorporating new wastewater infrastructure The lack of suitable wastewater facilities in Forrest is an impediment to community development and poses a public health risk. Installing new wastewater infrastructure will advance many other improvements, such as residential development and health and wellbeing. Developing a fully integrated water management plan will set up the community for a sustainable future and help achieve all five community goals. Wastewater infrastructure is an urgent priority. (see section 2.4 for details)

Mountain Bike Trails Design Project Upgrading the mountain bike trail facilities and trail network will help achieve four community goals. Upgraded trails will also benefit horse-riders and walkers. This project has been through extensive community consultation, and with funding, can be realised quickly (see section 2.4 for details).

Revitalised Forrest Common (and Forrest Caravan Park) precinct The Forrest Common located on Station Street is a 1.5ha township parkland that is well used by the community and visitors and includes a playground, tennis courts, car park, picnic and BBQ facility, and expansive lawn area. A Master Plan developed by the community and Colac Otway Shire in 2019 to revitalise this precinct has been endorsed and is awaiting funding. The Forrest Caravan Park is a leased area adjoining this precinct and is due for lease renewal in 2021. Addressing these will help achieve four community goals.

Improve communications infrastructure Many residents noted frustrations with poor internet and mobile service. Not only are these safety concerns for residents - bushfire safety information is increasingly moving online, and the defunding of the $A B C$ puts their crucial bushfire services at risk. It is also an impediment to local business growth and affects education opportunities for youth and the whole community. This will help with all five goals.

\section{Changes to zoning laws to allow residential development on agricultural land adjacent to township boundary.} The lack of housing for residents is a central problem in the community. Changes to zoning laws is a step toward fixing this problem. Development adjacent to and within township boundaries will support the school and local businesses and provide access to services where a bushfire place of last resort can be provided and the CFA and Police are present. This will facilitate development of housing both for locals and tourist accommodation and will help with four community goals.

Regular public transport links A once-weekly bus to Birregurra, Colac and Apollo Bay is a clear lack of accessibility. More frequent bus services to local centres will provide mobility for local residents and reduce reliance on private cars, improving health and wellbeing. This will help with four community goals.

Community garden An integrated community garden with the Forrest Learning Centre will help with two community goals, and will be easily achievable as the garden at the school already exists.

Second CFA truck An appropriately resourced volunteer firefighting brigade fulfils two community goals and will go a long way toward assisting with bushfire safety, and is a 'quick win' for which there has been strong community support and fundraising. 
8 Forrest \& District Plan $>>$ TOWARDS 2030
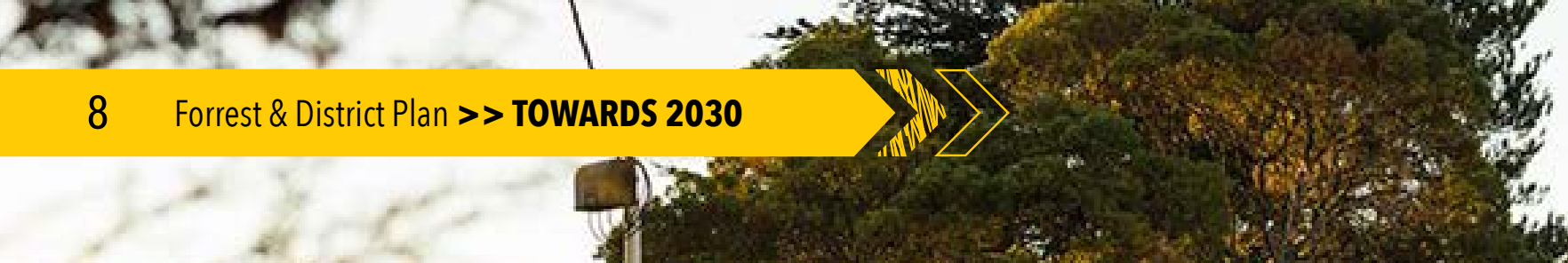

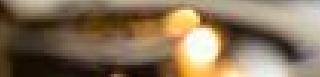

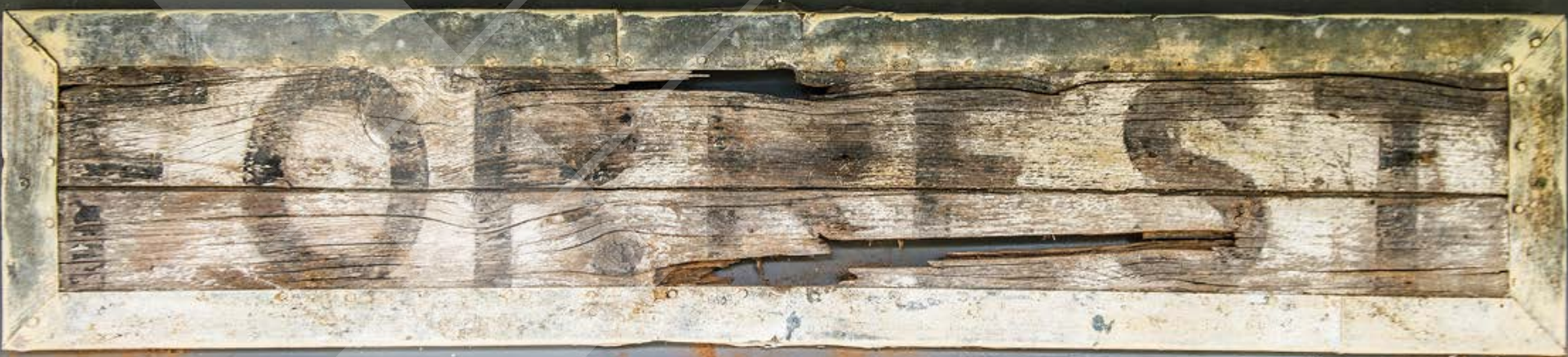




\section{NTRODUCTION}

Forrest is a small rural township set in the cool temperate rainforest of Gadubanud and Gulidjan country in the Otway Ranges (the Otways), Victoria, Australia. It is surrounded by the smaller hamlets of Barwon Downs, Gerangamete and Barramunga, which are all part of the Maar Nation. This collective region is known as Forrest and District. At the 2016 census Forrest had a permanent population of 230 and the Forrest and District had 473 people. In addition to permanent residents, a number of part-time residents increase the population. Forrest and District acts as a central hub for the northern gateway to the Otways and regularly attracts visitors to the town. Numbers swell on weekends and there are visitors to Forrest on any day of the week. During special events such as the Forrest SoupFest and the Otway Odyssey, numbers can grow to beyond 5000 .

\section{Commitment to country}

We acknowledge the Maar as a sovereign Nation and pay our respects to all Traditional Owners: those who live on Country, those passing through, and their ancestors who carefully and thoughtfully managed and cared for the Country that we have all been lucky to call home since the beginning of time. We commit to working openly and honestly with Traditional Owners to ensure that culturally appropriate and respectful relationships with Maar people and their natural resources are always upheld.

\section{A community-owned plan for the future}

In April 2020, the Forrest and District community began writing a community development plan for the near-term future, titled the Forrest \& District Plan: Towards 2030.

The Plan emerged from the research partnership between the community (through the Forrest Gateway Project) and Deakin University's program to adapt the United Nations Sustainable Development Goals (SDGs) in local communities. It clarifies the highlevel goals of the community and the projects that are needed to support them. It builds upon the spirit of community-led decision making that was embodied by the Forrest Futures consultations (2017 \& 2019 in collaboration with DELWP). A well-supported process of community engagement empowered the community to think strategically about what they wanted. This Plan grew from that ethos.

The Plan is a resource coordinated and owned by the community. It has been prepared collaboratively with the local community, traditional owners, Forrest and District Community Group (FDCG), Deakin University's Local Sustainable Development Goal Program Team, Colac Otway Shire Council, and the Victorian Department of Environment, Land, Water and Planning (DELWP).

The Plan reflects the community's priorities as determined by the work that Deakin University and DELWP have undertaken in their localisation of the UN's Sustainable Development Goals (see Appendix) for Forrest, and draws on the Transitioning Towns Toolbox as developed by Regional Development Victoria.

The information contained in this Plan may sometimes only address Forrest, as opposed to Forrest and District. In part, this is due to the central nature of Forrest's location and services - it is a hub for the surrounding communities. The future of Forrest and its services (economic and social) will have a significant impact on the district townships.

\section{A transition town}

Since European settlement the area has seen significant change, and most recently over the past 20 years, the local community has experienced a period of adaptive re-use. Following a 150-year history in forestry (logging and milling) that ended around 2003, Forrest reinvented itself to connect with the forests in a new way through tourism, hospitality and recreation, and a richer understanding of the significance of the cultural landscape, capitalising on the natural landscape and becoming the Gateway to the Otway Ranges. Around the same time, there was a decline in local agriculture, which the community adapted to by evolving agricultural and food systems.

This document tells of the transition by the community to the currentday drivers of tourism, regional population growth and increasing climate change. It aims to support the community to achieve its goals of a stable society, economy, and environment into the future. 


\section{TOWARDS 2030}

\subsection{Sustainability principles of the plan}

The Plan is underpinned by the three pillars of sustainability - society, economy, and environment. Researchers from Deakin University are working with the Forrest community to find ways to make Forrest socially inclusive, with a thriving economy and healthy local environment, guided by the principles of the UN Sustainable Development Goals (SDGs). The SDGs are a set of 17 goals adopted by all UN member states, based on the 2030 Agenda for Sustainable Development (see Appendix).

The SDGs can empower local communities and give them an autonomous voice to advance their own local sustainability ideas. To guide long-term planning and decision-making, researchers, governments and communities must work together to achieve sustainable futures. As part of the Deakin research,

\subsection{The community's 5 goals}

Using the data collected through the Forrest Futures II engagement process in 2019 (see section 4), five specifically tailored Goals were developed with the Forrest and District community. These Goals are:

\section{A bushfire-safe community \\ Forrest and District's location in Gadubanud Country at the edge of the Great Otway National Park puts it at high bushfire risk. A bushfire place of last resort and increasing bushfire safety is a community priority.}

\section{A diverse and sustainable economy}

Tourism in Forrest and District is here to stay, and working in tourism isn't for everyone. Diversifying the sorts of jobs that can be done in the area will make for a more resilient and better long-term outcome for all. This will also provide opportunities for young people that do not currently exist.

\section{Great public and private infrastructure} Improving public infrastructure, particularly an effective waste water treatment system, will enable the aspirations and long-term viability of Forrest and District.

\section{A cared-for community} Forrest and District are a supportive and inclusive community. This goal encompasses community programs, support for people with disability, accessibility to all, community governance, and the health and wellbeing of residents, which has a strong connection to the beautiful natural environment, and has been a practice of the Maar for eons.

\section{A secure future}

There are many threats which could affect the community. Resilience against threats such as climate change, public health risks, and bushfire are community priorities. The community have stated a strong commitment to respect and honour Indigenous peoples' connection to Forrest and District, and work in collaboration with Eastern Maar representatives over future developments. 


\section{Some of the ideas provided by the community are listed here, with their associated goal.}

"Explore housing, land and farming co-operatives"

"Be a model sustainable, adaptive town that demonstrates what is possible for others"

"Co-housing using environmental and social design - ensure a variety of affordable options for all socioeconomic groups"

"Consider how wastewater can be used for production"

"Solar farm/microgrid for town and sustainable power for low-income households" "Community energy plan" "Housing affordability, so that people and families who want to participate and live in Forrest and District can"

"Facilitate sharing of produce; local markets; reducing travel to Colac; increasing intake of healthy,

fresh wholefoods; increasing local income"

"Sharing practices of self and our relationship to Country, to relearn these knowledges and stories that have been here since time immemorial"

"Training in progressive farming techniques"

"Better maintenance of tracks would allow for more walking - good for health"

"Services and access to keep me living in Forrest as I age"

"More support for Neighbourhood House to deliver health and social services on a needs basis"

"Lack of transport to access support services - opportunities for community transport? Community minibus?"
"If fire impacts town - plans (should already be)

in place for best-practice rebuild. (We need to)

transition to a real fire-adapted town"

"Clean energy, sustainable agriculture, revegetation of carbon dense forest"

"Parks Vic to maintain forest tracks for firefighting access"

"Encourage businesses that cater to local as well as tourist needs"

"A First Nations-led approach to cultural tourism that supports self-determination and knowledge exchange with local community"

"Environment, health, ecology, coastal science, forest conservation,

community development - all jobs that would be good
GOAL 2:

Diverse and

sustainable economy to create in Forrest"
"Education focused on keeping children in the area. Focus on futuregrowth/ sustainability" proofing employment/

\section{GOAL 3:} and private infrastructure Great public
"Involvement with First Nations/Maar planners who can balance interconnected themes of country, culture and identify highlighting cultural expression"

"Sewerage still remains a big issue and prevents new growth and new business"

"Channel routes - Colac-Forrest Rd, Birre-Forrest Rd, Apollo Bay-Forrest Rd, require urgent attention"

"Rail trail - an extended rail trail would link biking culture with food trail opportunities and sustainable tourism/transport"

"Improve wireless internet as reception poor on outskirts" 


\subsection{Plan impact}

The population of Forrest and District was 473 as at the 2016 Census, however the number of people who will be impacted by this plan is far greater than this. The COVID-19 pandemic has affected visitor numbers but in general the number of residents plus visitors is much higher. During special events such as Forrest SoupFest and Otway Odyssey, the number of visitors can grow to beyond 5,000. Colac Otway Shire receives over 1 million visitors each year, some of whom will pass through Forrest and District.

Colac Otway Shire are aiming for population growth in Colac $(20,000$ people by 2050), and the G21 Region (Geelong Regional Alliance) estimates that the region will grow to 500,000 people by 2050. This points very strongly to regional development opportunities that Forrest and District can place itself to take advantage of by realising some of the objectives identified in this Plan.

In the face of the COVID-19 pandemic, we have all been forced to challenge assumptions about the location of our workplaces. Forrest and District could capitalise on this by becoming a remote working hub for the community and visitors.

If Forrest and District are enabled to achieve their infrastructure ambitions, this will not only support the townships and their permanent residents, but also keep visitors safe and local businesses prosperous.
It will also address broader regional issues such as investment in bushfire safety. Maintaining and growing the population will ensure crucial local services such as the Forrest Primary School and Early Years Centre remain and are strengthened.

The place-based planning demonstrated in this Plan can enhance the delivery of government services with the focus on the community rather than individual services. This will enable the strengthening of links to, and involvement of state agencies within Forrest and District, particularly Parks Victoria, DELWP, Barwon Water, Regional Roads Victoria and Fire Rescue Victoria/CFA.

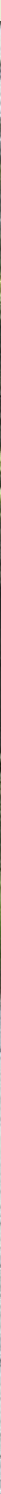




\subsection{Recent projects and investigations}

Although many consultations have informed the Community Goals and plans for the next 10 years, there have been four major community infrastructure projects that have received extra funding for feasibility studies and community attention. The following projects are seeking funding and further commitment to be advanced and completed.

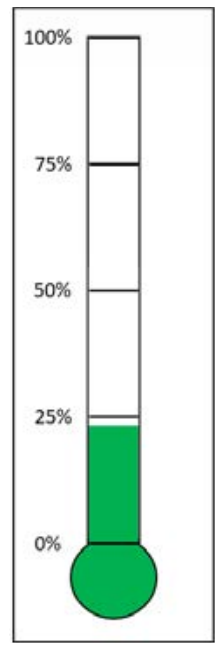

\section{FORREST MOUNTAIN BIKE TRAILS PROJECT (Supports 4 Community Goals)}

- Total project budget: $\$ 4.55$ million

- Funds committed to date: $\$ 1.05$ million

- Remaining funds required: $\$ 3.5$ million

The development of the mountain bike trail network began around 2005 with an initial investment of $\$ 500,000$ by the Victorian State Government (DELWP). DELWP have demonstrated strong support and commitment for investment in recreational facilities, by working collaboratively with the local community, Colac Otway Shire and the Forrest MTB Club. This investment in public infrastruture has been the catalyst for private investment particularly in accommodation and hospitality venues in and around the township. Since then, Forrest has become known for its mountain bike trails which attract many domestic and international cycling enthusiasts each year. It is a Council and DELWP priority to procure funding to complete the implementation of the Forrest Mountain Bike
- Ongoing investment: Trails maintenance (DELWP), Local Government (planning) and inkind Forrest Mountain Bike Club committee

Strategic Plan (G21 Geelong Regional Alliance, 2019). When completed, this strategic plan is estimated to draw up to 40,000 cycling enthusiasts per year, which will support more employment and increase demand for accommodation, resulting in an increased annual economic benefit of $\$ 8.4$ million for the Forrest region. REMPLAN provides data specifically for Colac Otway which indicates the following for 2016-17:

- Jobs supported by tourism: a total of approximately 950 jobs were supported by the tourism sector in Colac Otway.

- Tourism wages: tourism generated $\$ 39.9 \mathrm{~m}$ in wages in 2016-17.

- Tourism GVA (Gross Value Added): tourism accounted for \$74.3m in GVA.

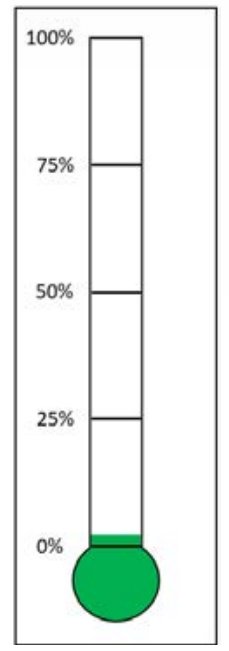

\section{FORREST GATEWAY TO THE OTWAYS CENTRE (Supports 5 Community Goals)}

\section{- Total project budget: $\$ 12$ million}

- Funds committed to date: $\$ 250,000$ (State Government for community-led feasibility studies 2018-2020)

Through a grant from DELWP's Virtual Centre for Climate Change Innovation, the community has undertaken studies to assess options for improving socio-economic and environmental sustainability and resilience for the community in the context of climate change. A central outcome of the studies is the design for the Gateway to the Otways Centre, which is to be built on one of the vacated DELWP sites. This will be a state-of-the-art building functioning as a bushfire place of last resort, while also housing community facilities and the CFA station, together with a multipurpose centre for interactive visitor experiences and climate change education and research.

Community management of these sites presents a unique opportunity for Forrest to establish
- Remaining funds required: $\$ 11.75$ million

- On-going investment: in-kind Forrest Gateway Project steering committee

and strengthen a range of community services and assets sorely needed in the township and surrounding districts. This process has enabled the consideration of long-term community development aspirations that serve not just the Forrest community, but also the many visitors who come to Forrest to experience the Otway region. Whilst there are many dimensions to resilient communities, designing new community infrastructure that responds to our changing climate and potential bushfire impact will be vital for Forrest's community resilience. The residents of Forrest identified this as one of their highest priorities as part of the Forrest Futures engagement process and this seeks to address aspects related to developing a fire-adapted community building as a central pillar within the community's broader aspirations. 


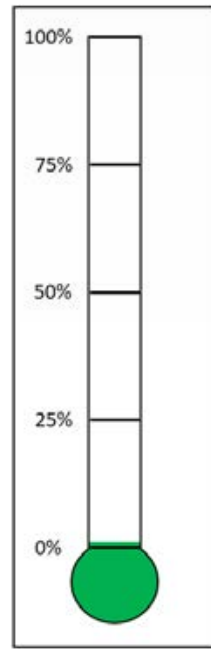

\section{FORREST WASTEWATER INVESTIGATION AND ECONOMIC ASSESSMENT (Supports 5 Community Goals)}

- Total project budget (preferred solution): \$10.1 million

\section{- Funds committed to date: $\$ 120,000$ (Barwon Water feasibility studies 2017-2020)}

The Forrest and District Community Group approached the Victorian Water Minister in late 2016 to raise concerns about wastewater issues that were affecting the town. As a result, Barwon Water and Colac Otway Shire Council partnered with the Forrest community to investigate opportunities for wastewater improvements across the township. This partnership acknowledged the growing role tourism plays in Forrest and the regional economy, and the increasing stress this may place on existing wastewater systems in the town.

Council commissioned an initial audit of the existing on-site systems to determine the extent of the problem. This work confirmed there were widespread problems across the township where a large proportion of existing systems were inadequate for managing loads from existing houses in the town. The audit indicated that the total number of systems that were considered to be failing and/or impacting on health and the environment was approximately $60 \%-70 \%$.

It was determined that the township was currently (and would continue to be) well below the World Health Organisations target for Disease Protection due to discharge of wastewater off-site (four times below the WHO threshold). Many of the smaller properties in the town centre are too small to
- Remaining funds required: $\$ 9.98$ million

- On-going investment: in kind Forrest and District Community Group committee

safely contain wastewater on-site under current EPA standards.

A full description of the options can be found here https://www.yoursay.barwonwater.vic.gov. au/28609/widgets/181978/documents/110921

While there was a range of wastewater infrastructure solutions presented to community, Solution Package 3 received the most votes from the community and was therefore nominated as the preferred solution for addressing wastewater issues. This solution involves a combination of on-property and off-property treatment and irrigation of recycled water. This provides the dual benefits of providing water for use by residents whilst also reducing the treatment and irrigation requirements at the local water recycling system. The proposed solution is to be delivered and managed by a single responsible management entity. All on-property systems will also be managed by the management entity and not individual homeowners.

Barwon Water has now engaged Marsden Jacob Associates (MJA) to undertake a cost-benefit analysis for the preferred Forrest wastewater solution. The aim of MJA's work is to collect the data required to understand the costs and benefits of the system holistically. This will help plan any next steps. 


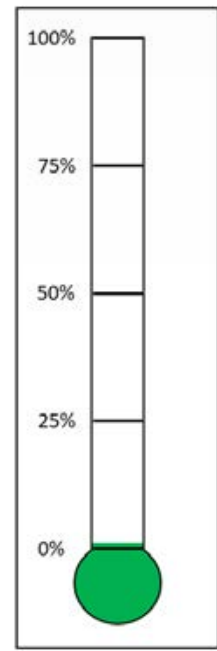

\section{FORREST COMMON MASTERPLAN (Supports 4 Community Goals)}

- Total project budget: $\$ 1.7$ million

- Funds committed to date: $\$ 15,000$

The Forrest and District Community Group were successful in receiving a funding allocation under Council's 2017/18 Small Town Improvement Program (STIP) to develop a master plan for the Forrest Common. The Forrest Common is located on Station Street, Forrest and is used by locals and visitors, including caravan park patrons, people using the local mountain bike trail network and Tennis Club members. The Forrest Common is 1.5ha in size and is classified as township parkland as per the Colac Otway Public Open Space Strategy (2011). The parkland has the following existing features:

- BBO and shelter

- Playground

- Limited natural shade areas

- Picnic tables and seats

- Bike racks

- Lawn area

- Interpretive signage/ information board for the Forrest History walk

- Tennis courts

- Skate pad

- Car parking area.

The community advocated for the Forrest Common to be developed with guiding themes and stories, represented through the installation of bespoke, unique and customised elements that represent the character and history of Forrest. The proposed development of the Forrest Common Master Plan is supported by the Colac Otway Public Open Space Strategy (2011). However, the level and standard of development proposed is higher than the Standards for Open Space Development for a Township park
- Remaining funds required: \$1.55 million

- On-going investment: in kind Forrest and District Community Group sub-committee

as outlined in the strategy. The estimated cost for full implementation of the plan is $\$ 1,696,569$ over four or more stages, with an additional, ongoing maintenance cost annually of approximately $\$ 25,000$ following completion of the works. Officers have prepared a minimum stage 1 scope of works that would see a portion of the play and path network development completed in line with Council's typical spend and may assist the community in leveraging funding for further improvements. The total cost of minimum stage 1 works is estimated to be $\$ 311,751$. The implementation of the master plan is subject to future Council budget considerations and the ability to access funding from other external funding sources.

Adjoining this land is the Forrest Caravan Park. In June 2020, the community were consulted about an Expression of Interest process for the new 20 year lease. The purpose of this community consultation was to provide an opportunity for the Forrest and District community to comment on the area of land included, but also to better understand what the Forrest community wants to achieve from the caravan park lease. The lease for the Forrest Caravan Park, which was originally drawn up in 2001, expires in April 2021 (negotiations are currently underway for a one year extension). The Colac Otway Shire Council has decided to test the market by inviting Expressions of Interest (EOI) from operators interested in managing the Forrest caravan park.

\section{TIGER RAIL TRAIL}

\section{- Total Project budget: $\$ 9$ million • Currently no active support to extend this Trail}

The "Tiger" Rail Trail was officially opened on Sunday 12th June, 2011 and was held in conjunction with the Forrest Soup Fest. Currently $7 \mathrm{~km}$ of the trail is completed from the Forrest end. The trail begins in Forrest, across the road from the Terminus Hotel on Henry Street. It is a short but wellmaintained trail, with interpretative signage along the way. It is a critical linking trail for the Mountain Bike Trail network, connecting the Southern and Northern trails. It is also well used by walkers and horse-riders accessing the Forrest Recreation Reserve.
The original construction of the rail line to Forrest from Birregurra began in 1889 and was completed at a cost of 96,000 pounds. It was opened to Deans Marsh on December 19, 1889 and to Forrest on June 5, 1891. The line was used by tourists bound for the coastal resorts of Lorne and Apollo Bay. The Forrest line was closed in 1957.

The trail's "Tiger" moniker comes from the days when trains stopped running between the towns of Birregurra and Forrest. A converted Dodge sedan, painted black and yellow, ferried passengers instead.
The grand vision for this trail was to start in Birregurra, on the main Melbourne - Warrnambool rail line, meander along the old railway formation, through Deans Marsh, to the existing section near Barwon Downs and on to Forrest, for a total length of $30 \mathrm{~km}$. A feasibility study in 2015 for this extension found it unviable due to opposition from landowners whose land the trail would run through, and because of an estimated $\$ 9$ million cost for replacing 22 bridges along its length. 


\section{Forrest \& District Plan $>>$ TOWARDS 2030}

Smoking ceremony at Forrest \& District Men's Shed opening

\section{Commitment to country}

We acknowledge the Maar as a sovereign Nation and pay our respects to all Traditional Owners: those who live on Country, those passing through, and their ancestors who carefully and thoughtfully managed and cared for the Country that we have all been lucky to call home since the beginning of time.

We commit to working openly and honestly with Traditional Owners to ensure that culturally appropriate and respectful relationships with Maar people and their natural resources are aways upheld.

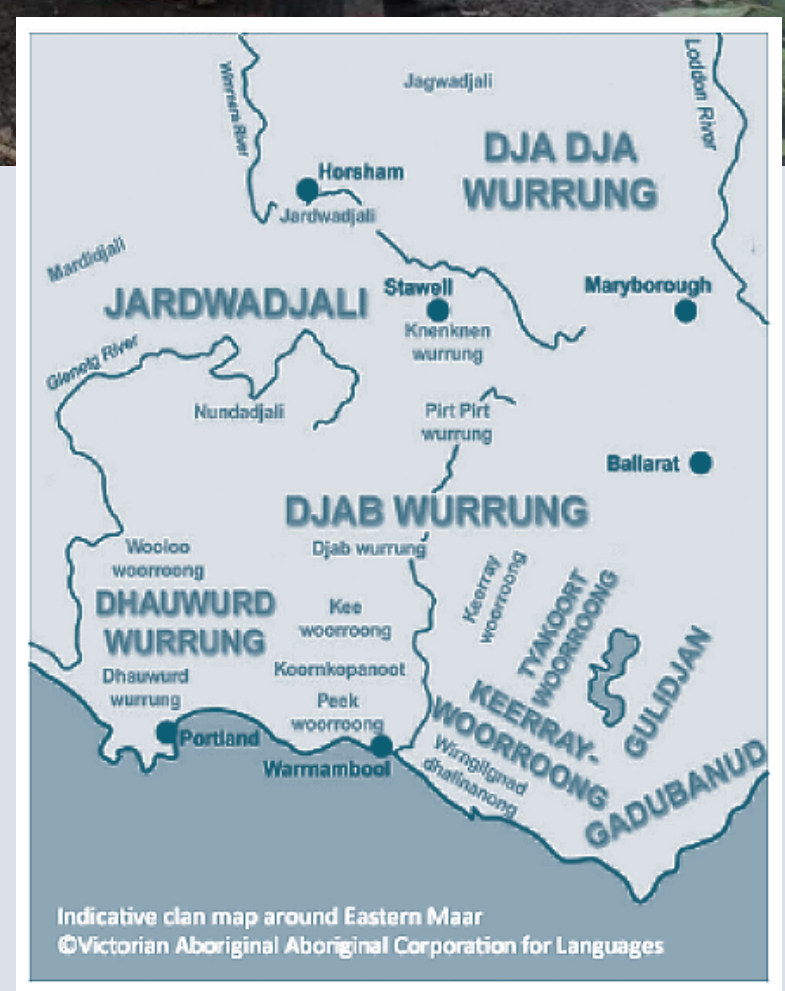


3

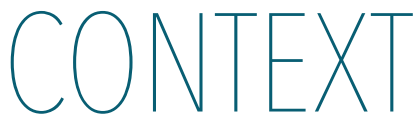

Forrest \& District have long been places where people have congregated for ceremony, celebration and culture. This tradition continues today with both local people and visitors from afar sharing the rich landscape.

\subsection{Forrest and District's first people}

As mentioned throughout this document, Forrest and the surrounding district lie proudly within the borders of the Maar nation. Despite the population declining upon the invasion of Europeans due to disease and genocide, we are very lucky to have survivors of the ancestors active in our district to this day.

Eastern Maar people continue to maintain economic, traditional, cultural, familial and spiritual ties in Forrest and District. Through the leadership and cultural authority, Traditional Owners are able to practice laws and customs, strengthen systems of governance, and nurture connection to Country.

Indigenous ecological knowledge allows interaction with Country and its plants and animals. It guides

\section{Recognised Aboriginal Party}

Eastern Maar were appointed a Recognised Aboriginal Party on 5 December 2013.
A Recognised Aboriginal Party is the primary source of advice and knowledge on matters relating to Aboriginal places or Aboriginal objects in their region. Their core functions include:
- evaluating Cultural Heritage Management Plans
- assessing Cultural Heritage Permit applications

the identification and utilisation of resources for traditional purposes and the basics of life. The Country of Forrest and District is resource and landscape rich, with reliable food sources all year. This meant that ancestors could avoid travelling far and were able to construct both permanent and semi-permanent settlements. From these settlements they undertook traditional land management practices, including the use of fire, and farming practices to sustain themselves on local food sources. The local Indigenous community continue to practice sustainable living today by several means, including hunting for traditional game such as kangaroo and duck and the harvesting of edible plants such as the Daisy Yam and Pigface.

- making decisions about Cultural Heritage Agreements

- providing advice on applications for interim or ongoing Protection Declarations

- entering into Aboriginal Cultural Heritage Land Management Agreements with public land managers

- nominating Aboriginal intangible heritage to the Victorian Aboriginal Heritage Register and managing intangible heritage agreements.
Oral stories that pre-date western settlement scatter the landscape of Forrest and District like a mosaic of largely untapped knowledge, However, despite what has been lost, much survives in language throughout the district. Sharing and reciprocity are such important parts of Gadubanud Story and form part of a complex cultural support system in terms of caring for country, our enormous waterways, and the people who live on Country.
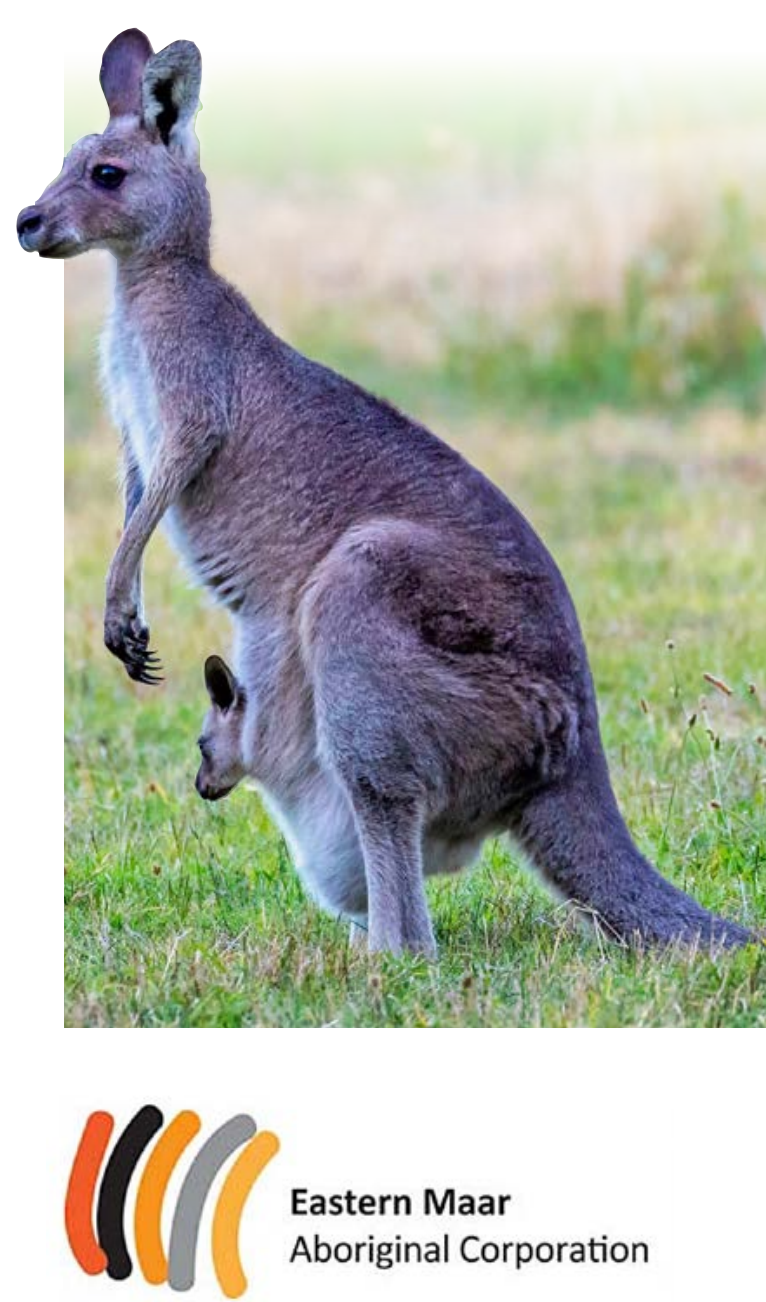

Eastern Maar Aboriginal Corporation 


\section{International Indigenous Design Charter}

The International Indigenous Design Charter takes into consideration the needs of the diverse communities and cultures globally and has 10 principles:

\section{Indigenous led:}

Ensure Indigenous stakeholders oversee creative development and the design process.

\section{Self-determined:}

Respect the rights of Indigenous peoples to determine the application of traditional knowledge and representation of their culture in design practice.

\section{Community specific:}

Ensure respect for the diversity of Indigenous culture by acknowledging and following regional cultural understandings.

\section{Deep listening:}

Ensure respectful, culturally specific, personal engagement behaviours for effective communication and courteous interaction. Make sure to be inclusive and ensure that recognised custodians are actively involved and consulted.

\section{Indigenous knowledge:}

Acknowledge and respect the rich cultural history of Indigenous knowledge. This includes designs, stories, sustainability and land management, with the understanding that ownership of knowledge must remain with the Indigenous custodians.

\section{Shared knowledge} (collaboration, co-creation, procurement):

Cultivate respectful, culturally specific, personal engagement behaviours for effective communication. This involves courteous interactions to encourage the transmission of shared knowledge by developing a cultural competency framework to remain aware of Indigenous cultural realities.

\section{Shared benefits:}

Ensure Indigenous people share in the benefits from the use of their cultural knowledge, especially where it is being commercially applied.

\section{Impact of design:}

Consider the reception and implication of all designs so that they protect the environment, are sustainable, and remain respectful of Indigenous cultures over deep time: past, present and future.

\section{Legal and moral:}

Demonstrate respect and honour cultural ownership and intellectual property rights, including moral rights, by obtaining appropriate permissions where required.

\section{Charter implementation:}

Ask the question if there is an aspect to the project, in relation to any design brief, that may be improved with Indigenous knowledge. Use the Charter to safeguard Indigenous design integrity and to help build the cultural awareness of your clients and associated stakeholders.
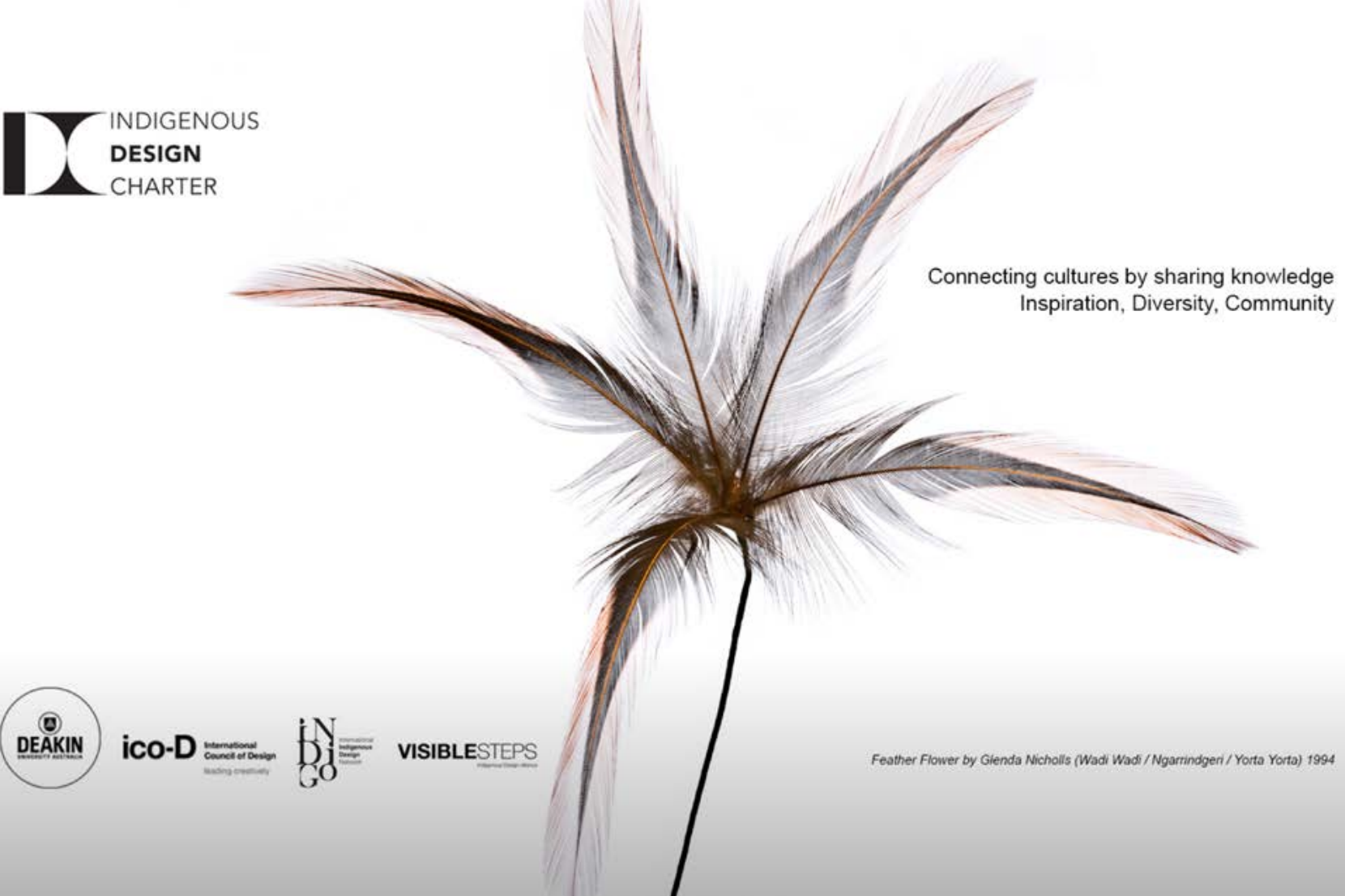


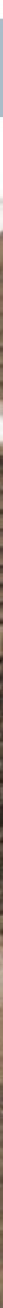

\subsection{Forrest and District - since 1890}

European settlement at Forrest was established in 1890, named after state MP Charles Forrest, who advocated for the rail line extension to Forrest. Historically, the region was a timber town with four sawmills in Forrest and neighbouring Yaugher. All of these mills are now closed. After the cessation of logging in the Otways in 2005, the Victorian Government made funds available for the creation of dedicated mountain bike trails in the Yaugher area. The project was the first time in Australia that mountain biking had been used as a driver for tourism and economic development. It was seen as an addition to the burgeoning local eco-tourism industry, and now makes up a large portion of the economy in Forrest, with over $60 \mathrm{~km}$ of sign posted "single track" in the area.

Forrest swiftly became one of the best holiday destinations in the Great Ocean Road hinterland, situated just a 30-minute drive through the Otways from the iconic coastal route.

The rural communities of Forrest and District lie at the northern gateway to the Otways. Forrest acts as a central hub for the area, which is known for mountain biking, hiking, camping, fishing, wild life watching, beer, food, wine and relaxation. The West Barwon River flows through the township and it is near the West Barwon reservoir, which services Geelong.

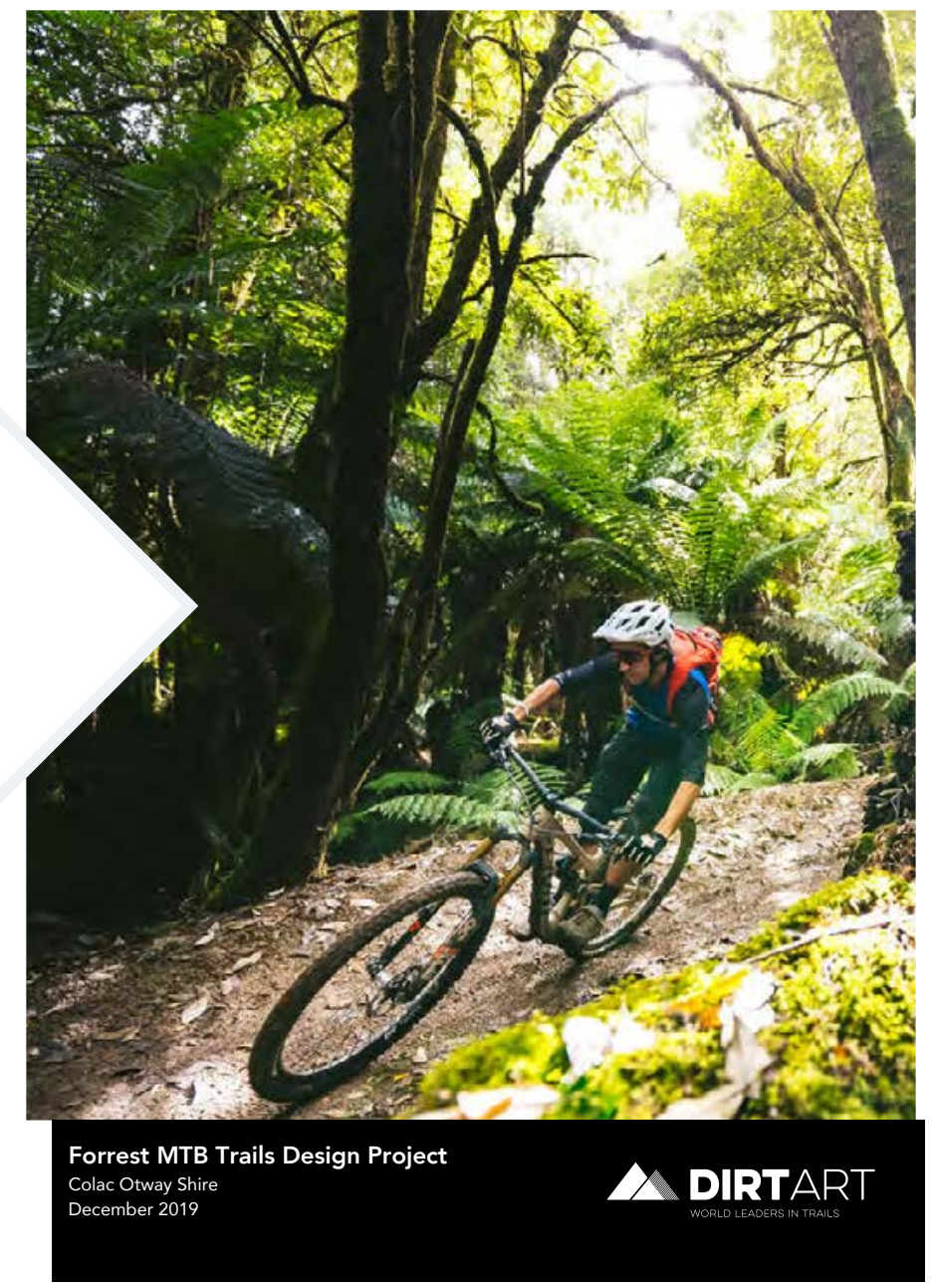




\subsection{Topography and landscape}

\section{Forrest in the Otway Ranges}

The Otway Ranges (the Otways) is characterised by diverse forest environments, and the communities of Forrest and District are situated on its northern slopes. The mountain range rises to $500-600 \mathrm{~m}$ off the surrounding plains and coast, and Forrest sits at the foot of the ranges at $182 \mathrm{~m}$ above sea level.

The dissected ridges of the ranges are a defining part of the landscape of the Otways, particularly where the ranges extend south to the sea at locations such as Mount Defiance and Cape Otway. Streams and waterfalls are common throughout the ranges, with an average rainfall that varies from about $600 \mathrm{~mm}$ near Anglesea to 2000mm near Lavers Hill, with Forrest receiving about $1000 \mathrm{~mm}$ per year.

The forests of the Otways are dominated by eucalypt species. The vegetation around Forrest varies from Heathy Woodland and Shrubby Foothill Forest to Wet Forest. Areas to the north also include extensive farmland and associated grasslands.

The Forrest district, Otway area and Barwon South West region are ecologically diverse, incorporating the hinterland forests of the Otways and the Great Ocean Road coastline. The area contains some of the most significant environmental assets found in Australia, including several endemic species, Ramsar-listed waterbodies, and protected habitats.

Forrest is surrounded by a mix of native forest, farming and semi-rural land. Soil types and climate of this area are suitable for agricultural production of dairy, beef, and produce: particularly potatoes, fruits, and mushrooms. They are also well suited for growing trees, and there are timber plantations in the region: south of Beech Forest; and to the north and southwest of Forrest.

\section{Bushfire risk}

The Otways District is recognised as one of the highest bushfire risk areas in Australia and the world (Bradstock, 2010). An assessment of bushfire risk found that Forrest has one of the highest bushfire risk profiles within Colac Otway Shire (Otway District Bushfire Planning Collaboration, 2016). This is due to a range of factors including the extent and proximity to dense vegetation, weather, climate, and the likelihood of fire reaching town and with the potential for significant house loss.

The surrounding topography has the ability to increase the severity of bushfires through the development of large convection columns, which can create bushfire-induced wind storms and support the launching of embers well ahead of a fire. With the increasing impact of climate change, the risk factors are predicted to increase, particularly around the drying of the vegetation, the length of fire seasons and the increased number of high-risk fire weather days.

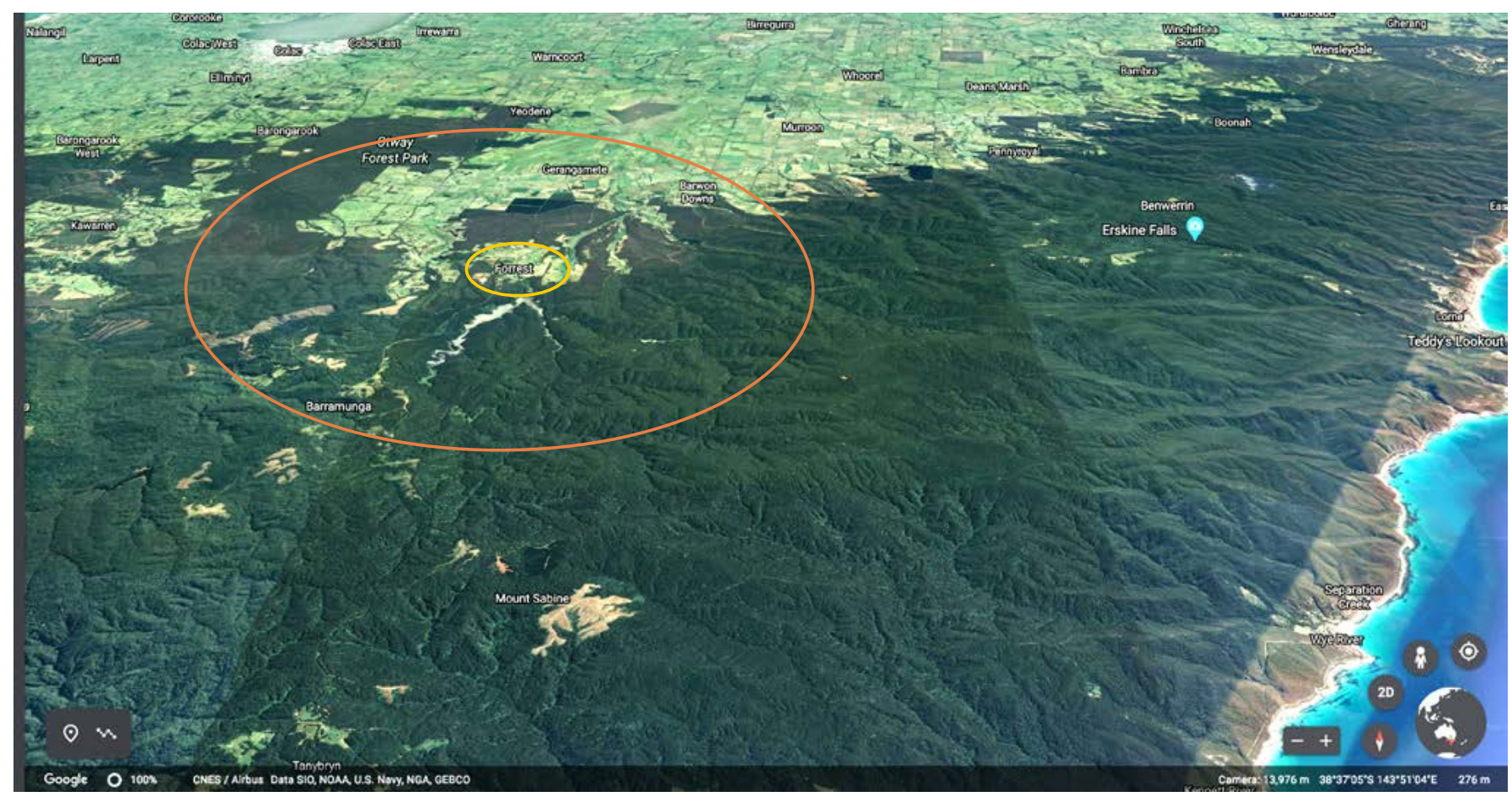




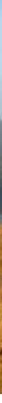

\section{Barwon River and West Barwon Reservoir}

The Barwon River begins in the creeks of the inland slopes of the Otway Ranges. The Upper Barwon sub-catchment is located along the inland slopes and plains of the Otway Ranges to the north of Lorne and east of Colac, and comprises 1,822 km of rivers and streams.

Work began on the West Barwon dam in 1959 and the reservoir was officially opened in 1965. It was constructed near Forrest by the Geelong Waterworks and Sewerage Trust.

This water system forms part of the Barwon catchment and has some of the state's most flow-stressed waterways. Significant population growth and a changing climate are expected to place increasing pressures on the health of the catchment's waterways and its natural landscapes. Parts of both the Great Otway National Park and Otway Forest Park are within this landscape; however, grazing for livestock (beef, sheep and dairy) and forestry dominate land use in the area, bringing significant economic benefits to the region.

A key threat to the area's waterways is uncontrolled stock access to waterways that, if stock are not fenced out, can erode banks, damage riparian vegetation and reduce water quality through sedimentation and effluent contamination. Further threats include bed instability and degradation, changes in flow regimes and reduced riverine connectivity, degraded riverbank vegetation and loss of instream woody habitat. Willows (Salix spp.) and reed sweetgrass (Glyceria maxima) threaten a number of waterways in the upper section of the Barwon.

In sections along the Upper Barwon, water has ceased to flow at times of drought. The Upper Barwon also experienced a large-scale fish death event in June 2016, linked to an acid event that impacted water quality and the health of the river. In 2019, the Corangamite CMA in partnership with Barwon Water coordinated the release of $485 \mathrm{ML}$ of water from the West Barwon Reservoir as part of a new 1 gigalitre (GL, billion litres) entitlement of water for the environment recovered through the Central Region Sustainable Water Strategy. The aim has been to improve river health of the upper reaches by flushing sediment, wetting riparian vegetation and connecting habitat pools that provide a refuge for native fish and other fauna.

In early 2019, The Victorian Government established the Barwon River Ministerial Advisory Committee (Barwon MAC) to facilitate a community-led approach to the future management and protection of the Barwon catchment. The Barwon Action Plan aims to ensure the iconic Barwon catchment can thrive and be enjoyed as a natural treasure for many years to come. The Action Plan will be released in late 2020 .

\section{Boundary Creek}

Historic management of groundwater pumping in the Boundary Creek catchment near Yeodene has had an environmentally significant impact. Reductions in flows caused by groundwater extraction coupled with a drier climate and the ineffective regulation of passing flow conditions all contributed to the drying out of Big Swamp. This resulted in the activation of acid sulfate soils and ongoing release of acidic water to the lower reach of Boundary Creek. Ecological impacts of this have included loss and/or reduction of fish, crustacean and mammal species in the Barwon River and its creeks, and fish kills along the Barwon River; although sampling in 2020 indicated that the river has recovered from the 2016 fish kill event. Barwon Water have acknowledged the problem and their role and have established a Remediation and Environmental Protection Plan to improve water quality in Big Swamp, stabilise the acidification process that takes place due to the drying and wetting of the acid sulfate soils in the area, and reduce the risk of acid flush events from Boundary Creek in the long-term. This plan will run until 2023, and monitoring will continue beyond this time. Improvements are anticipated within 10 years of the commencement of remediation. 


\section{The regional context}

The community sits within the Colac Otway Shire Local Government Authority. The Shire has a population of approximately 21,000 people, with about 13,000 people living in the shire's major centre of Colac. Colac Otway Shire is part of the larger G21 Geelong Region Alliance.

To the east and south of Forrest, within $30 \mathrm{~km}$, is access to the Great Ocean Road. The Great Ocean Road is a National Heritage-listed $243 \mathrm{~km}$ stretch of road along the southeastern coast of Australia between the Victorian towns of Torquay and Allansford. The Great Ocean Road region receives over 3 million domestic daytrip and over 785,000 international daytrip visitors each year (Great Ocean Road Regional
Tourism Board, 2019). Colac Otway

Shire currently receives just over one million visitors per year. Forrest is an important hinterland township for the Great Ocean Road, and tourism provides direct and indirect jobs.

The population of the $\mathrm{G} 21$ region is forecast to grow to 500,000 by 2050 (G21 Geelong Regional Alliance, 2015) and the Colac Otway Shire Council believes that the Shire, and in particular Colac, is well positioned to cater for some of that growth. The Colac 2050 Growth Plan (Colac Otway Shire, 2019) is a long-term strategy that guides the location of new housing, associated servicing infrastructure (e.g. water drainage), and open space for the township of Colac. The plan sets an aspiration to expand the township's population to 20,000 persons by 2050 .
In November 2019, the duplication of the Princes Highway West from Winchelsea to Colac was completed. The Princes Highway Duplication project is a key route for regional commuters, freight traffic and tourists as a feeder route to the Great Ocean Road.

Melbourne's western region is one of the fastest growing in Australia. The area covered by the West Growth Corridor Plan will eventually accommodate a population of 377,000 or more people (Victorian Planning Authority, 2011). This growth, along with planning for the Regional Rail Link and Outer Metropolitan Ring Transport corridor, will forge stronger connections and relationships between regions, particularly between Geelong and the recreational opportunities of the Otways.

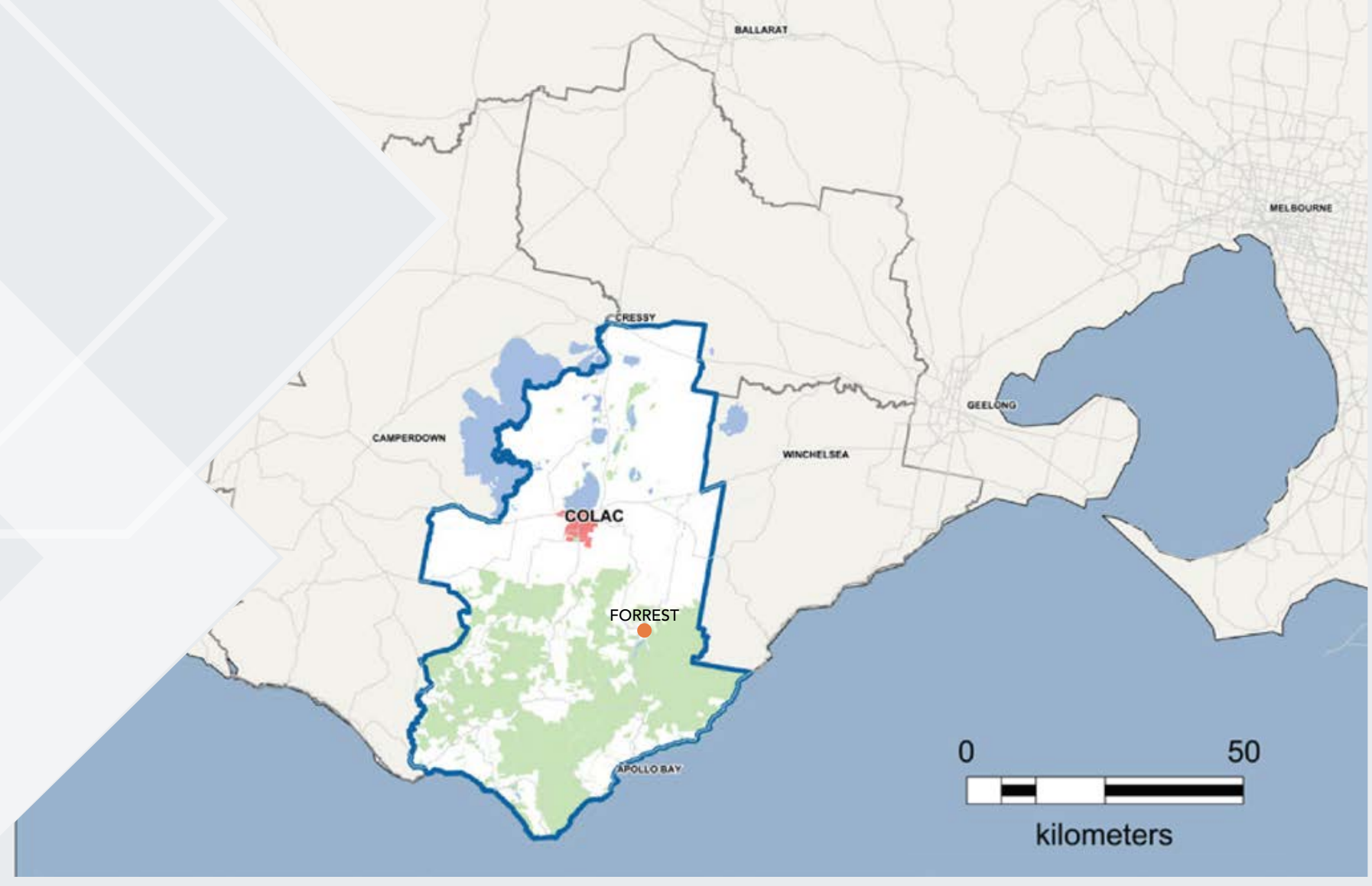




\title{
3.4 Forrest Historical Timeline
}

\section{First inhabitants - Gadubanud and Gulidjan peoples}

\author{
1880s European settlers arrive in the Barwon Valley at Yaugher and begin farming hops, root crops and running \\ dairy cows \\ 1885 School opens at Yaugher (settlement near current football ground) \\ 1890 Town of Forrest surveyed and first land sales held \\ 1891 Completion of rail line to Yaugher Valley, renamed Forrest after politician Charles Forrest. Tramways built to feed \\ timber from the bush mills to the Forrest rail head
}

1900s Forrest grows rapidly, exporting timber and agricultural produce by rail.

\section{Businesses flourish}

1902 Mechanics Institute built (public hall)

1906 School moved to Forrest township

1913 Police Station opens and Forrest Commission commences

1915 Bush nursing service inaugurated

1920s

1926 Daily road motor coach service to Colac commences. Football ground in town relocated to better site at Yaugher

1930s Geelong water channel work started at Forrest

1932 Forrest Dramatic Society formed to provide entertainment during the Great Depression

1937 'The Tiger' rail car introduced for improved passenger service

1939 Black Friday bushfires burn around Forrest

1940s Royal Commission into the ' 39 fires orders relocation of bush mills to townships

1942 War conditions throttle town activities

1943 First proper post office started in a shop, formerly the railway station

1947 Three sawmills set up in town

1950s

1952 'The Tiger' rail car stops running

1953 Lake Elizabeth formed due to landslide following heavy rains

1956 Mains electricity connected to Forrest. Electrical goods shop opens

1956 Peak year for native forest logging at the back of Forrest

1957 Railway ceases operation as uneconomic for traffic being offered

1959 Shire opens rubbish tip, first one for town

1959 Fire brigade formed

1960s Timber allocations decline, mills begin to close

1963 Town holds its first debutante ball Infant welfare centre opens

1964 Long established bakery burns down. No more local bread.

1965 West Barwon reservoir opens and gives Forrest water service

1966 New publichhall opens on Grant St. after fire destroyed earlier building

1969 Town has three profitable general stores

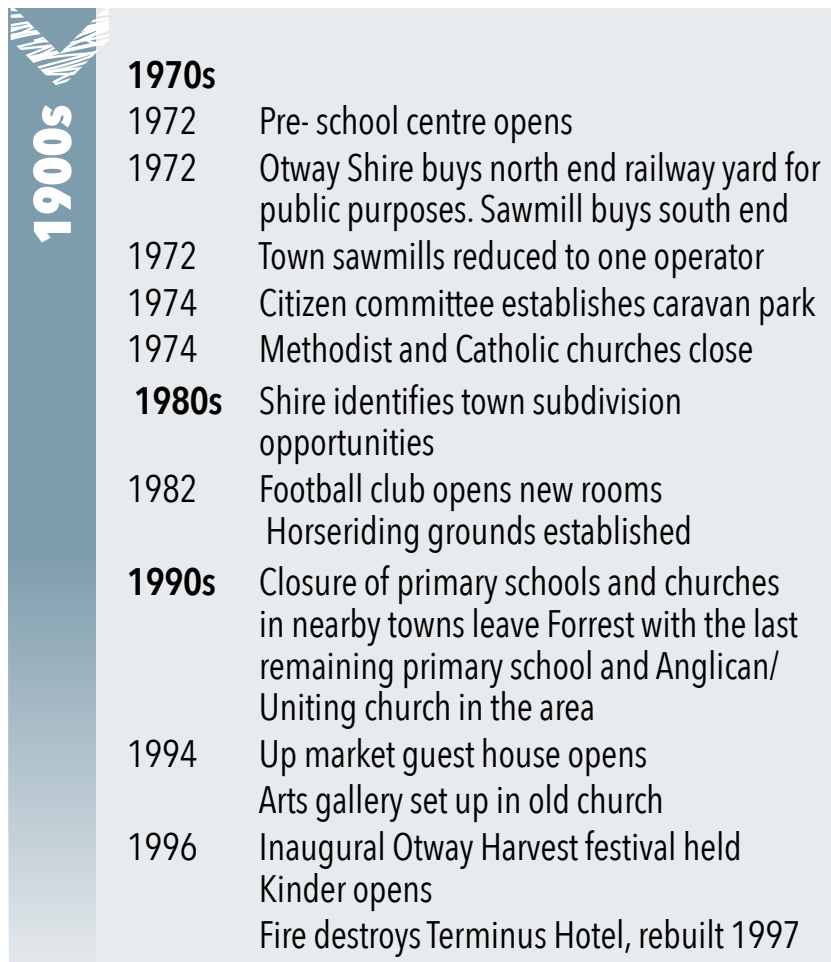

\section{0 to 2020 s}

2003 Last operating sawmill quits town site

2003-2010 Decline in dairy farm operations

2004 Great Otway National Park established

2004 Forrest SoupFest commenced

2005 Forrest mountain bike trails opened

2007 Neighbourhood house opens at the hall, auspiced by Otway Health

2009 Public infrastructure investment in mountain bike trails increases tourism and encourages new businesses

2011 Tiger rail trail opens

2012 Telstra mobile phone tower erected $2 \mathrm{~km}$ from township after local campaigning against Optus tower in centre of town.

2014 Air BnB accommodation venues flourish

2016 DELWP relocates to Barwon Downs

2016 Forrest football club goes into recess

2018 Forrest Gateway Project - feasibility studies for development of 47 Grant Street

2019 DELWP site (47 Grant Street) handed to community management

Forrest Men's Shed officially opens

2020 Forrest and District Plan Towards 2030 


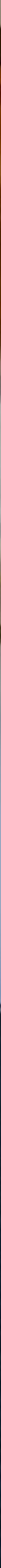


4 COMMUNITY ANALYSIS

\subsection{Community Snapshot (Census data)}

The rural communities of Forrest, Barwon Downs, Gerangamete and Barramunga are similar in composition. The census in 2016 showed that the population is ageing, with the median age 11 years older than for the state, and the percentage of people under 25 falling.

The median weekly income is onethird lower than for the rest of the state. However the median rent and mortgage repayments are concurrently lower than for the whole of Victoria, and there is a lower percentage of Forrest's residents under rent stress ( $>30 \%$ of household income). Forrest has a slightly higher percentage $(0.6 \%)$ of its population under mortgage repayment stress (>30\% of household income) than the rest
Forrest and District's best assets are their people. There is a strong community aesthetic which is demonstrated by the number of community groups. The environment is also a key drawcard for both residents and visitors.

of Victoria. This paints a picture of a community which is less well-off, whose homeowners are having a little more difficulty paying off mortgages, and whose renters pay less in rent, than the state average.

Table 1: 2016 Census data for all communities - Forrest, Barwon Downs, Gerangamete and Barramunga

\begin{tabular}{|l|c|c|c|c|c|}
\hline & Forrest & Barwon Downs & Gerangamete & Barramunga & AVERAGE \\
\hline All People & 230 & 131 & 105 & 7 & 473 (TOTAL) \\
\hline Male & $44.5 \%$ & $57.5 \%$ & $52.3 \%$ & $100 \%$ & \\
\hline Female & $55.5 \%$ & $42.3 \%$ & $47.7 \%$ & $0 \%$ & \\
\hline
\end{tabular}

Median age

52

52

42

45

Families

55

37

19

0

Average children per family, for families with children

\section{5}

2

2.3

For all families

0.4

0.5

0.9

0.45

All private dwellings 148

96

50

0

12

Average people per household

2

2

2.8

2

Median weekly household income

$\$ 875$

$\$ 866$

$\$ 1,374$

$\$ 949$

$\$ 1,016$

Median monthly mortgage repayments

$\$ 1,538$

$\$ 1,165$

$\$ 1,400$

$\$ 0$

$\$ 1,368$

Median weekly rent $\$ 225$

$\$ 166$

$\$ 200$

$\$ 0$

$\$ 197$

\section{Average motor vehicles per}

dwelling

1.7

1.8

2.4

2
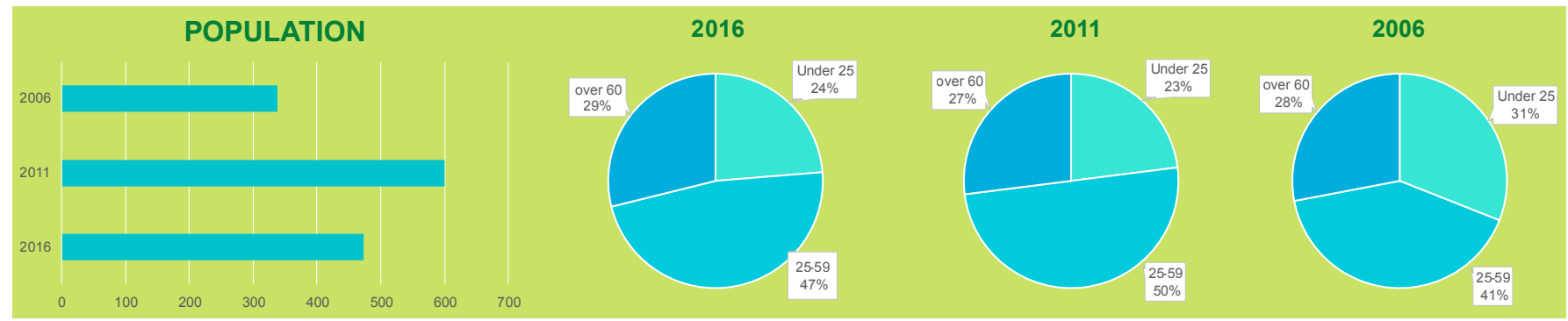

Figure 1: Population changes from 2006 to 2016 in Forrest and District (data not available for Gerangamete and Barramunga for 2011 and 2006). 


\begin{tabular}{|l|c|c|c|c|}
\hline \multicolumn{4}{|c|}{ Table 2: Demographic changes over time in Forrest, with comparisons to Regional Victoria and Australia } \\
\hline Measure & Forrest & Regional Victoria & Australia \\
\hline Population (2016) & 230 & $1,433,805$ & $23,401,945$ \\
\hline Population (2011) & 238 & $1,368,451$ & $21,504,691$ \\
\hline Population (2006) & 170 & $1,300,506$ & $19,855,287$ \\
\hline \% change 2011 to 2016 & $-3.5 \%$ & $+4.8 \%$ & $+4.8 \%$ \\
\hline \% change 2006 to 2011 & $+40.0 \%$ & $+5.2 \%$ & $+8.3 \%$ \\
\hline \% under 25 years old & $22 \%$ & $30 \%$ & $32 \%$ \\
\hline \% between 25-59 years old & $48 \%$ & $43 \%$ & $47 \%$ \\
\hline \% over 60 years old & $30 \%$ & $27 \%$ & $21 \%$ \\
\hline M/F \% split & $44.5 \% / 55.5 \%$ & $49.1 \% / 50.9 \%$ & $49.3 \% / 50.7 \%$ \\
\hline \% with non-Australian ancestry & $30.2 \%$ & $59.9 \%$ & $66.4 \%$ \\
\hline \% Indigenous population & $1.3 \%$ & $1.6 \%$ & $2.8 \%$ \\
\hline
\end{tabular}

\subsection{Community Strength}

\section{LIVEABILITY AND COMMUNITY}

The information below may sometimes only address Forrest, as opposed to Forrest and District. In part, this is due to the central nature of Forrest's location and services - it is a hub for the surrounding communities. The future of Forrest and its services (economic and social) will have a significant impact on the district townships.

The community has a sense of pride about their region. It is regarded as a pleasant place to live, with access to open spaces, recreation options, and has a small-town charm. Since the increase in tourism, the hub of Forrest now enjoys multiple places to congregate for coffee, lunch or a beverage at various venues. This has attracted a number of part-time residents and Forrest's population swells at weekends. The primary school is held in high regard and is a drawcard for many young families. However, rising property prices mean many young families cannot afford to live in the district.

Unique attributes for Forrest \& District include: small-town charm; West Barwon reservoir; Lake Elizabeth; a learning centre that incorporates a primary school, kindergarten and after-school care; DELWP Forest Fire Management depot at Barwon Downs; world-class mountain bike trails; and close proximity to the coast and Great Ocean Road. Forrest and District's position at the gateway to the Otways and bordering on agricultural regions means it is a nexus for land and asset managers.

One of Forrest's greatest assets is access to the natural environment, with the bush within immediate access, and visible from most people's houses. This is a drawcard for tourism (discussed below), and studies show that spending time in contact with nature is associated with good health and wellbeing (White et al., 2019), which is important for permanent residents. One common theme identified from community engagement activities is connection with nature.

The following is a sample of responses from the community survey in 2015 regarding what people like most about living in Forrest:

$>$ Fresh air and stress free living

$>$ Historic, biodiversity and cultural significance. Community of artists.

$>$ School community is awesome

$>$ Just very pleasant and not far from everything

$>$ The peace and quiet, trees, nature, birds 


\section{ECONOMY}

The community's full-time employment levels are slightly lower than average at $49.3 \%$, with part-time employment slightly higher than average at $37.5 \%$. Whilst Forrest offers local employment, a considerable number of residents who may live in the area for lifestyle and family reasons travel to major centres such as Colac and Geelong for work.
The most common employment industries are:

- Government and health (Colac Otway Shire, DELWP, Barwon Water, Colac Area Health, Forrest Primary School)

- Tourism and hospitality

- Agriculture

- Building and construction

Nature-based tourism is one of the largest income generators for the region, relying upon the natural assets of the hinterland forests of the Otway Ranges and the Great Ocean Road coastline. Large numbers of national and some international tourists come to the region to visit waterfalls and the rainforest, go fishing and bird-watching, and other adventure activities (Arup, 2018).

Table 3: Employment information for Forrest and District

\begin{tabular}{|l|c|c|c|c|c|}
\hline & Forrest & Barwon Downs & Gerangamete & Barramunga & Australia \\
\hline Employed full time & $41.5 \%$ & $51.3 \%$ & $55.8 \%$ & No data & $57.7 \%$ \\
\hline Employed part time & $41.5 \%$ & $38.2 \%$ & $32.7 \%$ & No data & $30.4 \%$ \\
\hline Away from work & $9.3 \%$ & $5.3 \%$ & $0 \%$ & No data & $5 \%$ \\
\hline Unemployed & $7.6 \%$ & $5.3 \%$ & $11.5 \%$ & No data & $6.9 \%$ \\
\hline Occupation & Forrest & Barwon Downs & Gerangamete & Barramunga & Average \\
\hline Professional & $28.8 \%$ & $16.4 \%$ & $7.0 \%$ & & $17.4 \%$ \\
\hline Managers & $14.4 \%$ & $37.7 \%$ & $51.2 \%$ & No data & $34.5 \%$ \\
\hline Labourers & $16.2 \%$ & $14.9 \%$ & $18.6 \%$ & No data & $16.5 \%$ \\
\hline $\begin{array}{l}\text { Technicians \& trades, machinery } \\
\text { operators \& drivers }\end{array}$ & $22.5 \%$ & $10.5 \%$ & $7.0 \%$ & No data & $13.3 \%$ \\
\hline $\begin{array}{l}\text { Community \& Personal Service, } \\
\text { Clerical \& Admin }\end{array}$ & $18.0 \%$ & $16.4 \%$ & $16.3 \%$ & & \\
\hline Other & $0 \%$ & $4.5 \%$ & $0 \%$ & No data & $1.9 \%$ \\
\hline
\end{tabular}

Table 4: Top industries worked in by residents of Forrest and District

\begin{tabular}{|l|c|c|c|c|}
\hline Industry & Forrest & Barwon Downs & Gerangamete & Barramunga \\
\hline Government and administration & $17.2 \%$ & & & \\
\hline Hospitals, and other social assistance services & $15.5 \%$ & $13.6 \%$ & & No data \\
\hline Accommodation, cafés and restaurants & $13.8 \%$ & $15.9 \%$ & & \\
\hline Beef and dairy cattle farming & $8.6 \%$ & $29.5 \%$ & $83.3 \%$ & No data \\
\hline Building \& other industrialised services & $6.9 \%$ & & & \\
\hline
\end{tabular}




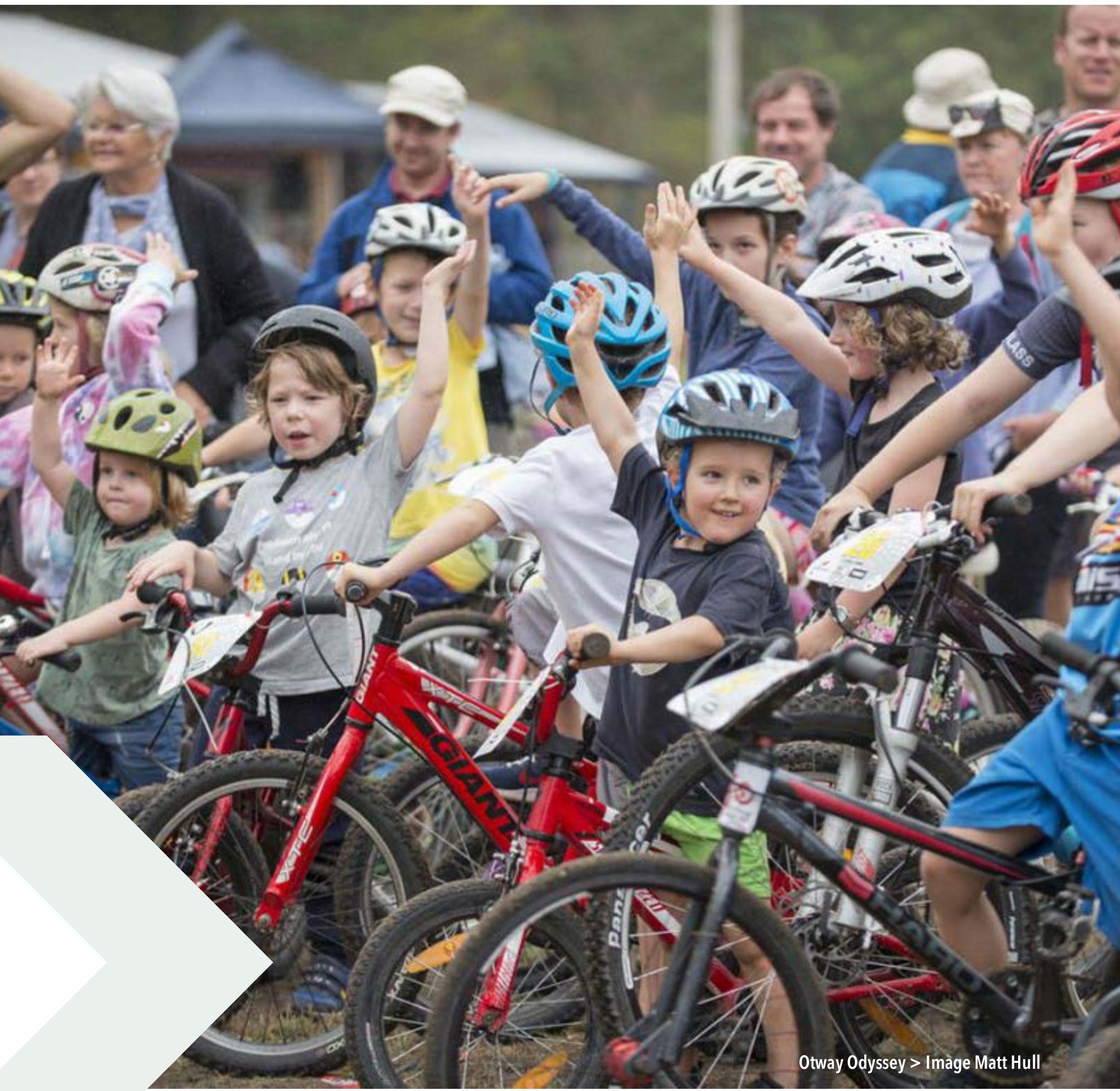

Building on these assets, Forrest has capitalised on the development of world-class mountain bike trails and access to walks and waterfalls. The local hospitality and tourism businesses provide a critical infrastructure to support this growing economy, with great places to stay, eat, relax and enjoy fresh air.
Local events such as the Otway Odyssey Mountain bike race and Forrest SoupFest are further economic drivers for the town.

In addition to the regional tourism drivers, the Shire attracts 32,000 cyclists per year to Forrest's and other mountain bike trails. There are 16 trails in Forrest, ranging from 'easy' to 'very difficult'. The trails are located on Crown Land to the north and south of the Forrest township, with the trails network crossing a number of land tenures including the Otway Forrest Park, Great Otway Forest Park, and land managed by Barwon Water. 


\section{SERVICES}

Forrest and District have access to most services within a 30 minute drive - principally these are located in the regional centre of Colac. However, without regular and frequent public transport services in the towns, attending these requires access to a car.

\section{Table 5: Services and the time it takes to travel to them by car from Forrest}

\begin{tabular}{|c|c|c|c|}
\hline & Within town & Within 30 min drive & Within $1 \mathrm{hr}$ drive \\
\hline Supermarket & & $\bullet$ & \\
\hline Chemist & & $\bullet$ & \\
\hline Clothing store & & - & \\
\hline Petrol station & & - & \\
\hline Car service & & - & \\
\hline Post office & - & & \\
\hline GP & & - & \\
\hline Dentist & & - & \\
\hline Chiro/Physio & & - & \\
\hline General hospital & & - & \\
\hline Surgical hospital & & - & \\
\hline Maternity hospital & & - & \\
\hline Nursing home & & - & \\
\hline Kinder/day care & - & & \\
\hline Primary school & - & & \\
\hline Secondary school & & $\bullet$ & \\
\hline P-12 & & & - \\
\hline University & & & - \\
\hline TAFE & & - & \\
\hline Football team & & - & \\
\hline Basketball team & & $\bullet$ & \\
\hline Heated pool & & - & \\
\hline Multi-purpose community centre & - & & \\
\hline Movie theatre & & - & \\
\hline Gallery & - & & \\
\hline
\end{tabular}




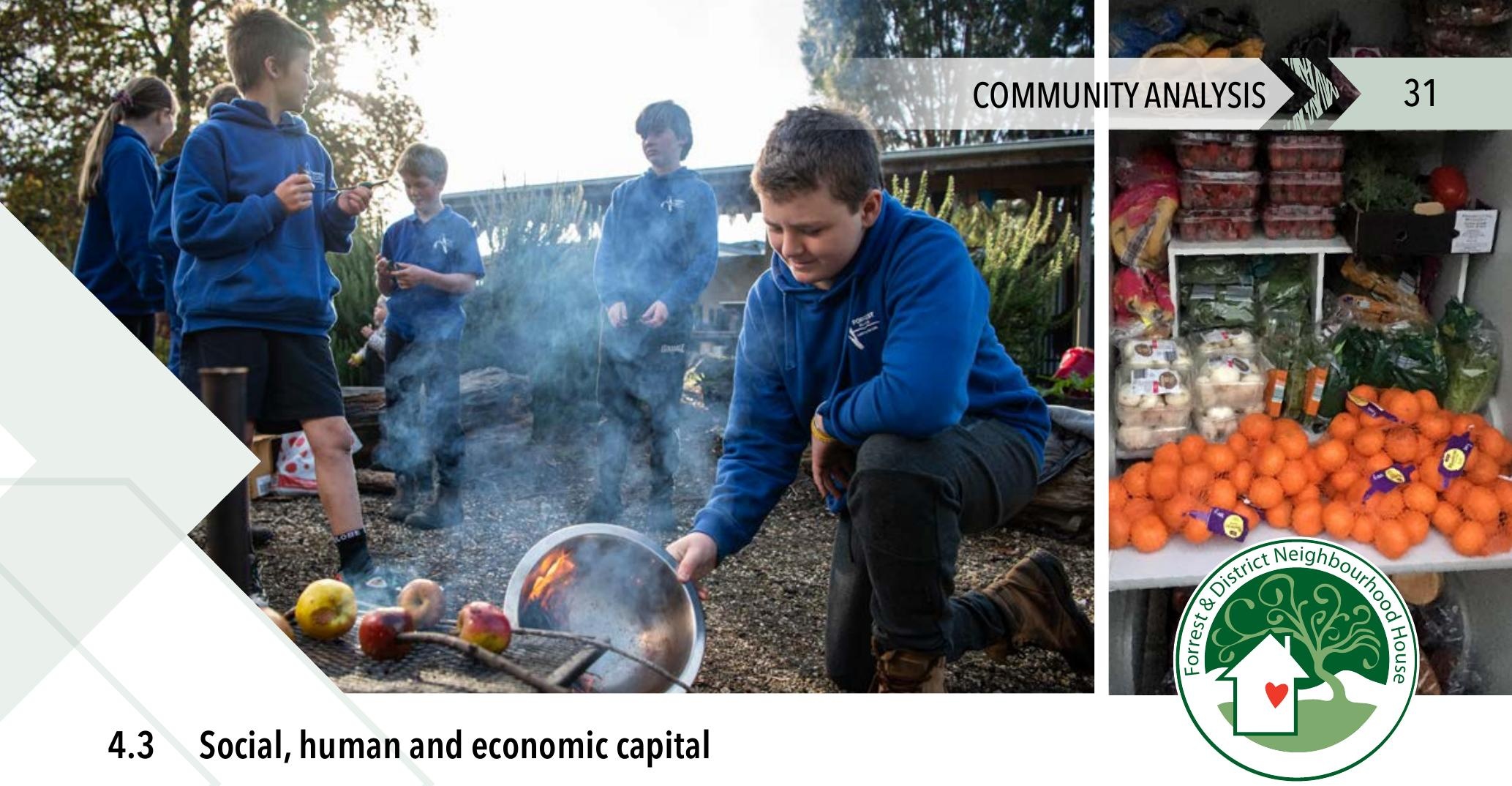

\section{SOCIAL CAPITAL}

\section{The Forrest Learning Centre}

is integral to the fabric of the Community. It provides a focal point and gathering place for local families. The school takes in students from the Forrest community, as well as providing a bus service to bring students from the neighbouring hamlets of Barwon Downs, Gerangamete, and further to Yeodene. In 2020, the population of the school was 34 . Kindergarten and occasional care have been available since 1996 and has evolved into long day care and after school care based on meeting parent needs, providing a valued service for full-time working families.

Over the past five years, the Primary School has shown indicators of a strengthening community, with higher than average NAPLAN results (one of the highest in the state in 20162018), and a school family occupation index (SFO) at its lowest point since 2010. The SFO indexes are based on parental occupations (not incomes), and indicates that the parents in the community perform medium to high skilled jobs and/or are qualified professionals. It also indicates that the levels of education among the parent community are high.

\section{The Forrest and District Neighbourhood House Inc.} brings people together to connect, learn and contribute to the local community through social, educational, recreational and wellbeing activities, using a unique community development approach. The Neighbourhood House is an Incorporated Association that receives some of its funds through the Victorian State Government. This funding allows the Committee to employ a Coordinator for 25 hours a week. Other funds are sought through a range of grants and fundraising activities. The Neighbourhood House was originally auspiced and supported by Otway Health (now Great Ocean Road Health) but became an Incorporated Association in 2014 after the community decided to take on all governance, financial and employer responsibilities.

Based out of the Forrest Hall until 2019, the Neighbourhood House has relocated to the new Community Hub at 47 Grant Street (former DELWP site), and developed an extensive community development program whose strategies currently include community lunch, book club, yoga, playgroup, dance, weekly bike ride, youth group, community gym, community library, exercise class, FoodShare cupboard, and Studio Forrest art group. In addition, the organisation provides IT access, a recycling hub and facilitates regular community events such as Forrest Got Talent, Women of the Otways dinners, community heroes awards and a comedy night. The Neighbourhood House provides space for visiting health professionals and the Forrest Historical society. People also attend the building during opening hours to seek referrals and support in times of crisis or just to have a cuppa and chat.

Local volunteers are supported to build skills and are currently engaged in a number of governance, program support and delivery roles. The organisation is further supported in its work by the statewide network of Neighbourhood Houses and through a range of strategic partnerships and collaborations. The Forrest and District Neighbourhood House is a dynamic, responsive and adaptive organisation whose potential will continue to develop in direct response to the needs and aspirations of our community. 


\section{Forrest \& District Plan $>>$ TOWARDS 2030}

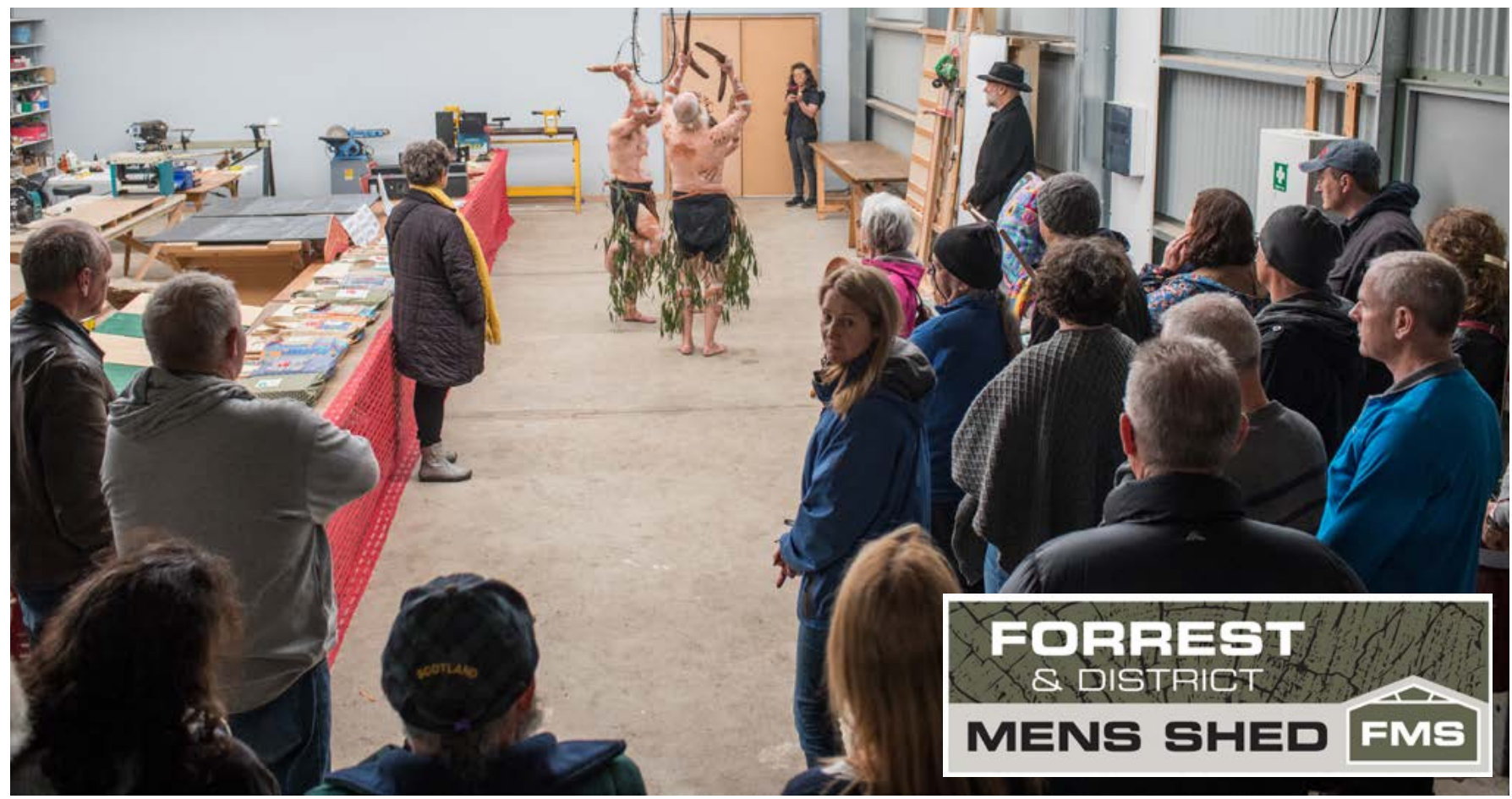

In 2013, a parcel of land from Colac Otway Shire was acquired by an active bunch of locals to set up the Forrest and District Men's Shed, a member of the Australian Men's Shed Association. During 2017-18, the Men's Shed received funding to construct a new facility, to offer education, training, and community engagement opportunities for the men of the community, and their families and friends. This Shed also has a meeting place with kitchen facilities. In October 2019, the Men's Shed was officially opened by dignitaries from the Colac Otway Shire following many years of hard work from the members, and $\$ 68,000$ in federal, state and local government grants.
The Men's Shed provides an ideal forum for people to share interests and activities and socialise in a safe, secure and non-judgemental environment. The Men's Shed is also home to the King Parrot Pickers, a local bluegrass band who regularly get together for jam sessions and fun on alternate Sunday afternoons.

\section{Forrest and District has almost 30 groups, clubs and committees including:}

Forrest and District Community Group

Forrest Gateway Project

Forrest Public Reserves Committee

Forrest and District Neighbourhood House CofM

Forrest Primary School Council

Forrest, Barwon Downs and Gerangamete CFA

Youth Group

Book Club

Studio Forrest

Forrest Cricket Club

Anglican Church and Op Shop

Forrest Football/Netball Club

Forrest Tennis Club
Forrest Mountain Bike Club

Forrest Horse Riding Club

Forrest Recreation Reserve

Forrest and District Historical Society

Lions Club of Forrest and District

Forrest and District Men's Shed

The Forrest Post Editorial Team

Forrest Special Events Club (Forrest SoupFest committee)

Barwon Downs Tennis Club

Otway Harvest Trail

Country Women's Association

Upper Barwon Landcare Group 


\section{HUMAN CAPITAL}

Members of the community have been the drivers of many town projects such as the wastewater investigation, Forrest Common re-development, Forrest Mountain Bike Trails Design Project, and the Forrest Gateway to the Otways Project.

In April 2019, three former DELWP sites including 47 Grant St were transitioned to community management, as a result of the participation, energy, vision and activism of the community. The Community Hub at 47 Grant St is managed under a DELWP Category 3 Management Committee, known as the Forrest Public Reserves Committee. Tenants of this site include the Neighbourhood House and Forrest CFA. It is also anticipated this will become the Forrest Gateway to the Otways concept development.

The in-kind contribution of community members attending meetings as committee members; writing submissions; applying for grants; coordinating maintenance, repairs and working bees for community assets; as well as professional services such as report writing and communications are critical to the progress of many community projects. These volunteered hours make projects possible and improve community cohesion.

Service organisations and local committees in the community support festivals and have attracted events, such as Forrest SoupFest. In 2004, the Forrest and District Lions Club started this festival with approximately 200 attendees. It has grown in size and popularity, and in 2019 attendance was over 7,000. The committee estimates this festival brings in over $\$ 100,000$ to the local economy during the June long weekend.

\section{ECONOMIC CAPITAL}

The natural environment of Forrest and District is not only a drawcard for residents, but also tourists.

Investment in tourism infrastructure, both publicly and privately owned, has increased over the past five years. This not only provides employment opportunities, but also offers socialising and recreation opportunities for residents and tourists alike. The community has undertaken extensive consultation regarding an upgrade to the Mountain Bike Trail network, as detailed in the next section.

Since 2015, tourism and hospitality venue growth in town has reflected the increased tourism demand and popularity of the township, and includes the following businesses:

Forrest Brewing Co

Forrest General Store

Terminus Hotel

Forrest Caravan Park / Wonky

Stables

Forrest Guesthouse

(and Bespoke Harvest

Restaurant 2013 - 2018)

Forrest Hire Bikes (and formerly Forrest Corner Store café/bike hire 2012-18)
Platypi Chocolate Café

Susanna Weddell Jewellery

Antiques on Station St

Forrest Op Shop

Top Bike Tours

Trees Adventure (Yeodene)

Otway Eco Tours

(platypus tours)

In addition, Forrest offers a range of accommodation venues, with approximately 40 providers, and over 180 beds.

Festivals and events are a regular feature on the Forrest calendar, and have included:

Otway Odyssey Mountain Bike competition

Forrest 6-hour ride

Forrest SoupFest

Run Forrest trail run

Forrest Festival (no longer operating)

Aside from tourism, there are a number of other businesses that contribute to the local economy. These include:

Evans Earthmoving

Forrest Foods

Wattle and Wire

and a range of trade businesses and primary producers.

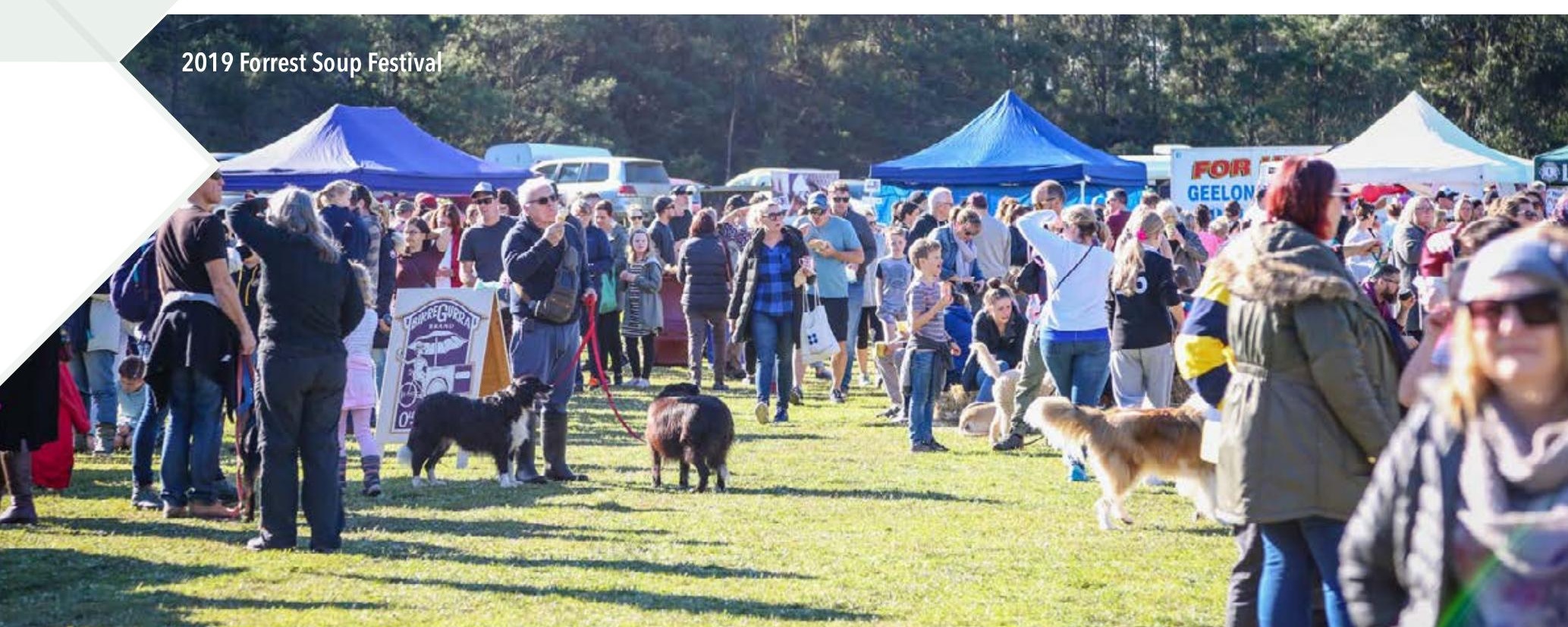




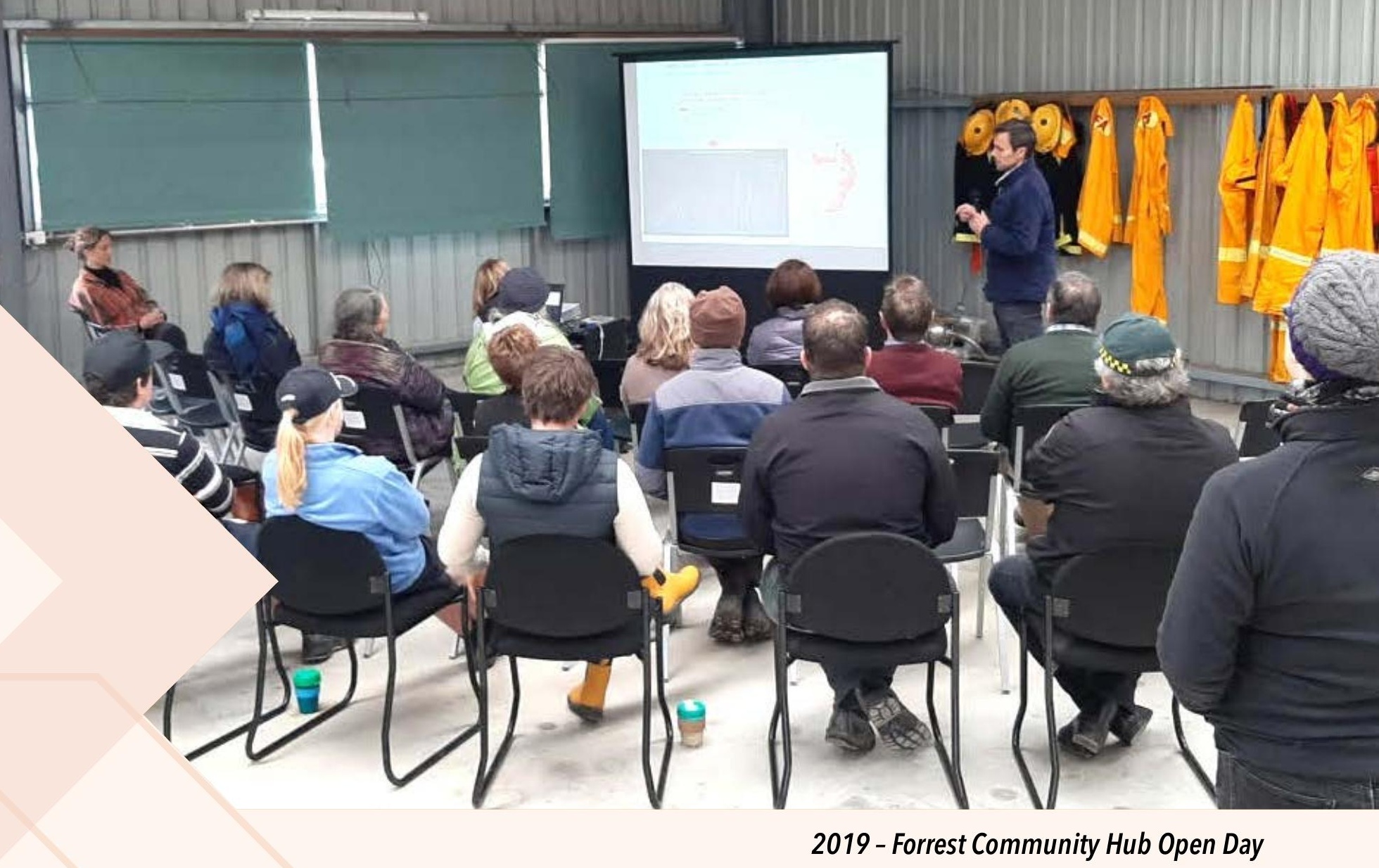

January February March/April May/June July

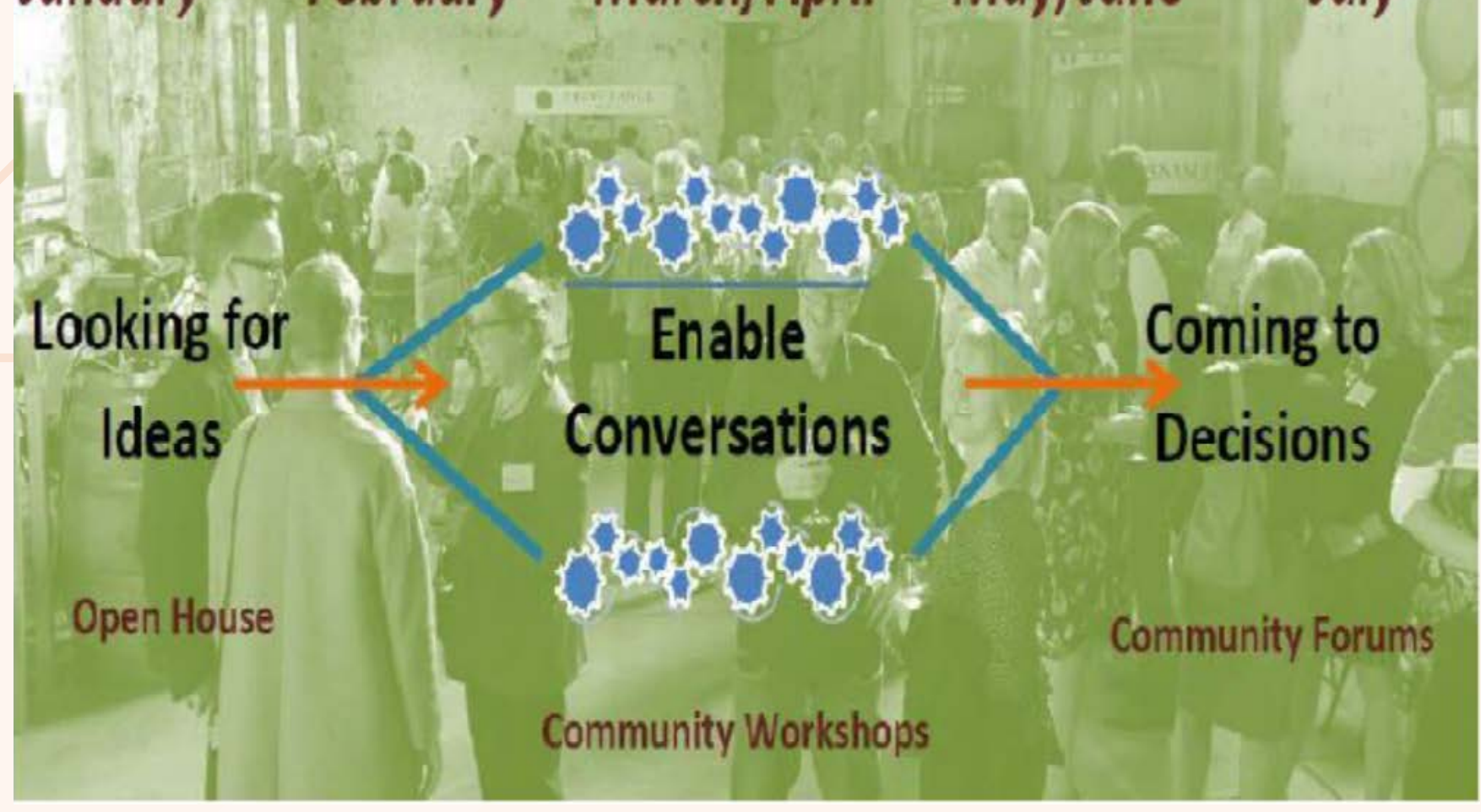




\subsection{Key themes}

Common themes were identified in the Forrest Futures II engagement, and they included six main areas:

\section{NATURE}

\section{Beautiful landscape \\ Otways \& Great Ocean Road Connection to Country}

"Natural environment in your actual backyard"

"Understanding that we have something precious"

"Green, rural, close to Colac, close to the beach"

"Ensure planning overlays for Forrest include "Township - Character" requirements that link to natural aesthetics, rural setting and ecological development"

"Weaving First Nations ecological knowledge into practice"

"Lots of visitors enjoying the natural environment and contributing economically to the local community"

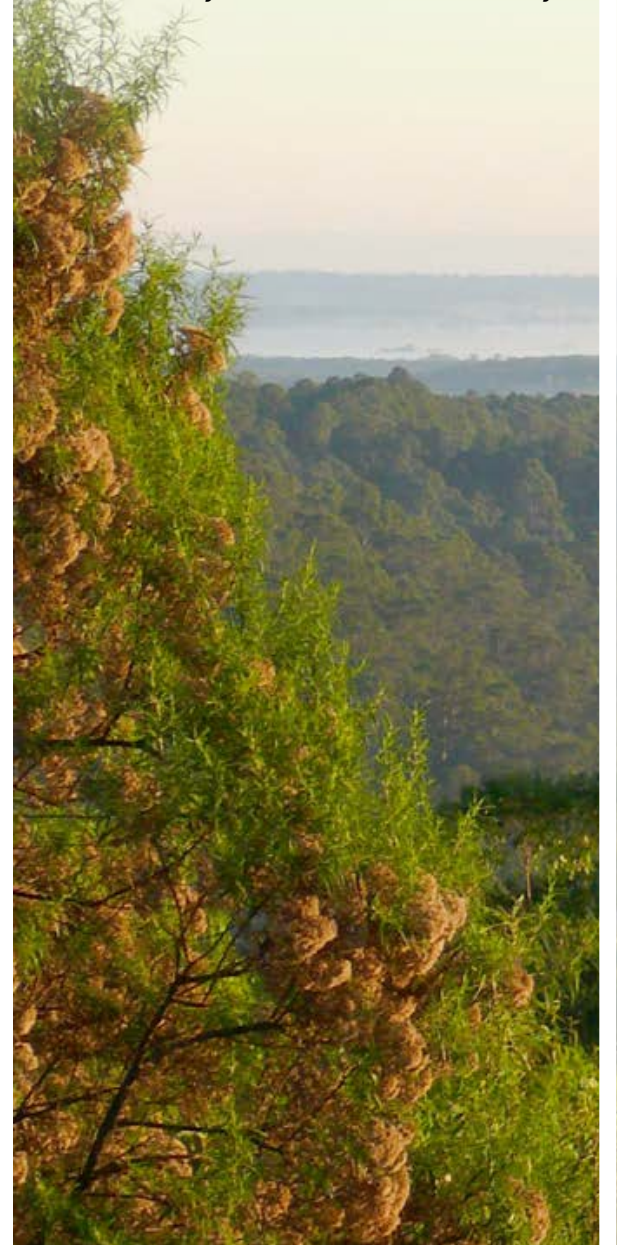

\section{COMMUNITY}

\section{Supportive and connected \\ Small-town charm \\ Includes young and old}

"Engage kids in multi-generational conversations about the future"

"Co-housing using environmental and social design. Ensuring a variety of affordability options for all socioeconomic groups"

"Services and access to keep me living in Forrest as I age"

"Engage and learn from traditional owners and practices"

"Focused activities on building kindness and continued tolerance because these shared skills will see us through changes positive and negative"

"Indigenous knowledge (especially land management, fire use) being centrally used in discussions - equal relationships for land management with Indigenous locals and agencies solving challenges together"

"Talking about change - people have very different ideas of change. Many projects - don't assume funding will be approved for all"

"Small town diversity - different voices heard"

"Cultural divide between older residents and newer city-arrivals. But relationships still exist and don't suffer. Everyone has to get along and they do. People help others who are struggling"

\section{INFRASTRUCTURE}

Inadequate wastewater system Mountain Bike Trail development Key assets reflect town character "Sewerage still remains a big issue and prevents growth and new business"

"Consider how wastewater can be used for production"

"Encourage microgrids, selfsustainable lifestyles, be a beacon for future-proofing local economies embrace the environment"

"Explore planning overlays (plus other incentives) that encourage more business and permanent residential accommodation options"

"Parking plan developed for Forrest by Council - need focus on funding and implementation, not just plans"

"NBN has not improved internet access"

"Fall-back place of refuge to help avoid loss of life in bushfire" 


\section{"A future to look forward to" Forrest Futures II, September 2019}

\section{RECREATION}

Tourism, mountain biking, sport,
camping, horse-riding, arts
Infrastructure
"Maintenance of mountain bike
trails and improvements to ensure
that Forrest remains a viable tourist
attraction (a lot of competition in the
space now)"
"Challenge the balance of housing
and Airbnb/tourism accommodation"
"Attract different skills - e.g. recreation
(massage, healing centre, spa centre,
conference)"
"Encourage businesses that cater to
local as well as tourist needs"
"How to engage owners of
accommodation places in town/
planning needs?"

Tourism, mountain biking, sport,

Infrastructure

"Maintenance of mountain bike trails and improvements to ensure that Forrest remains a viable tourist attraction (a lot of competition in the

"Challenge the balance of housing "Attract different skills - e.g. recreation (massage, healing centre, spa centre, conference)"

"Encourage businesses that cater to local as well as tourist needs" accommodation places in town/ planning needs?"

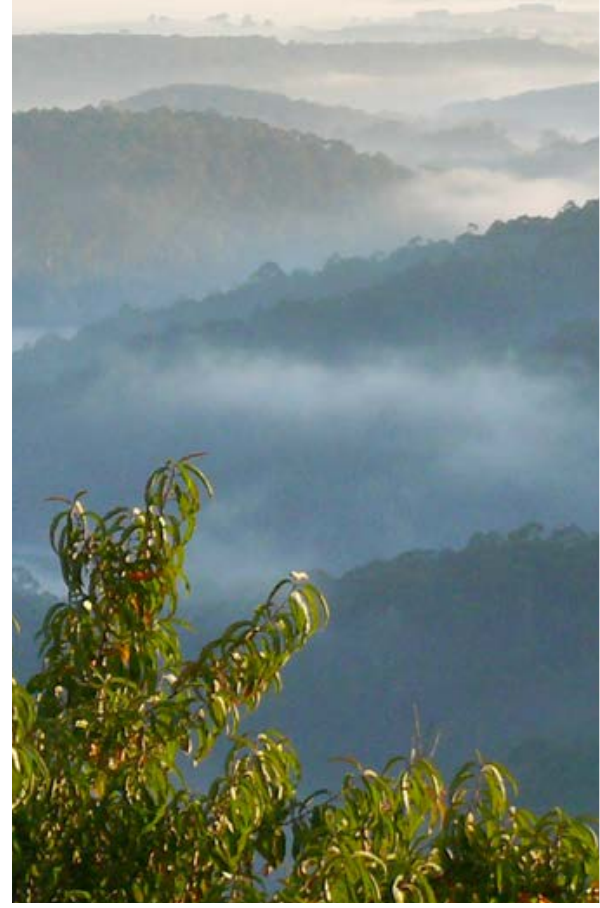

\section{CHALLENGES}

Bushfire vulnerable

\section{Climate change}

\section{Agricultural adaptation}

"Reduced access to healthcare in the town; e.g. 20 minute drive when no petrol in the car means people won't visit the doctor when required"

"Who will own the land and farms and work them in 20-30 years?"

"Everyone's a farmer but how do we manage runoff pollution in the rivers?"

"Increasing cost of insurance. Shift in space will come through in 2-3 years"

"Plan upfront for a fire disaster scenario. Don't rebuild town to burn again. A higher standard than current standards"

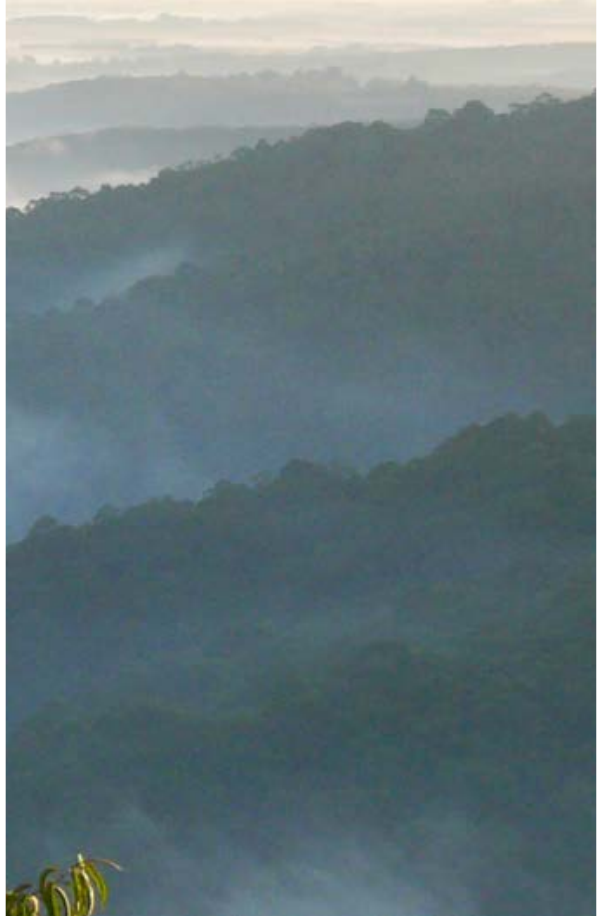

\section{THE FUTURE}

\section{Sustainability aspirations}

Food systems and sharing Energy independence

"Starting up a community supported agriculture (CSA) program with local growers and organic producers"

"Food processing facility in Forrest jobs, food miles"

"Embed town landscape as edible landscape - create a large community garden"

"Clean energy, sustainable agriculture, revegetation of carbon dense forest"

"Sustainability included in school curriculum - embedded through all subjects, teach problem solving"

"Education focused on keeping children in the area. Focus on futureproofing employment/growth / sustainability"

"Explore joint build opportunities for new home buyers (UK and Holland have some good models)"

"Off grid - microgrid, solar passive, built for our environment - utilise larger blocks better; subdivision of larger blocks/tiny homes"

"Employment on farms? Training in progressive farming techniques"

"New jobs should focus on: home based working (good internet required); small scale/community farming; incentives for tourism-based employment, such as guided walk tours in Otways"

"Environment, health, science, ecology, coastal science, forest conservation, community development - all jobs that would be great to create in Forrest" 


\subsection{Community Surveys}

The communities were involved in extensive consultation over the years 2015 to 2020. The following is a summary of these engagements.

\section{5 - FORREST AND DISTRICT COMMUNITY GROUP (FDCG) SURVEY}

An initiative of the FDCG, in 2015 the Community was surveyed about their thoughts on living in Forrest. A total of 61 participants (local residents and visitors) completed the survey, and questions related to the liveability and amenities of Forrest.

The survey was conducted during a period of great transition for Forrest, including:

- Forrest \& District Neighbourhood House transitioned to a local Committee of Management and financial management structure

- New website proposed (for community \& visitors) www. forrestvictoria.com

- Forrest Post newsletter launched

- Fire siren removed (later relocated)

- Expansion of services on offer at Forrest Primary School and Early Years Centre

- Forrest Football and Netball Clubs in recess while searching for participants

- Free wifi spot to be installed

Reponses and comments to questions about living in Forrest included:

What do you like most about Forrest?

Friendly community $\quad 76 \%$

Healthy lifestyle $\quad 71 \%$

Cafes/restaurants/pub $\quad 62 \%$,

Bushwalks $\quad 57 \%$

Convenient location $\quad 49 \%$

Bike tracks $\quad 40 \%$

The community groups available $38 \%$

Fishing 22\%

Other (please specify) $\quad 38 \%$
"The peace and quiet, trees, nature birds",

"Wonderful education at Forrest PS"

"Surrounding bush - birds, flowers, etc."

"Just very pleasant and not far from everything"

"The peacefulness of the bush, and the beauty of the birdsong"

"Environment, peace and quiet, flora and fauna. People willing to work together and doing their best for the town"

"Quiet and peaceful atmosphere"

"Fresh air, clear skies, hills are for evergreen"

"Closest community centre, diversity of people, relaxed atmosphere"

How can we make Forrest a better place to live (environmentally, socially, recreationally, other)?

More public transport to Colac, Geelong, Lorne, Apollo Bay $\quad 64 \%$

Better road maintenance $\quad 61 \%$

Better roadside vegetation maintenance $55 \%$

Bushfire refuge $\quad 58 \%$

More local employment $\quad 39 \%$

More entertainment $\quad 31 \%$

More activities/facilities for

younger people $36 \%$

More activities/facilities for

elderly people $17 \%$

More adult education

$9 \%$

What do you think Forrest needs most to stimulate its economy?

Greater variety of businesses $\quad 40 \%$ Longer business opening hours $19 \%$ Fuel $65 \%$

Other (please specify) $64 \%$
"Take away shop"

"Town sewerage"

"Better universal access to public spaces and amenities"

"Expanded governmental services to protect water catchment, fire prevention, public land maintenance and protection. Parks supervision." "More employment opportunities" "Market to sell local produce" "Local craft and produce store" "Promotion of Forrest PS and services such as childcare and pre-school services which is offered at Learning Centre"

"Music/arts events"

"Talk in terms as being a small town. It's not a city"

\section{"A festival of fungi"}

"More permanent housing so families can move in and work, play and boost school numbers"

"More places of interest for tourists. Camp for school groups to stay and bike ride/enjoy environment. Musicl Arts Festival Old time sports festival" "Increase opportunities for envirotourism"

"Upgrade history walk and make more of our timber history"

"Artist's studios creating artwork for sale" "Micro hydro-electric from the dam" "Grant St Parking improvements" "A viable set of primary production industries would provide employment and retain the younger generation/s" "Cheap housing for workers and families"

"I think it is fine the way it is and I do not want it to change much more." 


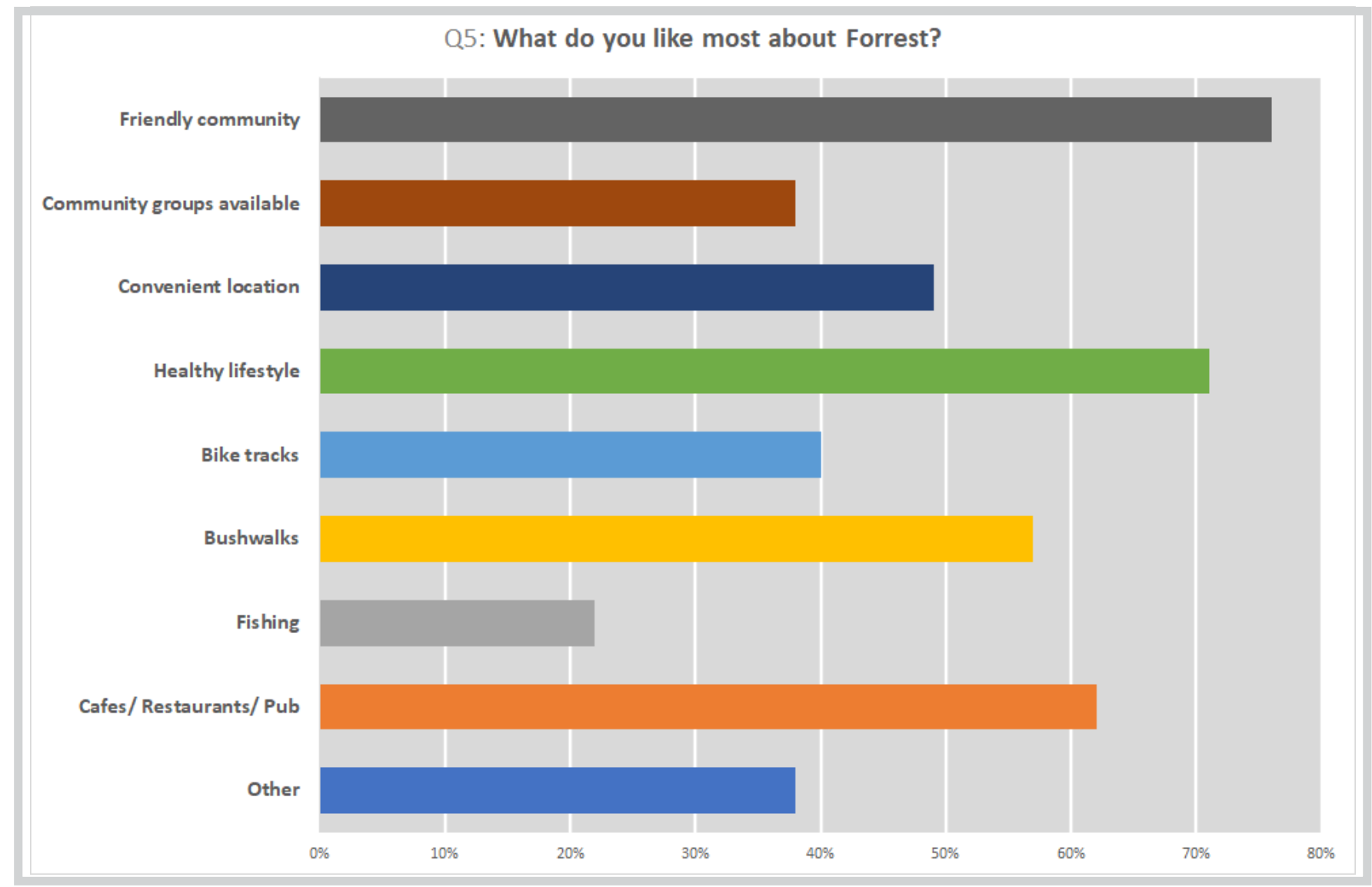

\section{Do you have any further comments to make about what you would like to see happening in Forrest to make the town even better?}

"Infrastructure, parking, rubbish bins, toilets in main street, playground"

"More opportunities to bring the whole town together. Like the school play where everyone was invited. A Christmas gathering?? Movie nights - summer and winter. Not things that you necessarily have to pay much to go to."

"The construction of a $\$ 2-3 M$ interpretation centre - wildlife, natural history, geology, forestry"

"Clean up the old mill site" "Just keep it clean and show off its beauty"

"Speed camera south and north ends of town"
"A weekly movie night at the hall"

"Recently a sculpture was formed in the Barwon Water reserve from wild fallen tree branches. Perhaps a series of these could be made along the river"

"Definitely more public transport to and from Colac",

"More car parking and mowing in town"

"Town stinks from the business septics, all you can smell is septic and hot food cooking",

"The control of cats in the Otways/ Forrest"

"Community engagement via regular community events, sports picnic day or occasional town market days. Community consultation important for inclusivity. Community Bushfire Planning results on display at prominent place"
"I think the town is growing at a nice gentle pace and this survey is helpful to keep it on track. Not letting it get too big too quickly"

"Extending the Rail trail is a project that has already been proposed. Would it be worth approaching Barwon water, to ask if the track next to the channel from Barwon Downs to Murroon could be an alternative route for walkers / cyclists?"

"The toilets at the south end of town are terrible given the enormous numbers of visitors and travellers that use them"

"Complete the Tiger Rail trail" "Just remember why we like Forrest and not to lose that" 


\section{7 - FORREST FUTURES PROJECT (COMMUNITY AT CENTRE OF DECISION MAKING, DELWP)}

The Forrest Futures Project was initiated to explore community interest in utilising additional public land in the Forrest Township. Over 100 participants were involved in a multi-stage consultation process over six months.

The announcement in 2015 by DELWP to relocate and develop a new work centre at Barwon Downs, $7 \mathrm{~km}$ north of Forrest, meant that three public land sites in Forrest became surplus to DELWP needs. A conversation in May 2015 between Forrest and District Community Group and the Otway District Manager David Rourke occurred, with a reassurance that the relocation would in no way place the Forrest community at a greater bushfire risk due to DELWP's departure.

This project was seen as a significant opportunity by DELWP to apply an engagement process that sought to empower community to make decisions and take control of the management processes under agreement with DELWP. To this end, the project team set out its aim to "Transition the DELWP Forrest work centre sites to possible community use under an agreed DELWP management structure (defined under negotiables and nonnegotiables) that meets the needs and aspirations of the Department and of the Forrest Community".

\section{COMMUNITY ENGAGEMENT EVENTS 2017}

\section{DELWP Open House - 27th \& 28th January 2017}

- Community Participation - Day 1 $=52$; Day $2=47$. Total 97 people providing 103 contributions

\section{DELWP Workshop 1 - 21 May 2017}

- World Cafe - 57 people and narrowing contributions down to 30 options

DELWP Workshop 2 - 18 June 2017

- Market Place - 38 people and narrowing contributions down to 10 options

\section{First Community Group led Community Forum \\ - 30 people attending. Led by community groups to seek community centred decision- making regarding which committee of management would lead the transition process}

DELWP staff at the Open House heard a broad range of ideas, ranging from easy to complex possibilities; this included five comprehensive written submissions. There were many ideas with similar themes which were combined into a summary for each site.

The Camp: Bike and Café Hub School camp - Neighbourhood Safer Place - Markets - Garden and Native Nursery - Multipurpose Centre Community Activities - Sell the site - Public toilets.

The Car Park: Leave as carpark - Sell the site - Exhibit large historic items.

The Main Depot: Market place Historic and Cultural Hub-Tourist Interpretative Centre - Physical Activity Centre - Move the buildings - Sell the site - Neighbourhood Safer Place - Combined CFA and Neighbourhood Safer Place Combined Community Hub and Neighbourhood Safer Place Multi-Purpose Centre-CFA Shed - Historical Society Centre - Nursery/ Garden Centre - Youth Centre School Camp - Business Activity Centre - Art Space - Public Toilets Community hub.

\section{Final thoughts from participants (as written):}

- Forrest needs a safer place

- Want building 14 for N/H House interests

- How about an Entry Arch - Forrest Gateway to the Otway's

- Better signage in town, hard to find things in town and get about, e.g. bike trails/walking tracks and Lake Elizabeth

- BMX track

- Great community engagement opportunity, would be nice to know if $\$$ avail for a solid proposal and the amount
- Go CFA

- Good that you're trying to keep them in the community

- Lots of good ideas

- Let's promote Forrest business development

- Forrest to make the decision!

- Important that the sites stay as a community space and important to think out of the box/no preconceptions

- Really good display
- Thanks for the investment in our town

- We need \$ commitment to fund feasibility

- Funding opportunities for Environmental, social, economic risk reduction - GREEN BONDS ethical investment scheme

- Funds generated by community enterprise, training, education, produce, - Community employment and enterprise

- Great to see DELWP genuinely committed to helping Forrest

The engagement process resulted in agreement to use the space for a bushfire place of last resort, a community hub (including the Neighbourhood House and the Historical Society), and a CFA station. The agreement was to use the sites as they currently stood until funding could be obtained to re-develop them. 


\section{7 - FORREST WASTEWATER INVESTIGATION (BARWON WATER AND COLAC OTWAY SHIRE)}

In 2017, Barwon Water and Colac Otway Shire conducted community engagement in Forrest to investigate opportunities for improved wastewater management. Community feedback over recent years told of a range of system issues leading to amenity and odour issues around the town, exacerbated during peak tourist periods.

Wastewater in Forrest is managed by home owners via individual on-site wastewater management systems (on-site systems) with approval and performance regulated by Council. An audit of existing on-site systems determined there was a problem across the township with a large proportion of systems deemed inadequate for managing loads from existing houses in the town $160 \%$ - $70 \%$ of systems considered to be failing and/or impacting on health and the environment).

Community consultation was undertaken to determine the key issues that were seen to be facing Forrest, including bad smells, polluted environment, risks to public health, community disruption when there are many visitors, and business disruption when there are many visitors.

Extensive consultation and investigations were undertaken for this project, and a number of potential options were then developed with the community and formulated into four Solution Packages for Forrest. While there was a range of views, Solution Package 3 received the most votes from the community and was therefore nominated as the preferred solution for addressing wastewater issues. This solution involves a combination of on-property and off-property treatment and irrigation of recycled water. This provides the dual benefits of providing water for use by residents whilst also reducing the treatment and irrigation requirements at the local water recycling system.

\section{8 - FORREST COMMON MASTERPLAN (COLAC OTWAY SHIRE)}

The development of a master plan for the Forrest Common was a 2017/18 Small Town Improvement Program (STIP) funded project. A draft master plan was endorsed for public consultation at the 26 September 2018 Ordinary Council Meeting and documents were on public exhibition from Monday 1 October 2018 to Monday 12 November 2018.

Fifteen formal submissions were received during this period. Council officers worked with the Forrest Common Master Plan Working Group to consider the feedback and it was determined during this process that some members of the community were concerned that the draft and proposed changes didn't capture how the community wanted to see the park developed.

Council officers continued to work with delegated community representatives and interested groups to prepare a revised master plan more representative of the collective community vision. Following extensive engagement and input from the local community, the final Forrest Common Master Plan was presented to Council at the November 2019 meeting for consideration and endorsement.

The plan was supported by Council, and will guide future development, upgrades and renewal within the Common. The implementation of the master plan is subject to future Council budget considerations and the ability to access funding from other external funding sources.

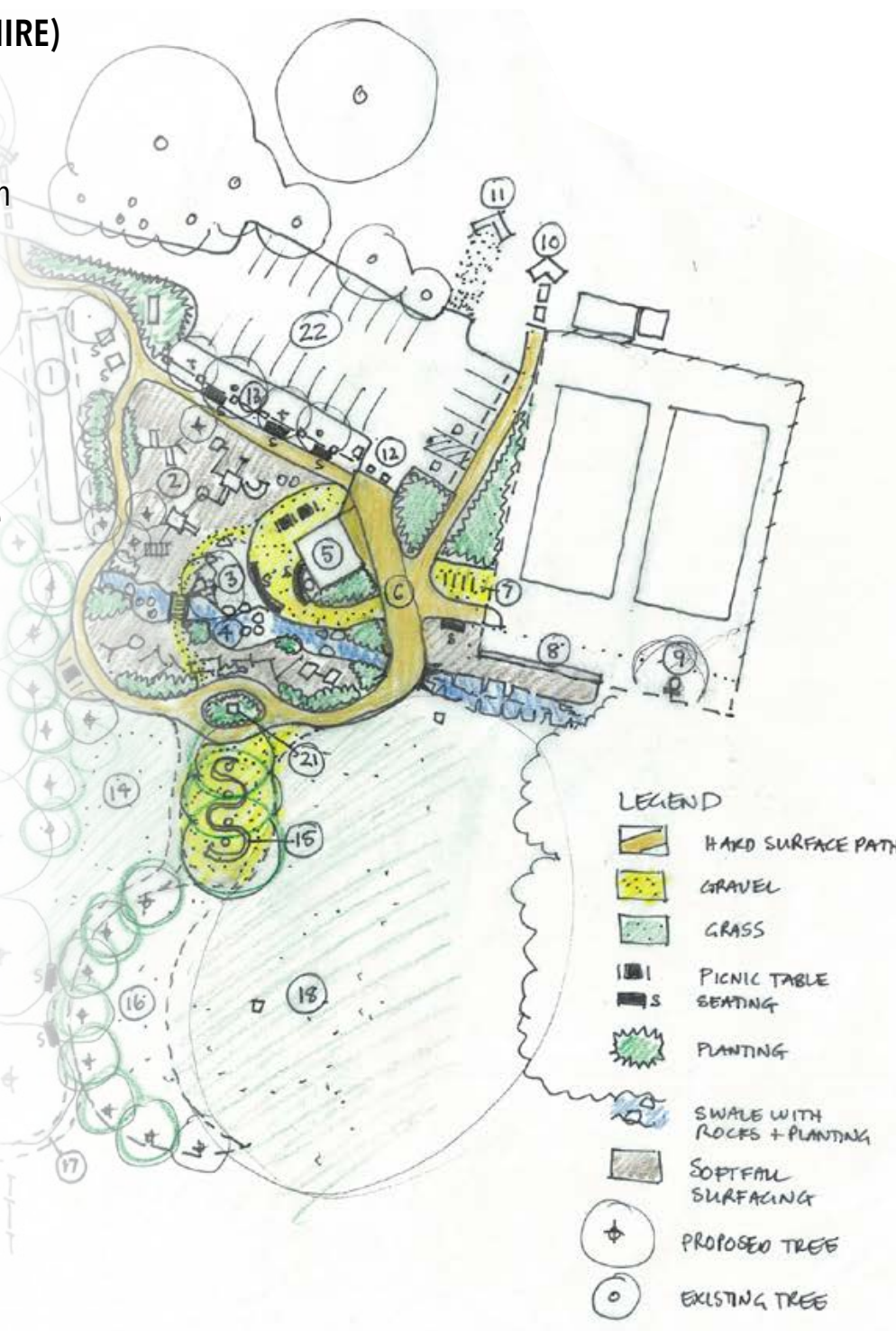




\section{9 - FORREST GATEWAY PROJECT SURVEY}

Following the Forrest Futures process by DELWP in 2017 to transition public land to community management, the Forrest and District Community Group auspiced funds to conduct feasibility assessments and proof of concept to redevelop the DELWP sites in Forrest. This project was known as the Forrest Gateway Project.

In 2018, the group received a $\$ 250,000$ grant through the Victorian Government's Virtual Centre for Climate Change Innovation to conduct a two-year feasibility study into the Forrest Gateway to the Otways centre. In March/April 2019, a community consultation process invited community feedback regarding possible uses of the site.

The survey was completed by 69 participants. The survey was designed to gather community comment on ideas for what could be included in the centre, with a focus on three main areas:
- Importance of having a fire refuge / bushfire place of last resort

- Options for income generation to enable maintenance and upkeep

- Enabling community services (Neighbourhood House) and a home for the Forrest and District Historical Society

Results included:

\section{Fire refuge / bushfire place of last resort}

Respondents generally felt that having a fire refuge or bushfire place of last resort was either extremely important $(75 \%)$ or very important (15\%). $62 \%$ of respondents thought it extremely important and $19 \%$ very important, that a new state-of-the-art fire safe facility is prioritised and built, rather than simply making best use of existing buildings.

\section{Income generating uses}

To enable ongoing maintenance and upkeep of the site, the following income generating uses were identified which respondents would like to see operating on the site:

Tourism/visitation/history experience (78\%)

Neighbourhood House (67\%)

Research and educational partnerships (58\%)

Consultancy rooms rental (46\%)

On-site fee paying (41\%)

Local council or state government involvement (38\%)

Commercial operations (renting space to businesses) (35\%).

Further responses relating to these areas included:

- Interactive tourism experience

The majority of respondents were supportive of increasing tourism as an option for generating revenue at the site and for increasing employment and income. Responses overwhelmingly stated the importance of keeping this nature-based tourism and some important cautions highlighted in the comments.

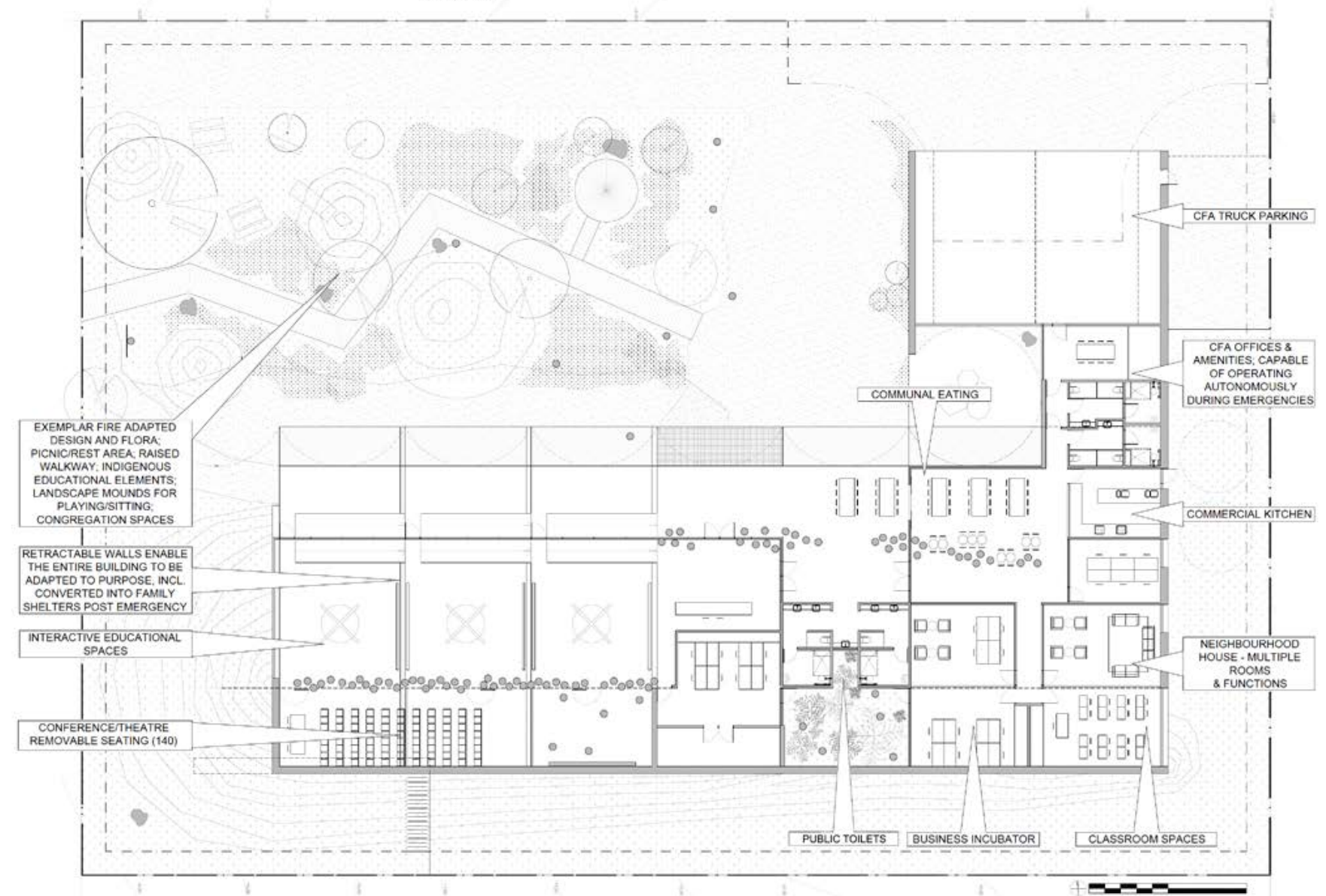


"Eco tourism is the only logical focus; nothing that would be a detriment to our natural environment".

"Not a visitor information centre! A 'science works' approach of interactive engagement".

"I hope that any tourism experience is also a learning experience".

\section{- Education \& Research facility}

The majority of people were supportive of a research facility in collaboration with universities or research organisations on the site. Respondents were also supportive of the idea to use the site as a learning hub for school groups, universities and open to the public in general.

"I'm a strong supporter of 'research to practice' activities, where the locals and general public can learn directly from the research activity. This requires a translation for the 'average' person, but means that the research can impact real change at the grass roots level. It would be ideal as a location for the education officers of the land managers to deliver educative sessions followed by field practice within walking distance".

\section{Historical Discovery Centre}

Preserving Forrest's history by having a Historical Discovery Centre as part of the site was seen as important to almost all respondents.

Additional comments regarding the project included:

"How good would it be to give our community a chance to learn and teach others about the precious Otways right here."

"Will bring jobs in science and environment and education to our future generations; will establish a culture and pride in our contribution to positive environmental stewardship, in a beautiful and creative way."

"Will increase pride and connections in town."
"I think there is a need to carefully consider the intersect of local people and visitors".

"It could play a role in managing our changing environment. It could keep local people and tourists safe in the case of an environmental emergency. It would certainly increase pride in our community and extend community connectedness".

"This is a fantastic project. I can't wait to see how it develops and be part of its growth. Well done to all involved."

"It will become a hub for the most important issues of our time and increase awareness to next generations of the ecology of our area and the planet in general".

"This seems like a project with so much potential for Forrest and its visitors. I'd really love to see a big indigenous focus here as well, paving the way for other areas to start truly acknowledging and bringing back our indigenous heritage".

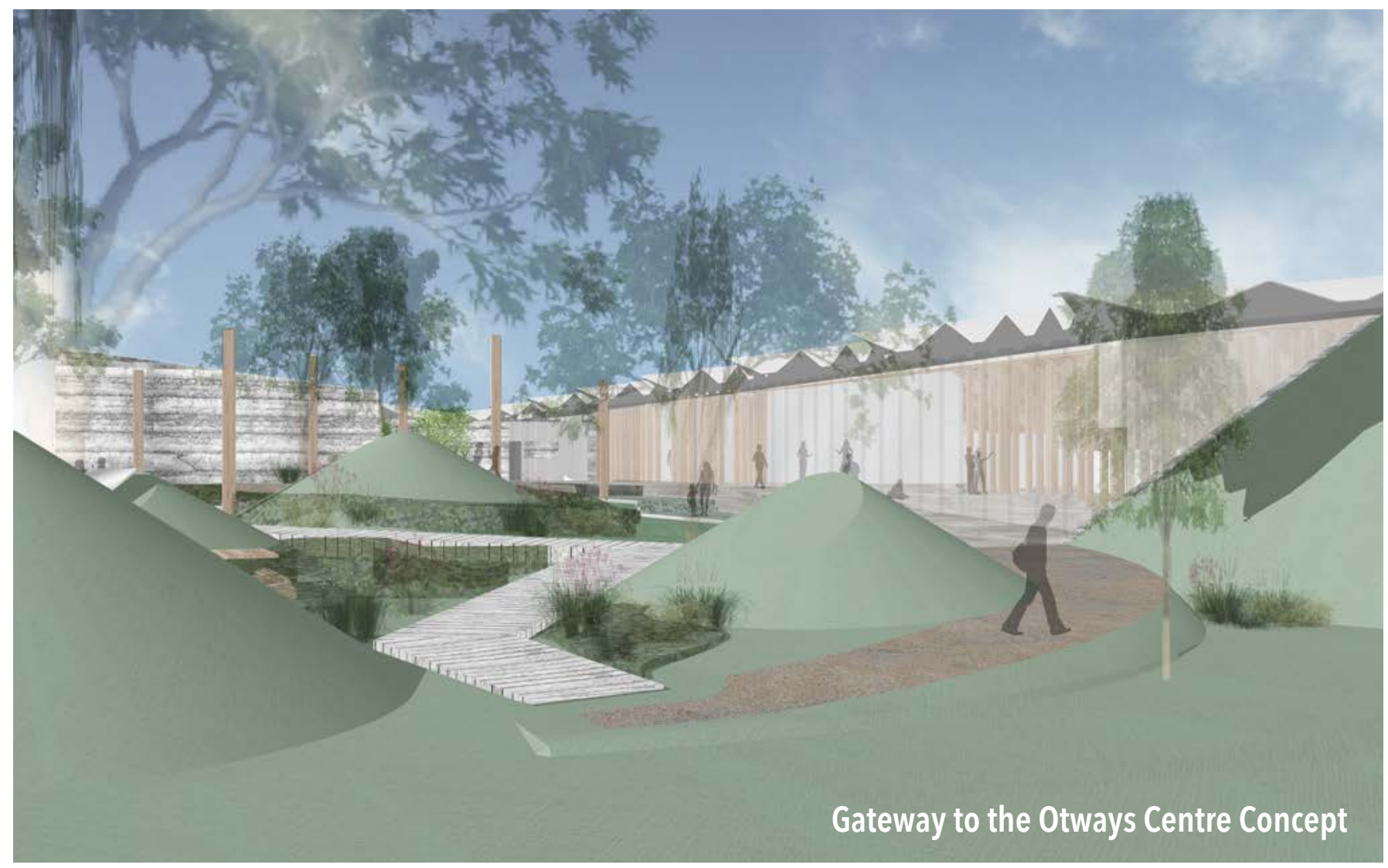




\section{9 - FORREST MOUNTAIN BIKE TRAILS DESIGN PROJECT (COLAC OTWAY SHIRE AND DIRT ART)}

Colac Otway Shire in conjunction with consultants, Dirt Art, conducted community engagement in Forrest to gauge community opinions around revitalizing the Forrest Mountain Bike trail network. The project included auditing existing trails, detailed design for current and proposed trails, a signage audit, design of traffic treatments, and master planning of the Forrest and Yaugher Trail Heads.

Residents and riders were invited to submit project ideas and questions via an online portal and via a social media survey. 340 supportive comments were made via the portal and social media platforms. Council also conducted four open house sessions with the community in May (two sessions), July and October 2019. A total of 102 different community members attended these sessions.

All forums provided Shire and the project consultants a valuable insight on the work required to meet the needs of the community and create a nationally significant mountain bike facility in Forrest. Key community consultation outcomes included:
- Overwhelming general support for the project

- Members of the horse riding community seeking shared trail access and development

- Residential concerns regarding trails being developed close to local houses

- Concern around environmental impacts

- Concern around access Forrest Mountain Bike Trails Design Project 21

- Retaining existing horse-riding loops at the Yaugher Trail Head

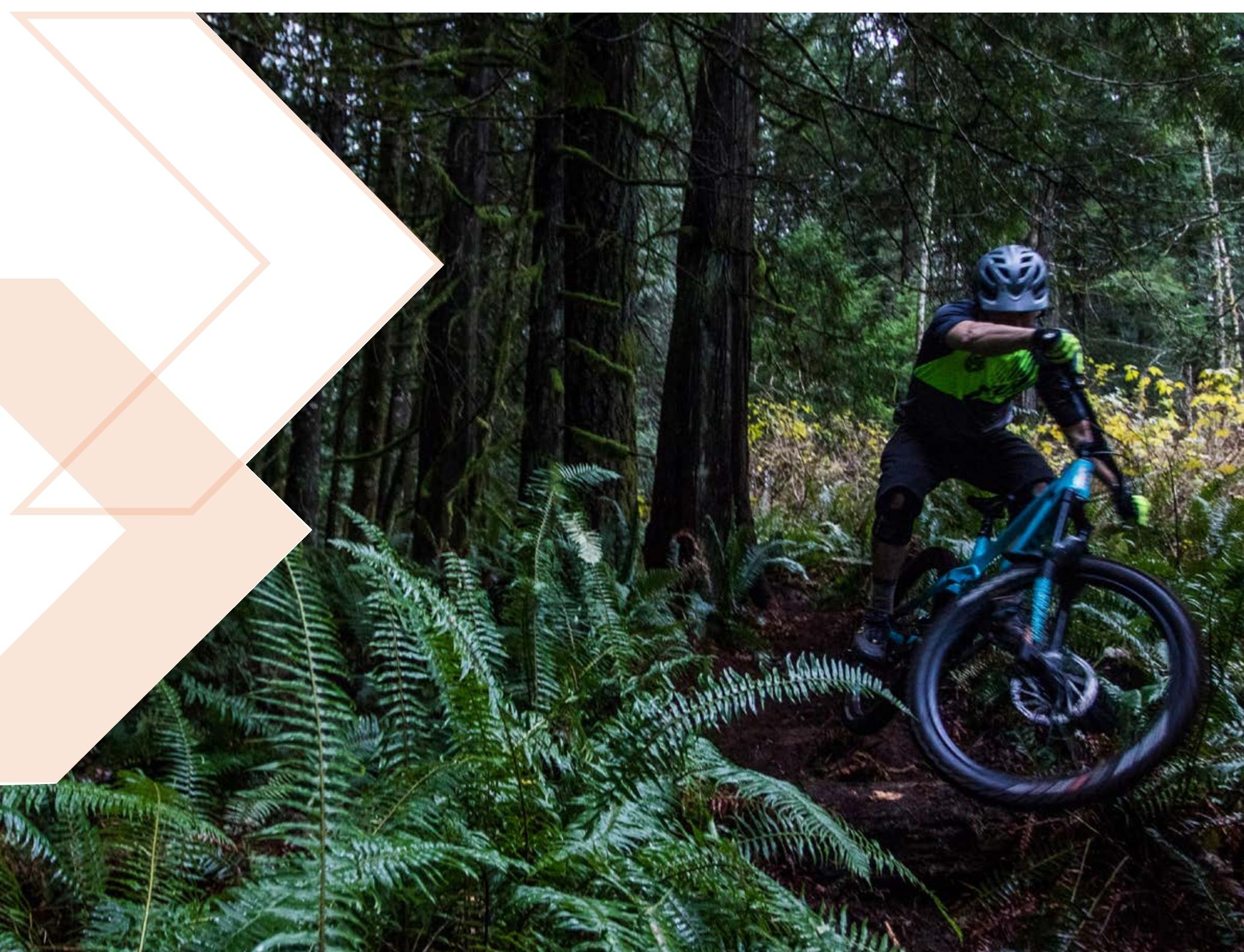




\section{0 - FORREST FUTURES II: LOCALISING THE UNITED NATIONS SUSTAINABLE DEVELOPMENT GOALS (SDGS) IN FORREST}

Following on from the Forrest Futures groundwork laid in 2017 by DELWP, the project entered a second phase of consultation with the community, facilitated by DELWP and in collaboration with Deakin University. The purpose of this was to prepare a town plan for Forrest for 2030 and beyond using the SDGs as a framework (see section 2.1).

The United Nations (UN) SDGs are a global framework to support action on the greatest challenges of our time such as climate change and inequality. To complement and augment national implementation, the UN has encouraged local authorities and communities to implement the SDGs at the local scale. Researchers from Deakin University began actively working with the Forrest community in June 2019. Their project focused on comprehensive research using mixed qualitative (participatory) and quantitative (modelling) methods to assess options for improving multiple socio-economic and environmental dimensions of sustainability. This project is co-funded by the lan Potter Foundation, and in collaboration with Monash University.

There were a range of community engagement activities to determine the shared aspirations and views of the community for their future.

Listening Post, Sept 2019 - each community member who participated was allocated three stickers to vote for their three top issues of concern for Forrest, framed by the SDGs (55 participants).

\section{Kitchen Table Discussion, Sept}

2019 - this was facilitated by DELWP with eight people of diverse experiences (a farmer, a local tourism business operator, a school administrator, and a government employee) to discover what they considered important for the future of the community.

\section{Semi-structured interviews were} conducted with employees of Colac Otway Shire to gain an understanding of the community priorities from a local government perspective.
Open House, Oct 2019 - To extend and confirm the research from the Listening Post and Kitchen Table Discussion, an Open House event presented the information gained from the previous activities. Visitors were invited to provide feedback and further ideas.

\section{Visioning and Ideas Workshop:}

To have the community articulate a shared vision for a sustainable future for Forrest in 2030, a Visioning and Ideas Workshop was conducted. To elicit this vision, the facilitator took the group through a guided visualisation which described a hypothetical walk through the town in 2030, and each attendee wrote down the changes they saw. Then, in small groups, the participants collated these visions into a mock newspaper template, and shared them as 'news articles' with the larger group.

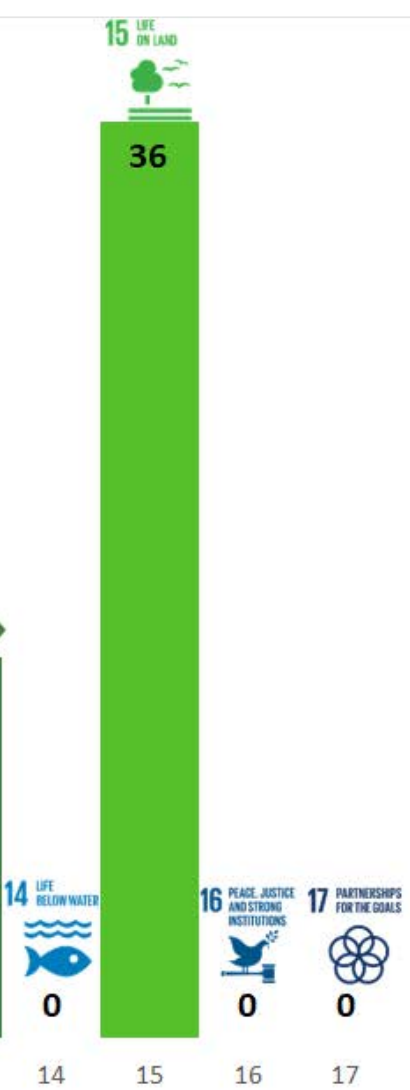




\subsection{Community infrastructure priorities 2020}

Small town community infrastructure is a function coordinated and supported by the local government authority, Colac Otway Shire Council. Council supports the initiative by communities to prepare their own community plan for the future. Each year, Council allocates funds for investment in community infrastructure. The identification of works is a combined effort of community-identified priorities and council budget.

Communities in rural areas generally aspire to the same standards of services as their metropolitan counterparts at the same rate/tax base; however, the costs of delivering these services in regional areas are significantly higher.

A township assessment considers the setting and the natural environment, heritage issues, streetscape and public land issues, infrastructure improvements/ needs, opportunities and constraints.

The previous strategy, released in 2012, proposed the following infrastructure changes:

1. Northern threshold to the town centre defined by a village green incorporating landscaping, seating and sculptural play feature (this was not achieved).

2. Linear botanic garden showcasing the area's native landscape character. Incorporate improvements to footpaths and the road edge, landscaping, seating, sculptural features and information about the plants growing there. This proposal would need to be undertaken in conjunction with the future drainage review (this was partially achieved).

3. Southern threshold to town centre to incorporate improvements to parking adjacent to the Forrest Brewery and Café, traffic calming to facilitate safe pedestrian crossing (subject to VicRoads agreement) and sculptural gateway feature (this was partially achieved).

4. Signage strategy (this was not achieved).

A 2020 update to the community infrastructure priorities forms part of this Plan and will supersede the Forrest part of the 2012 Birregurra and Forrest Township Community Infrastructure Plan

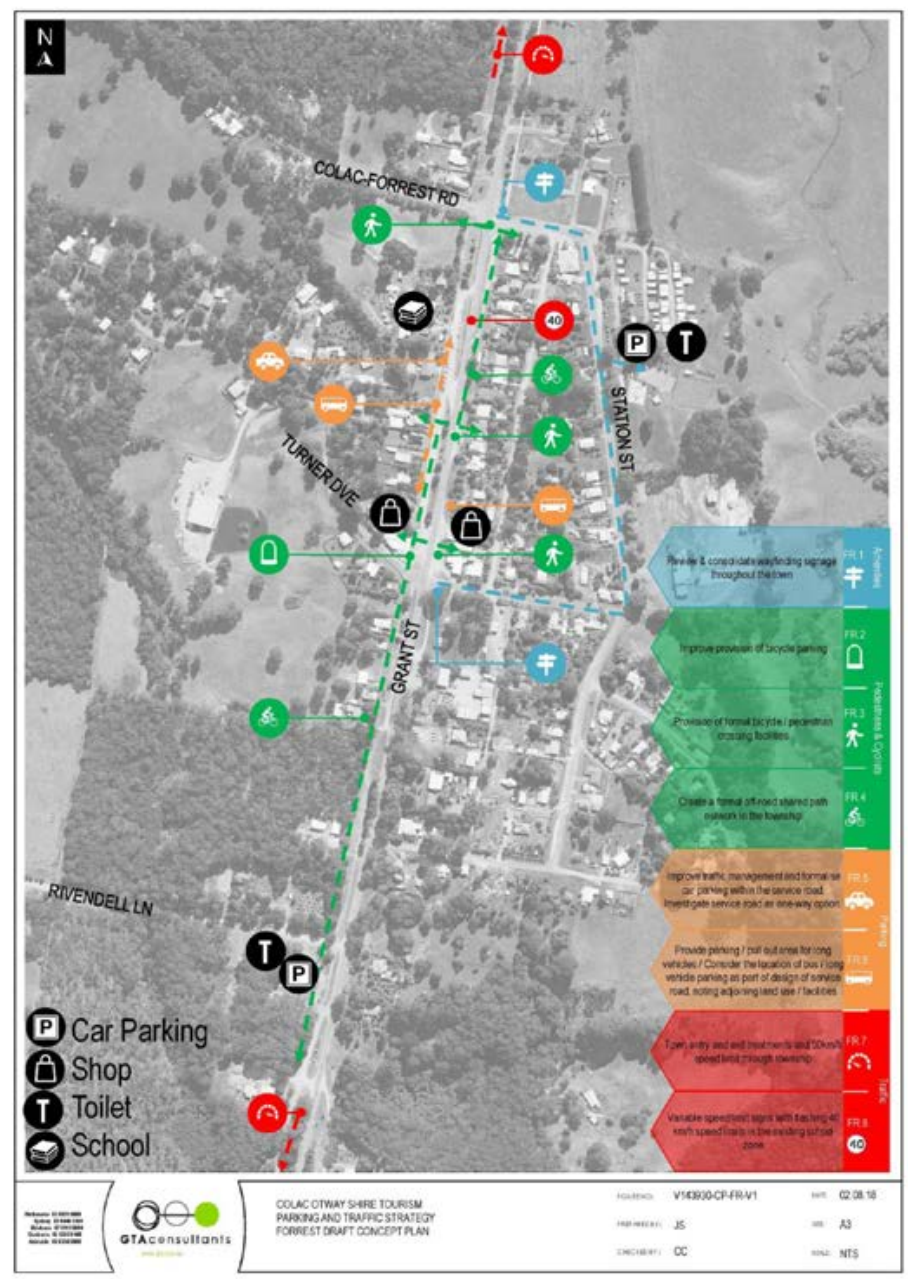

4.5 Forrest CIP proposals

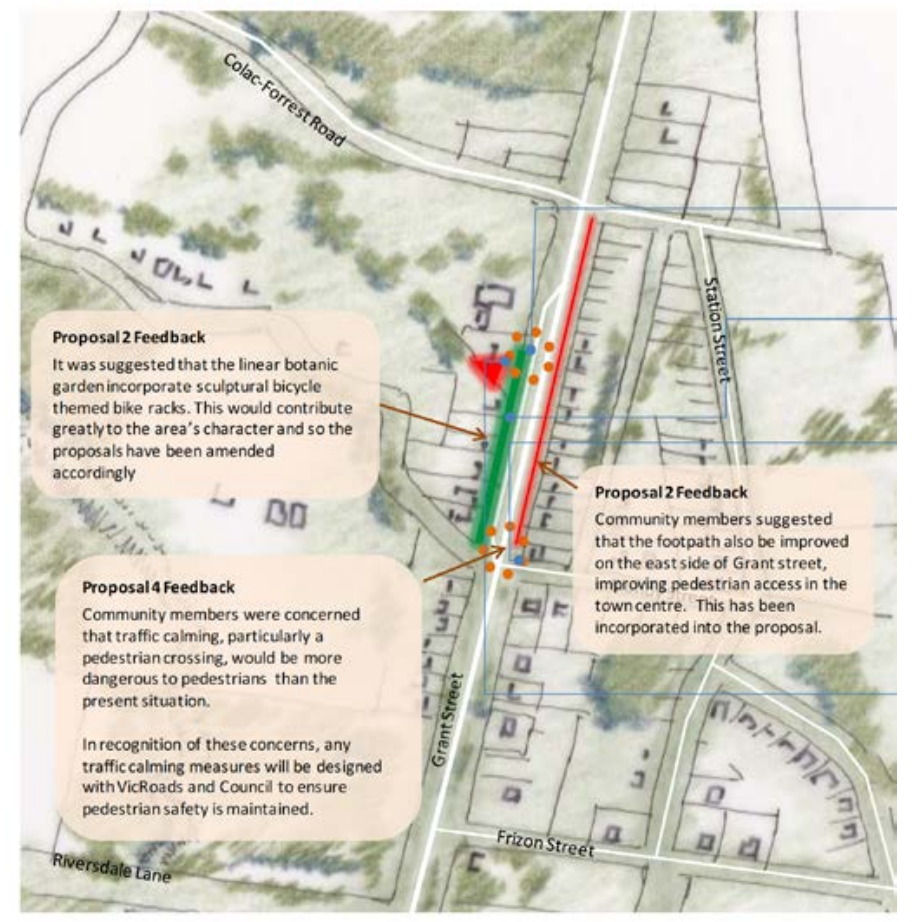


As part of preparing the Forrest \& District Plan: Towards 2030, the community worked with Council to update the Small Town Community Infrastructure Priorities. The community was invited to submit ideas for infrastructure improvements or changes (see Section 5.5 for full list).

1. Bushfire safe place/Gateway to the Otways Centre

2. An integrated town waste water facility

3. Improve current public toilets

4. Move public toilets to Grant St

5. Install a safe crossing on Grant St between Forrest Brewing Company and Forrest General Store

6. Electricity Micro Grid

7. Continue rail trail to Barwon Downs \& Birregurra

8. Dual use footpath from town centre to Barwon Reservoir along Grant St

9. Upgraded facilities at mountain bike trailhead
This list and ranking was developed in consultation with the community, through submitted comment, online facilitated discussion, and a survey. Based on Community Infrastructure ranking and feedback, the following projects have been identified as priority projects over the next 5-10 years. 23 people completed the survey.

10. Unique town wayfinding signage

11. Upgraded and improved mountain bike trails

12. Town hall upgrades (e.g. heating)

13. Car parking improvements on service road to the west of Grant St

14. Speed restriction signage and reduction measures (speed humps etc) on Turner Drive

15. Extend Barwon River walk to link with town centre

16. Art trail and sculpture trail along Barwon River

17. Community Gardens

\section{EXISTING COMMUNITY INFRASTRUCTURE}

Open Space and Recreation

Community and Cultural Facilities

\section{Early Years}

Primary School

Emergency Services
Mountain Bike trails

Mountain Bike shelter/trailhead

Mountain Bike skills park

Walking paths (multi-use)

Tiger Rail Trail

Forrest Common, Tennis court and BBQ facilities, Forret Terminus

Historical point

Forrest Caravan Park

West Barwon Reservoir and River walks

Forrest Recreation Reserve and Horse Riding Club

Public Toilets for tourists / visitors

Tennis courts at Barwon Downs and Gerangamete

Community Hub (47 Grant St): Neighbourhood House; Community Gym;

Studio Forrest (Art studio); Multipurpose room for meeting hire;

CFA Station

Community Hall at Forrest and Barwon Downs

Forrest and District Men's Shed

Forrest Pre-School and Day Care

Forrest Primary School and Out of School Hours Care

CFA - Forrest, Barwon Downs and Gerangamete

Police station

DELWP Barwon Downs Work Centre 


\subsection{Community ideas for town improvements towards $\mathbf{2 0 3 0}$}

The Community was invited to comment and suggest ideas for improving Forrest and District over the next 10 years, and these ideas are all collected below. They are listed with the goals they are aligned with, and sorted by the number of goals they will help achieve, to indicate the potential importance of each idea.

\section{IDEAS THAT MEET FIVE GOALS}

Forrest Gateway to the Otways Centre (incorporating a bushfire place of last resort)

Change town planning character overlay (post-bushfire)

Integrated water management plan (water supply, tanks, waste water, reuse and stormwater) Improve stability of power supply (outages occur regularly)

Improve internet access (mobile and fixed) and communications infrastructure generally

\section{IDEAS THAT MEET FOUR GOALS}

Housing options for local workers, including encouraging more permanent housing at caravan park

Options for farms to build second dwellings (change to zoning laws)

More permanent housing options

Enabling housing for long-term residents rather than B\&Bs

Increased options for short-term accommodation

Upgrade facilities at mountain bike trail hub for tourist and community use

Better access to public transport (e.g. use the rail trail to link to Birregurra or improve bus service)

Build a new caravan park at the recreation reserve/use it as camping overflow at times of high tourist congestion

Access for non-powered boats including canoes and kayaks on Barwon Reservoir, either open access or permitted access for annual triathlon

Epic mountain bike trail around the perimeter of the Barwon Reservoir

\section{IDEAS THAT MEET THREE GOALS}

Roundabout at Brewery corner and proper crossing

Creative in-town wayfinding signage designed with local art groups

Art gallery and studio (perhaps at old CFA building)

Upgrade hall to remove asbestos and improve facility for performances

Upgrade heating/air conditioning at the hall

Connect Barwon Downs and Forrest with a walking/horseriding/ bike track (not necessarily rail trail, possibly along channel)

Continue rail trail to Barwon Downs and then Birregurra

All-abilities infrastructure access to the reservoir for fishing

Swimming hole, swimming platform on the river's edge, downstream from the catchment

Recognition and preservation of original Forrest station site

Public art on the water-tower (at reservoir)

Street art on reservoir wall

Health and wellbeing precinct

Arts trail \& sculpture walk along Barwon River 


\section{Bushfire safe community}

\section{Diverse and sustainable economy,}

\section{Great public and private infrastructure}

4. Cared-for community,

5. Secure future

\section{IDEAS THAT MEET THREE GOALS}

Investigate alternative crops to encourage new businesses

Stock the Barwon reservoir with estuary perch, a native fish species

More action on wastewater

Wastewater treatment (for reuse e.g. crops)

Waste to energy

Weed eradication program (e.g. holly and blackberry removal between Hennigan Cres \& reservoir); set up Forrest LandCare to do this in partnership with DELWP

Caravan park that retains its affordability and community connectedness

Roof-top solar program for community observing social equity

Fresh inspection of buildings and sites for heritage listing

Retain community involvement/management of the Forrest common and caravan park sites

Expand the common to full 5 acres/Develop Forrest common in line with Master Plan

\section{IDEAS THAT MEET TWO GOALS}

Bushfire place of last resort

Second CFA truck

Prohibit camping on Forrest common

Greater access to tennis courts

Citizen science projects/school education

Create a Forrest history centre

Coordinated plan to promote Forrest as a foodie destination

Solar farm

Public toilet improvements

Better road signage on Turner Dve (40km/hr), traffic calming measures (e.g. speed humps)

Footpath on eastern side of road from town to Barwon reservoir (trail on western side of road plus

fire break could be repurposed to avoid destroying bushland)

Address dangerous crossing at Grant St and Tip Rd

Community gardens (possibly at school or caravan park)

Link the school with the arts proposals (listed above)

Energy microgrid(s)

\section{IDEAS THAT MEET ONE GOAL}

Remove native trees from roadsides

Service road carparking

Bus parking

Town beautification (e.g. tree planting on Henry/Station Sts) 


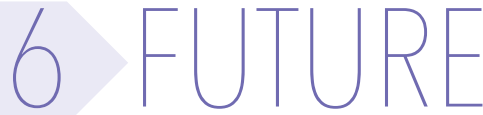

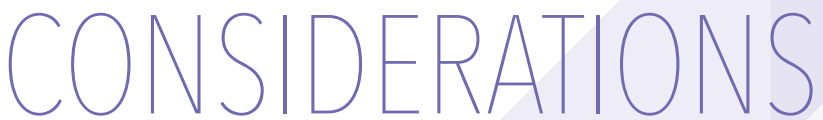

6.1 Drivers of change (future scanning)

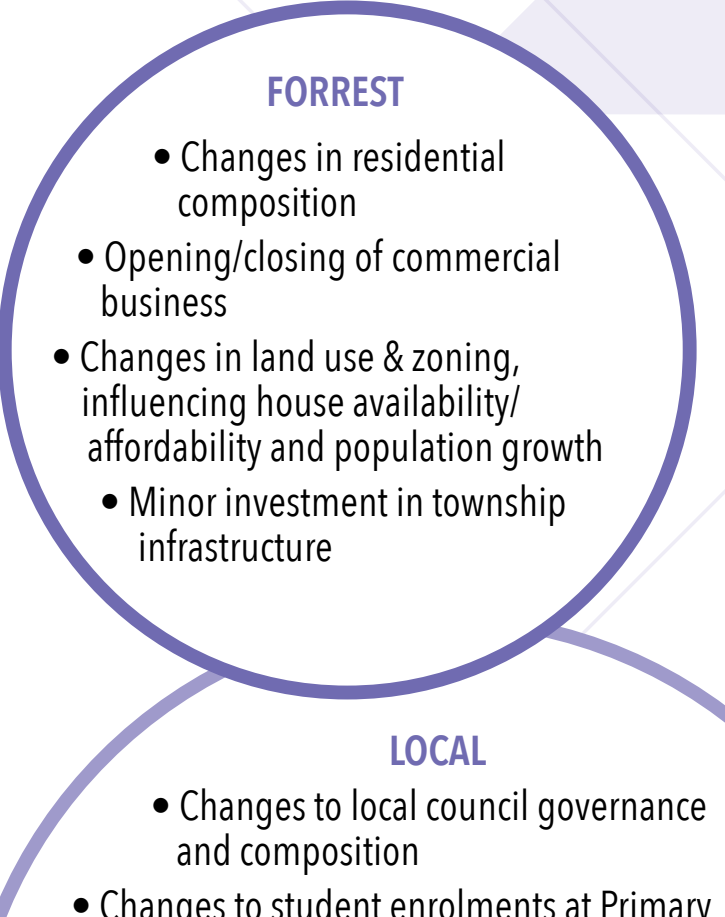

- Changes to student enrolments at Primary school/ increasing-decreasing

- Major weather event (bushfire) as a result of climate change

- Changes in infrastructure land use zoning

- Re-evaluation of the hinterland towns as population growth opportunities

- Major investment in regionally significant infrastructure within the town

- Any realignment of electoral boundaries at a local, state or federal level (i.e. no longer a marginal seat)

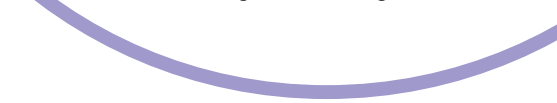

\section{POPULATION AND DEMOGRAPHICS}

Between 2006 and 2016, Forrest experienced a $35 \%$ increase in population. Over that time, the number of children aged $0-14$ decreased by $14 \%$ and people over 55 increased by $26 \%$. The median age of a person living in Forrest has increased from 41 to 52 . Forrest has a slowly increasing and ageing population, which will influence the needs of residents in the future.
There are a number of key drivers which will affect the future of Forrest and District:

- Population and demographics

- Residential land development

- Affordability of property and suitability of housing

- Inequality

- Local economy

- Environment

- Major infrastructure projects

- Transport and connectivity

- Local school

- Climate change

In addition, there are many government and stakeholder policies which may impact the community.

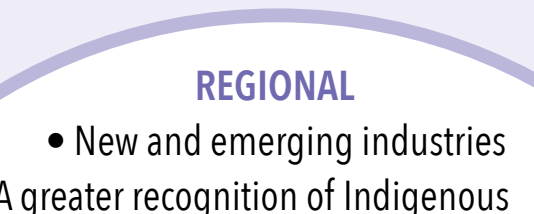

- A greater recognition of Indigenous

peoples' connection to Forrest \& District, and a committment to work in collaboration with Eastern Maar representatives over future developments

- Increased momentum desire for/towards regional living

- Changes to regional cities and service towns, Geelong, Colac, Warrnambool

- Growth in population across Melbourne's Western suburbs

- Investment in regional infrastructure, channel routes roads, rail, transport, increased train services from Colac and/or Birregurra, tourism infrastructure, Avalon airport

- Significant public/private investment in leisure and recreational infrastructure (i.e. Forrest Caravan

Park, Forrest MTB trails, Forrest Brewery expansion)

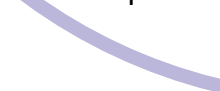




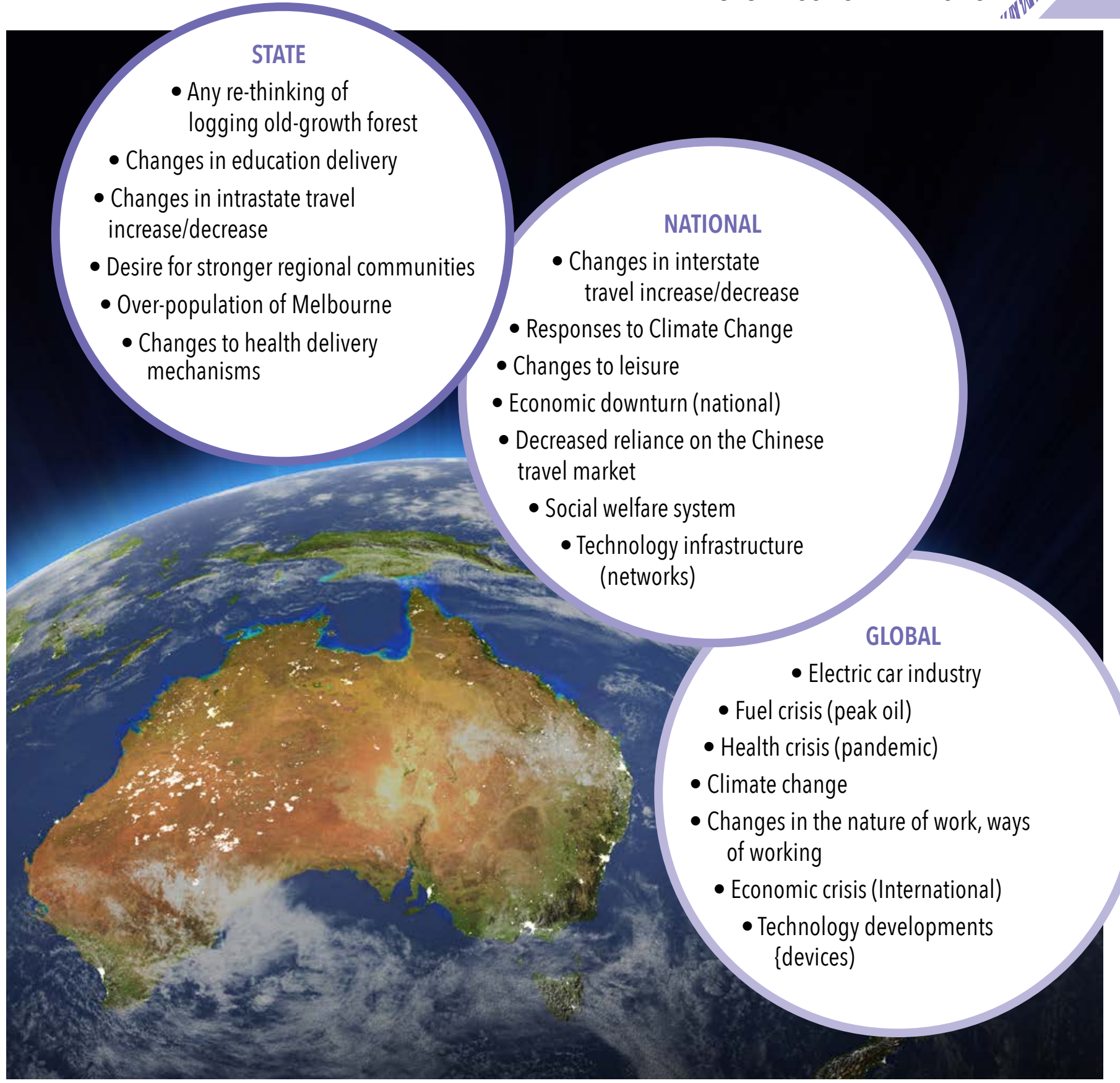

\section{AFFORDABILITY OF PROPERTY AND SUITABILITY OF HOUSING}

Cost and availability of housing has become an issue in Forrest over the last decade. Tourism businesses purchase properties for accommodation, removing them from the pool of available residential housing. This in turn drives up prices due to scarcity of supply. In addition, local tourism businesses must look outside of Forrest for staff, who then have to travel some distance as they cannot find local housing. Other potential new residents also struggle to find housing, and anecdotally must wait until existing residents move away or travel.

Median house prices have increased $188 \%$ since 2009, while median rents have only increased by $30 \%$. This should be viewed from the perspective of the limited supply of housing stock - the largest number of house sales in any year over that period has been nine, and the rental turnover is even smaller at a maximum of five per year. While it is still far cheaper to buy or rent in Forrest than in a metropolitan centre, the chances of locating a property are much smaller.

\section{INEQUALITY}

Along with this issue of housing, Forrest also grapples with inequality. In the greater Otway region, $19 \%$ of people live in poverty and the median family income in Forrest is $55 \%$ lower than for the rest of Victoria (2016). Twenty percent of all families in Forrest are single-parent families (and all single parents are women). The SEIFA score (a measure of socio-economic conditions) puts Forrest in the $30 \%$ most disadvantaged areas in the country, and the $20 \%$ most disadvantaged in Victoria. However, Forrest is a supportive community and provides assistance to those in need, for example community lunches and foodshare. 


\section{LOCAL ECONOMY}

Forrest experienced a major shift in local industry with the cessation of logging in 2008 and the decline of agricultural industries. The development of the Mountain Bike Trail system began the transition to a primarily tourism-based economy, capitalising on Forrest's beautiful environment. This transition was enhanced with private investment in local small businesses catering to both tourists and local residents. The expansion of the tourism industry is obstructed by limited housing supply for both accommodation and employees, and by ageing and failing infrastructure.

The G21 Colac Otway region profile identifies a number of economic development opportunities through the greater Colac Otway region, including dairy farming and processing; green energy; transport and logistics; tourism; and health care and social assistance. It also notes that the Forrest Common and Forrest Mountain Bike Trails Strategy projects are likely to have positive impact on future economic growth in the Shire.

The local community are happy to have tourism in Forrest, except where there is conflict with housing availability, but have expressed a desire for diversification of the economy so there are other options for employment growth within the town. Local small businesses are dominated by tourism/hospitality and farming. Additional businesses are prevented from being created due to lack of housing and office space (e.g. having service businesses move into the area - accountants, hairdressers, tradespeople etc) and poor connectivity (internet and transport). Agriculture is still a major part of Forrest and District, with local dairy and beef farms and mushroom growers.

\section{ENVIRONMENT}

Forrest's placement as the Gateway to the Otways means it is located in an enviably beautiful environment. The area is located in a biodiversity hotspot, and the Great Otway National Park provides protection for some of that biodiversity. This, along with the mountain bike trails, are the biggest drawcard of the local tourism industry. The local residents are proud of their pristine surroundings and dedicated to ensuring they remain so. Climate change and potential bushfire impact are both threats to the local environment.

Forrest and District is a growing hub for regenerative agriculture - where the land is improved as a result of agriculture and carbon is stored in biologically active soil. This limits the use of fertilisers, which reduces agricultural runoff into waterways, improving local water quality and the environment generally. 


\section{MAJOR INFRASTRUCTURE PROJECTS}

Forrest currently has several major infrastructure projects in planning (see Section 2.4).

\section{The Forrest Gateway Project} In 2019, three parcels of land were transferred to community ownership from DELWP. The Gateway Project has developed plans to build a multipurpose site incorporating a Bushfire Place of Last Resort, a community hub and the CFA station, together with a centre for interactive visitor experiences and climate change education and research.

\section{Wastewater}

The issue of sewerage and wastewater infrastructure has been developing for some years in Forrest and has recently come to a head. Ageing septic systems that don't meet current safety standards are no longer adequate and new infrastructure is urgently needed. This affects the local environment and biodiversity, the local economy (by limiting tourism), wellbeing of local residents, and additional development in the town.

\section{Forrest Mountain Bike Trails Design Project}

The Forrest Mountain Bike Trails were first opened in 2005, encompassing over $60 \mathrm{~km}$ of trails. A proposal was released in December 2019 to increase the Mountain Bike trail network by approximately $38 \mathrm{kms}$, including restructuring the existing trails and creating a new Trail Head. This plan is aimed to revitalise mountain bike tourism and reestablish Forrest as a nationally significant mountain bike destination.

\section{Forrest Common}

Colac-Otway Shire have been consulting with the Forrest community to revamp and reinvigorate the Forrest Common.

\section{TRANSPORT AND CONNECTIVITY}

Forrest lies on the route between Apollo Bay and Colac. It is a feeder route to tourism along the Great Ocean Road and the Great Otway National Park. State government are currently upgrading some portions of the Forrest-Apollo Bay Road, and are planning to undertake surfacing work on the Birregurra-Forrest Road near Seven Bridges Road. Recent upgrades to the channel routes to Forrest, such as the Princes Hwy between Winchelsea and Colac, and the Great Ocean Road, make it easier for tourists to visit the area, and safer for residents to drive.

There is one bus line that runs through Forrest, the Colac-Marengo route. This service runs only on Wednesdays and only once in each direction. During summer months, a more frequent bus service is offered for tourists. There is a V-Line station in Birregurra, but apart from the once-weekly bus, there is no connecting service from Birregurra to Forrest, and there is no alignment of the bus timetable with the train timetable. This puts a severe limit on residents who may want to avoid driving, and for tourists who wish to visit that do not drive.

The NBN has been rolled out in Forrest, but the service can be poor. NBN Fixed Wireless is known to suffer from congestion issues, and the distance to the fixed wireless tower can also affect internet speeds. The nearest tower to Forrest is in Barwon Downs, and towers have an effective range of $14 \mathrm{kms}$, which can be disrupted by terrain (trees, mountains, etc.), and precipitation. There is also limited mobile reception throughout Forrest. Improved internet access (fixed and mobile) would encourage new businesses which rely on connectivity, and better support the existing residents and businesses.

\section{LOCAL SCHOOL}

In the period from 1993-2001, schools in the neighbouring areas of Barwon Downs, Gerangamete, Yeodene and Barongarook closed down. That left the Forrest Primary School as the only primary school in the district (schools in Colac, Birregurra, Apollo Bay and Carlisle River being closest). Forrest Primary School contains the Forrest Pre-School (also the central pre-school for the district, the nearest being in Apollo Bay, Colac and Birregurra), in addition to long day-care and out of school hours care, assisting parents who need to travel longer distances for work outside of Forrest. The school is a significant employer with three fulltime and eight part-time staff, and one trainee. The school has offered traineeships to local residents for over 20 years.

With Forrest Primary School being the central school, pre-school, and childcare service for the community, it creates traffic for local businesses in town, such as the General Store. It also works with many of the community groups in Forrest. If Forrest were to lose its primary school, there would be many negative knock-on effects causing harm to Forrest's future.

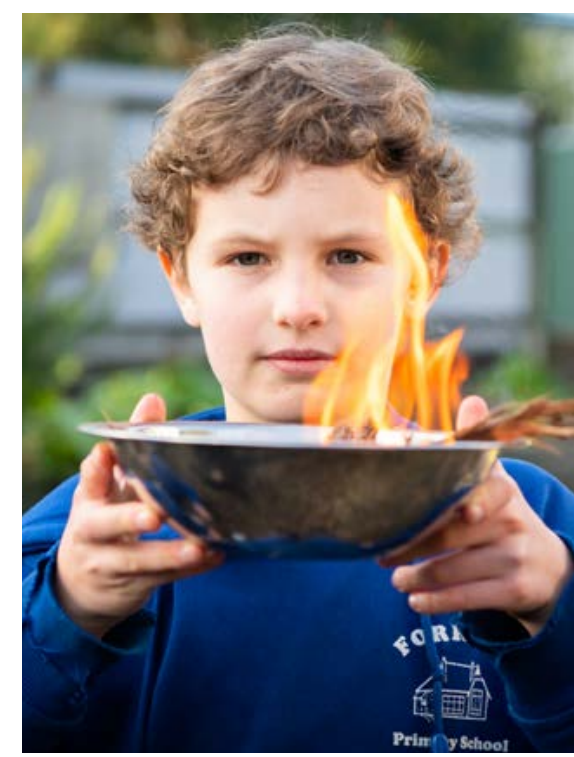




\section{CLIMATE CHANGE}

Human-induced climate change is a problem that will require a united, global effort to combat. However, the effects of climate change do and will continue to affect Forrest at a community level. Such effects include increasing temperatures, drying climates, increased frequency and severity of bushfires, droughts and extreme weather. As the gateway to the Otways, Forrest is vulnerable to bushfires and drought. The effect of climate change on biodiversity is a serious threat by itself, but may also affect Forrest's eco-tourism economy. Forrest is likely to be impacted by bushfire in the near future simply through the balance of probabilities, and climate change means that such an impact is likely to be harsher and stronger than it may otherwise have been. Even if Forrest isn't directly affected by bushfire in a given year, the influence of other bushfires will affect Forrest because of bushfire smoke and a general downturn in visitor numbers (as seen during the Eastern Victoria bushfires in 2019-20).
Encroaching sea level rise is already affecting communities along the Great Ocean Road, with landslips creating dangerous road conditions and impacting coastal properties. This could have positive or negative effects on visitor numbers to Forrest dangerous and unsightly conditions may drive people away from the region, or encourage them to visit areas further inland. Decreasing amenity along the Great Ocean Road could also push residents to move further inland, potentially into Forrest and District. This, coupled with the increasing cost of farmland as agriculture shifts south, away from drying and drought-affected northern Victoria, could make living in Forrest and District even less affordable than it currently is.

The Geelong region is anticipated to have significant population growth between now and 2050, and the water supplies for the region are al ready fully allocated. Providing water resources for the Geelong region without negatively affecting the environment is a sustainability challenge that needs addressing.

Increasing temperatures will also affect Forrest's residents, especially as the community is ageing. More frequent heatwaves will put older people, more susceptible to heatinduced illness, at risk. Forrest is occasionally subject to flooding (e.g. the spillover of Barwon Dam in 2012), and with the increase in extreme weather events this could become more frequent. To remain safe and stay resilient in the face of climate change, Forrest must anticipate more frequent bushfires, flooding and drought, and develop plans for sustainable recovery.

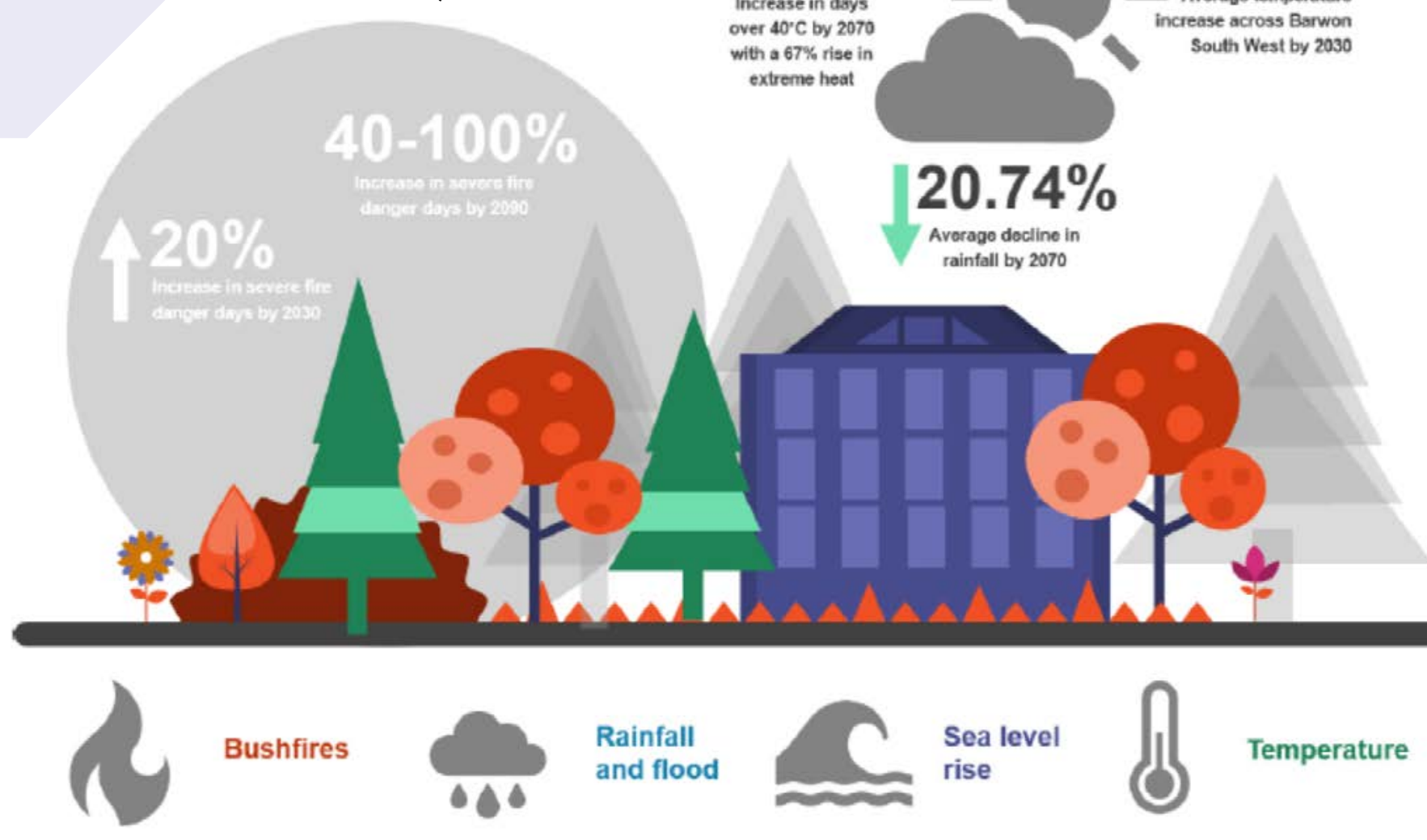

Figure 2: Projected climate change impacts in Barwon South West (Geelong Regional Alliance, 2018, CSIRO, 2015) 


\subsection{Current Government objectives}

Careful consideration has been given to the community's role in addressing government and stakeholder priorities, and this plan goes some way to addressing a number of those. A list of government and stakeholder policies has been compiled below.

\section{NATIONAL}

Federal government policies covering issues such as regional development, agriculture, water, digital connectivity (NBN), health, energy, biodiversity and threatened species, climate change, bushfire recovery, forestry, and land use.

$\begin{array}{ll}\text { Regional Institute of Australia } & \text { Project Agenda(s) } \\ & \text { - Future of Regional Jobs } \\ & \text { - Mid-Sized Towns (Colac, as it impacts / relates to Forrest) } \\ \text { - Regions in Transition } \\ \text { - Effectiveness of place-based transition packages }\end{array}$

\section{Tourism Australia}

Regional Development Australia
- Investing in Regional Development - Competition and Collaboration

Tourism2020

- Grow demand from Asia

- Ensure tourism transport environment supports growth

- Build industry resilience, productivity and quality

2011 The Great Ocean Road World Class Tourism Investment Study - A Product Gap Audit

Building Better Regions Fund (BBRF)

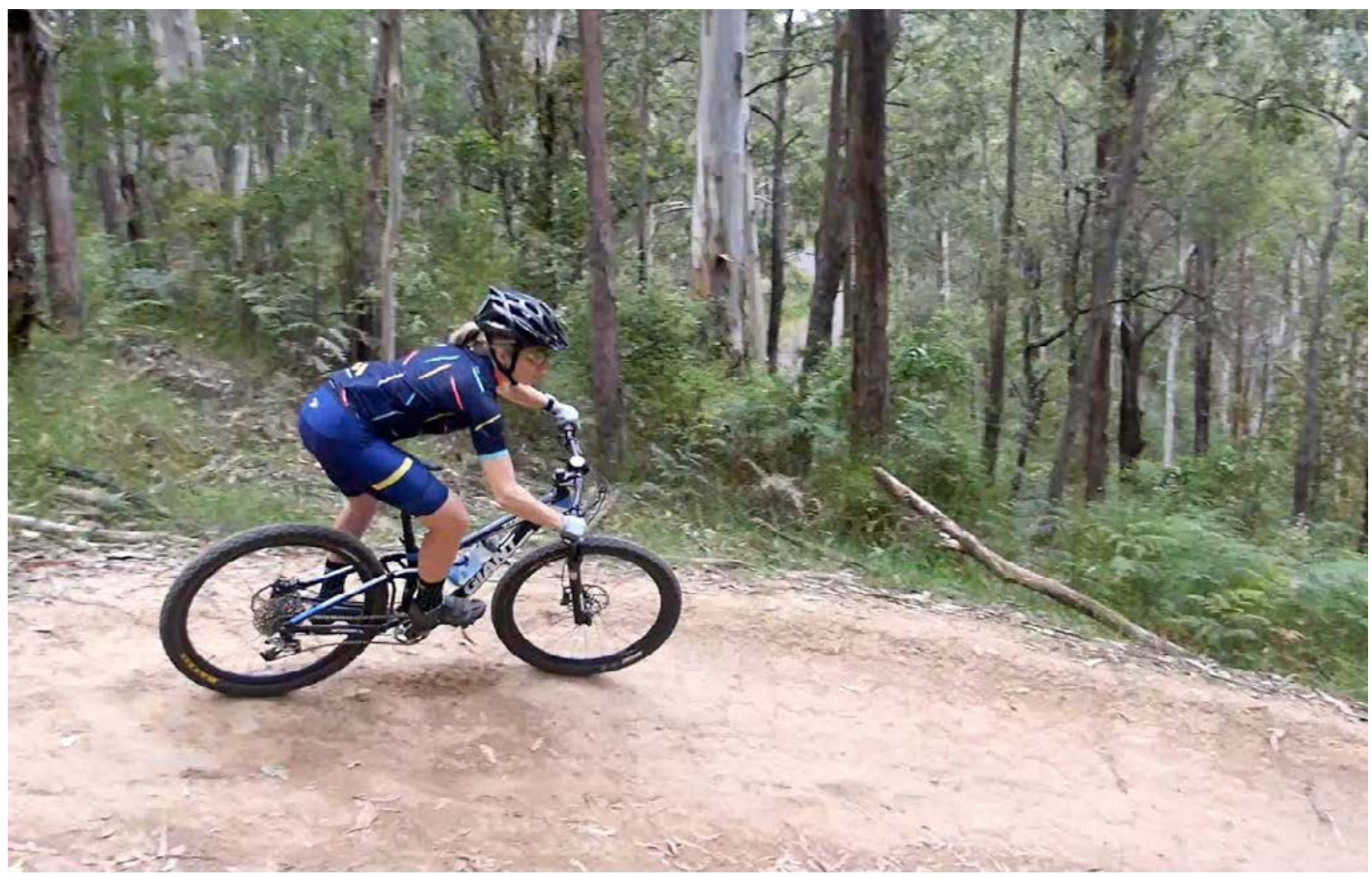




\section{STATE}

\section{Regional Development Victoria}

\section{Regional Roads Victoria}

Country Fire Authority

Federation of Victorian Traditional Owner Corporations

First People's Assembly of Victoria

Aboriginal Victoria

Department of Environment, Land, Water and Planning
VisitVictoria
Victoria's Regional Statement

2016 - 2020 Victorian Visitor Economy Strategy Action Plan Grants and Programs

- Stronger Regional Communities Program

- Regional Tourism Infrastructure Fund

- Regional Infrastructure Fund

- Regional Community Leadership Program

Fixing Country Roads Program

Koori Inclusion Action Plan

Victorian Cultural Fire Strategy

Treaty Negotiation Framework

Aboriginal Heritage Act 2006

Aboriginal Heritage Regulations 2018

2003 DSE A New Future for the Otways

2009 Caring for Country - the Otways and You: Great Otway National Park and Otway Forest Park Management Plan

Protecting Victoria's Environment - Biodiversity 2037

Victoria's Climate Change Adaptation Plan 2017-2020

State of the Environment 2018

Victoria's Climate Science Report 2019

Aboriginal Cultural Identity

Aboriginal Inclusion Plan

Current Corporate Plan

- Zero emissions, climate-ready economy and community

- Safe, sustainable and productive water resources

- Reliable, sustainable and affordable energy services

- A safe and quality built-environment

- Sustainable and effective local governments

- Reduced impact of major bushfires and other emergencies on our people, property and the environment

2013 - 16 Victoria's Regional Tourism Strategy

Victoria's 2020 Tourism Strategy

2014-2024 Victoria's Trails Strategy

\section{REGIONAL}

G21 Geelong Regional Alliance

Eastern Maar Aboriginal Corporation

Barwon Water

Great Ocean Road Regional Tourism
G21 Adventure Trails

Eastern Maar Country Plan

2017 Forrest Waste Water Investigation

Strategy 2030

Reconciliation Action Plan

2015-2025 Strategic master plan for the Great Ocean Road Region Visitor

Economy

2015-2017 Destination Action Plan: Otways 
LOCAL

Colac Otway Shire

Surf Coast Shire

Forrest and District
- 2002 Colac Otway Stormwater Management Plan (vol 1\&2)

- 2004 COS Economic Development and Tourism Strategy

- 2006-2010 Recreation Strategy

- 2007 Rural Land Strategy

- 2010-2018 Environment Strategy

- 2011 COS Rural Living Strategy

- 2011 COS Open Space Final Report

- 2013-2015 Environment Action Plan

- 2013 Roadmap for a Carbon Neutral Plan

- 2015 Domestic Wastewater Management Plan

- 2017-2021 COS Council Plan

- 2017-2021 COS Health and Wellbeing Plan

- 2017-2027 Climate Change Adaptation Plan

- 2019 COS Tourism Parking and Traffic Strategy

- 2019-2024 Economic Development Strategy

- 2020 COS Neighbourhood Safer Places Plan

- Colac 2050 Growth Plan

2019 Rural Hinterland Futures Strategy

- 2002 Nature-based tourism strategy

- 2004 Angahook-Otway Investigation

- 2005 Feasibility Study Into Increased Economic Activity In Forrest

- 2007 Reviewed Forrest Township Masterplan

- 2010 Forrest Structure Plan 2010

- 2011 Forrest Small Town Infrastructure Plan

- 2015 Forrest Mountain Bike Trail Strategic Plan

- 2015 Tiger Rail Trail Feasibility Study

- 2016-2019 Forrest Primary School Strategic Plan

- 2018 Forrest Mountain Bike Trail Economic Analysis

- 2019 Forrest Gateway to the Otways Assessing feasibility, building collaboration

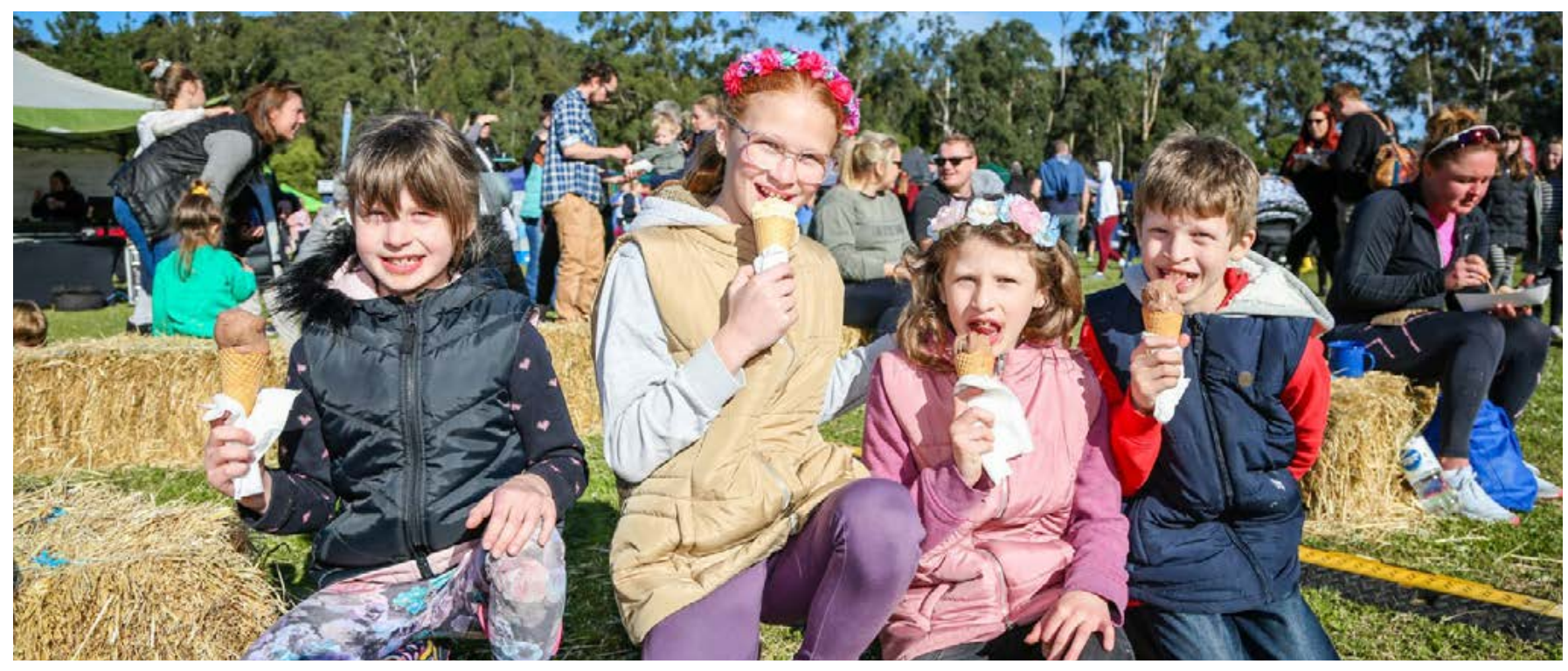




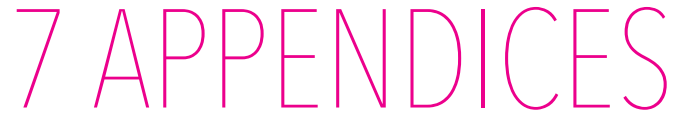

\section{Bibliography of previous strategies and reports}

Arup, 2018. Gateway to the Otways, Forrest - Assessing Feasibility, Building Collaboration. Sydney, Australia.

Arup, 2017. Colac Otway Shire Council Climate Change Adaptation Plan 2017- 2027 Climate Resilient Communities of the Barwon South West. Victoria, Australia.

Barwon River Ministerial Advisory Committee 2019. Our living rivers of the Barwon. Victoria, Australia.

Bradstock, R.A., 2010. A biogeographic model of fire regimes in Australia: current and future implications. Global Ecology and Biogeography 19,145-158. https://doi.org/10.1111/j.14668238.2009.00512.x

Building Environmental Assessment Company Pty Ltd, 2019. Forrest Gateway Project Thermal Modelling Report. Victoria, Australia.

Capire Consulting Group, 2012. Birregurra and Forrest Township Community Infrastructure Plans. Victoria, Australia.

Civic Collective, 2019. Colac Otway Region Profile. G21 - Geelong Regional Alliance, Geelong.

Colac Otway Shire, 2019a. Colac 2050 Growth Plan: Planning for Growth. Colac Otway Shire, Victoria, Australia.

Colac Otway Shire, 2019b. Forrest Common Masterplan Meeting Agenda Item.

Colac Otway Shire, 2018. Council Plan 2017-2021. Victoria, Australia.
Converlens, 2019. Modernisation of the Victorian Regional Forest Agreements: Independent Report on the Joint Victorian and Australian Government Consultation. Victoria, Australia.

CPG, 2011. Forrest Structure Plan. Victoria, Australia.

Decentralised Water Consulting, 2019. Forrest Wastewater Investigation: Final Project Report. NSW, Australia.

DELWP, 2019. Forrest Futures Project - 2017/19 Community at Centre of Decision-making (draft). Victoria, Australia.

DELWP, 2017. Forrest Futures Project: An evaluation of DELWPs community engagement approach. Victoria, Australia.

DELWP, 2016. Our Catchments, Our Communities: Integrated Catchment Management in Victoria 2016-19. Victoria, Australia.

DirtArt, 2019. Forrest MTB Trails Design Project. Victoria, Australia.

Forrest and District Community Group, 2015. Forrest and District Community Group survey.

Forrest Gateway Project, 2019a. FORREST GATEWAY PROJECT Community Consultation March / April 2019.

Forrest Gateway Project, 2019b. Gateway to the Otways, Forrest.

Forrest Gateway Project, 2019c.

Report into design and use elements in a bushfire-adapted community building in Forrest. Victoria, Australia.

G21 Geelong Regional Alliance, 2019. Colac Otway Region Profile. Victoria, Australia.
G21 Geelong Regional Alliance, 2015. The Geelong Region Plan: A sustainable growth strategy. Victoria, Australia.

Great Ocean Road Regional Tourism Board, 2019. GORRT Strategic Business Plan. Victoria, Australia.

GTA Consultants, 2018. Colac Otway Shire Tourism Parking and Traffic Strategy. Victoria, Australia.

Kiem, A., Austin, E., National Climate Change Adaptation Research Facility, 2016. Sustainable and thriving rural communities under climate change. Policy Information Brief 4.

Macroplan Dimasi, 2018. Forrest Mountain Bike Trails Economic Benefit Cost Analysis. Victoria, Australia.

Mckinna, D., Wall, C., 2019.

Transitioning Towns Toolbox: Tools for community building in small towns. Victoria, Australia.

Michael Smith \& Associates, 2018. Forrest Common Masterplan. Victoria, Australia.

Otway District Bushfire Planning Collaboration, 2016. Strategic fire management plan Otway District 2017 - 2020. Otway District Bushfire Planning Collaboration, Victoria, Australia.

Sykes Consulting/Urbis, 2011. Colac Otway Public Open Space Strategy. Victoria, Australia.

Victorian Planning Authority, 2011. The West Growth Corridor Plan. Victoria, Australia. 


\section{Glossary}

\section{Bushfire place of last resort}

A place of last resort when all other bushfire plans have failed.

\section{G21 - Geelong Region Alliance}

The formal alliance of government, business and community organisations working together to improve the lives of people within the Geelong region across five municipalities - Colac Otway, Golden Plains, Greater Geelong, Queenscliffe and Surf Coast.

\section{Regional Development}

The provision of assistance to regions for economic development. In Australia, there are Regional Development Associations coordinated by the Federal government and run by the State governments.

\section{Structure Plan}

A long-term guide for change to land use, building and public spaces.

\section{Sustainable Development Goals} (SDGs) A set of 17 goals adopted by all UN member states, based on the 2030 Agenda for Sustainable Development. The Agenda is a shared blueprint for peace and prosperity for people and the planet.

\section{References cited in this report}

Arup, 2018. Gateway to the Otways, Forrest-Assessing Feasibility, Building Collaboration. Sydney, Australia.

Barwon Water, 2020, Boundary Creek, Big Swamp and surrounding environment: Remediation and Environmental Protection Plan, Victoria, Australia.

Bradstock, R.A., 2010. A biogeographic model of fire regimes in Australia: current and future implications. Global Ecology and Biogeography 19, 145-158. https://doi.org/10.1111/j.14668238.2009.00512.x

Colac Otway Shire, 2019. Colac 2050 Growth Plan: Planning for Growth. Colac Otway Shire, Victoria, Australia.

G21 Geelong Regional Alliance, 2019. Colac Otway Region Profile. Victoria, Australia.

G21 Geelong Regional Alliance, 2015. The Geelong Region Plan: A sustainable growth strategy. Victoria, Australia.
Great Ocean Road Regional Tourism Board, 2019. GORRT Strategic Business Plan. Victoria, Australia.

Otway District Bushfire Planning Collaboration, 2016. Strategic fire management plan Otway District 2017 - 2020. Otway District Bushfire Planning Collaboration, Victoria, Australia.

Victorian Planning Authority, 2011. The West Growth Corridor Plan. Victoria, Australia.

White, M.P., Alcock, I., Grellier, J., Wheeler, B.W., Hartig, T., Warber, S.L., Bone, A., Depledge, M.H., Fleming, L.E., 2019. Spending at least 120 minutes a week in nature is associated with good health and wellbeing. Scientific Reports 9, 7730. https://doi.org/10.1038/s41598-01944097-3

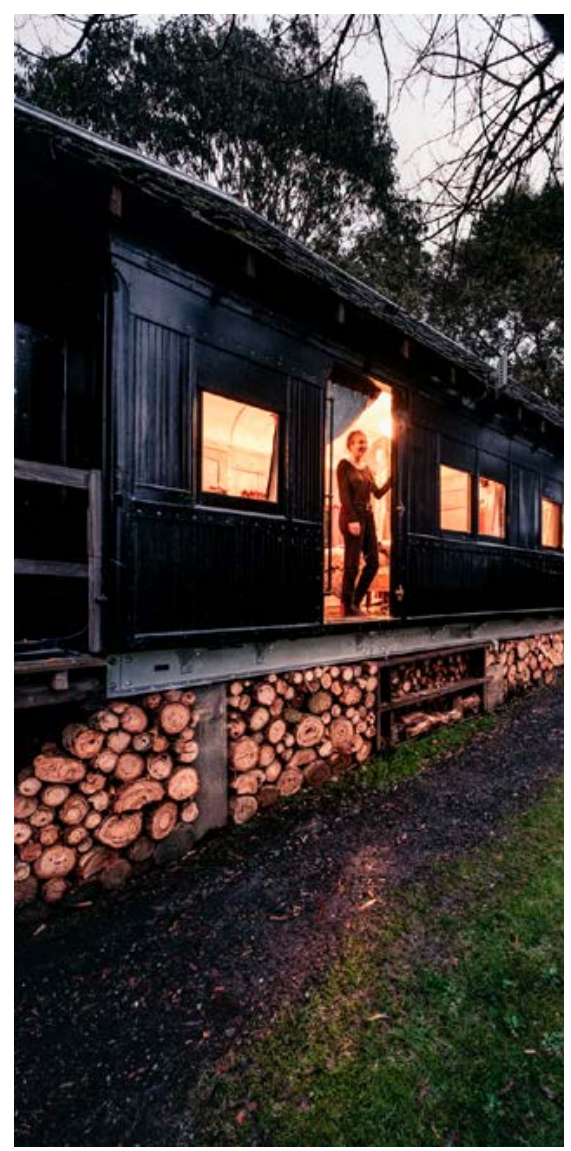




\section{SUSTAINABLE DEVELOPMENT}

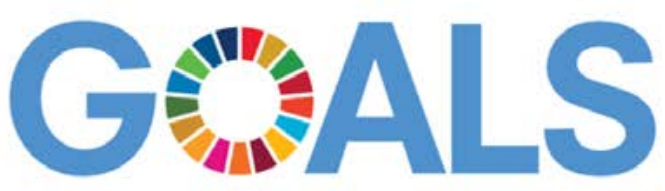

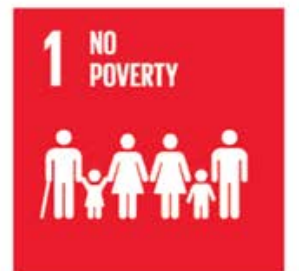
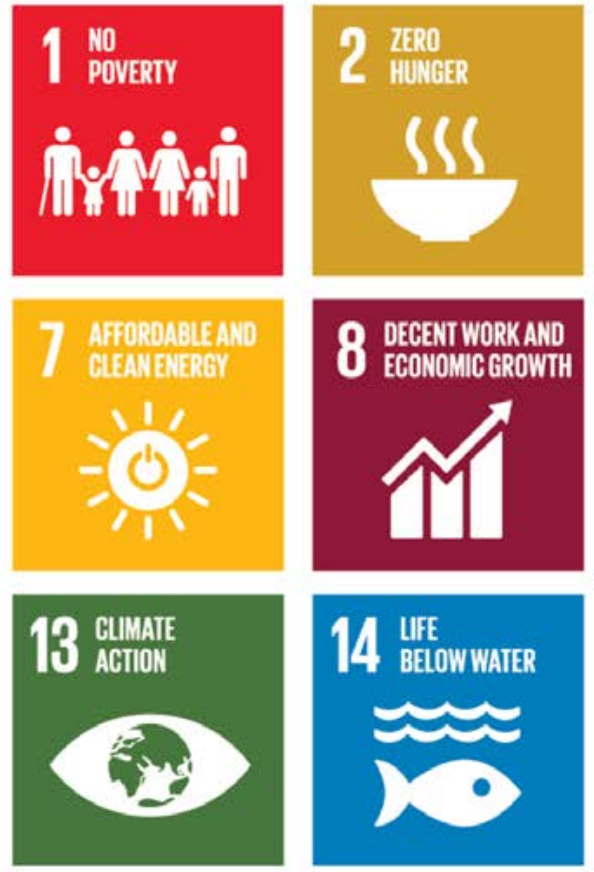
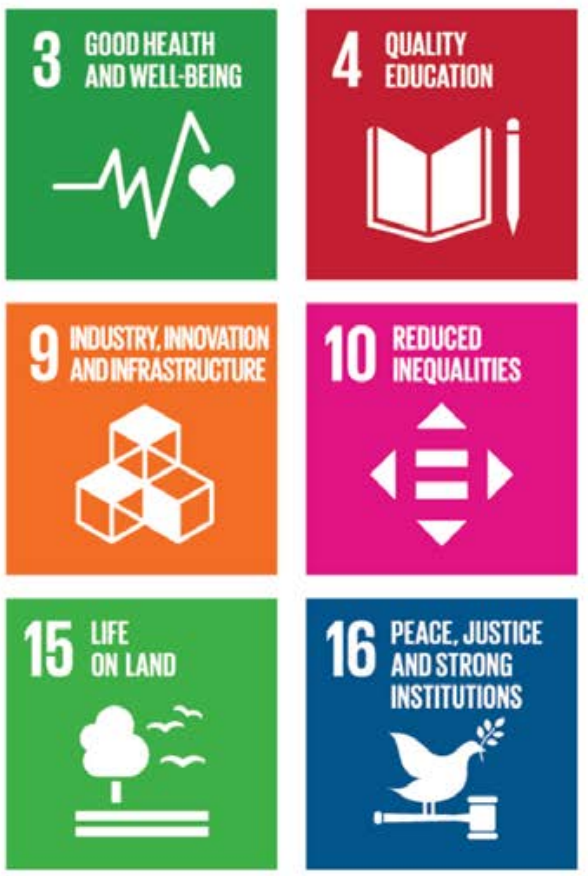
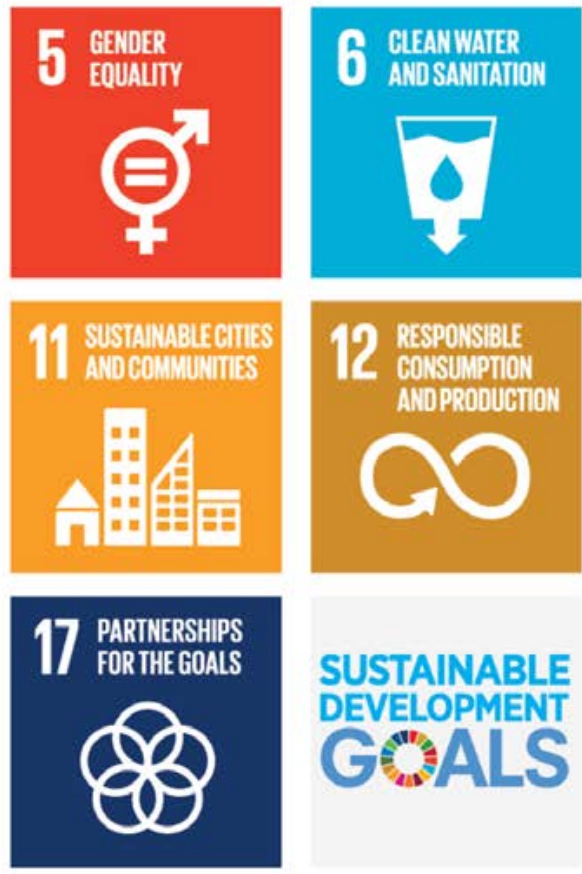

SUSTAINABLE DEVELOPMENT Gể.

\section{Sustainable Development Goals}

The Sustainable Development Goals (SDGs) are an agenda developed by the United Nations and are intended to guide development for a sustainable future. The SDGs were adopted by all UN member states in 2015 and their horizon is 2030 - that is, countries should intend to achieve all 17 goals by 2030. The United Nations believe that it will require contributions from all levels of society to achieve the SDGs, with government, business and community working together.

The aim of Deakin University's Local SDGs Program is to find ways to implement the SDGs at a community level. We can adapt the SDGs to be relevant to the concerns of a specific community and thus advance sustainability at the local level. Work undertaken in Forrest in 2020 to identify the priority SDGs for the community in Forrest found that there were six SDGs of special importance:
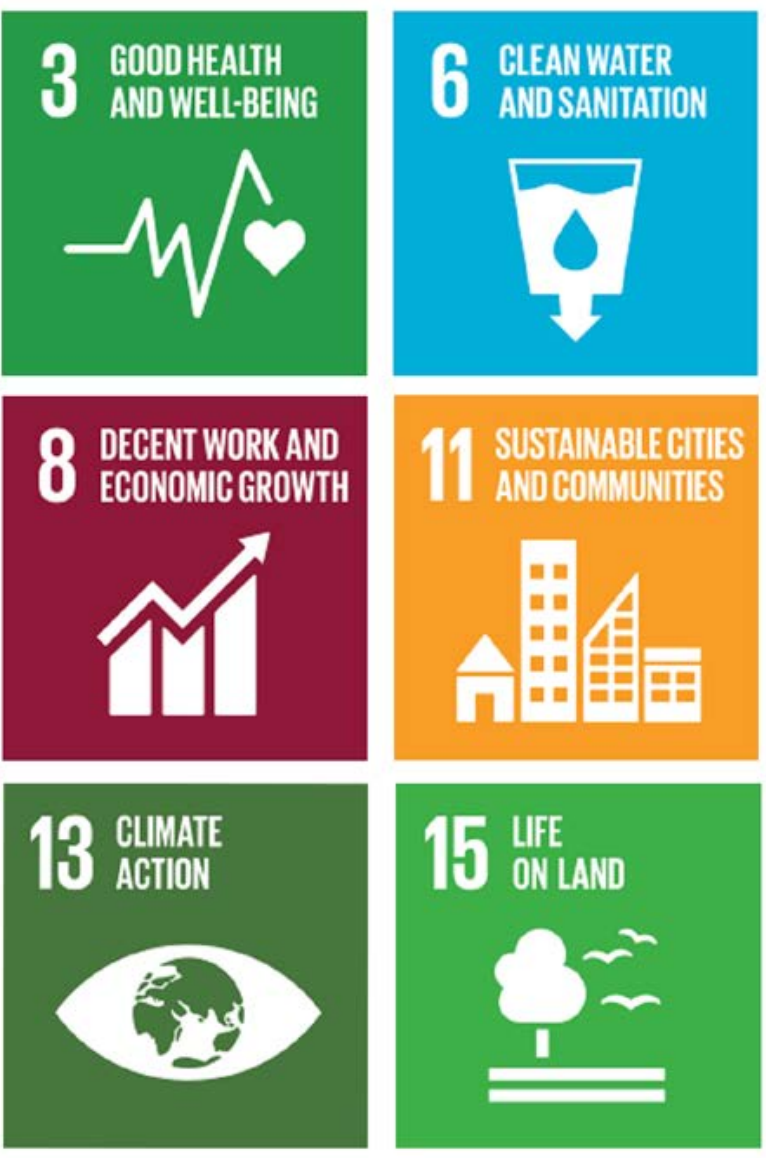
These goals were consolidated and renamed in order to be meaningful for the community. The correspondences between the five community goals and these SDGs are as follows:

\section{COMMUNITY GOAL}

A bushfire safe community

A diverse and sustainable economy

Great public and private infrastructure

A cared-for community

A secure future

\section{SDG}

3 Good Health and Wellbeing, 11 Sustainable Cities and Communities 13 Climate Action, 15 Life on Land

8 Decent Work and Economic Growth, 11 Sustainable Cities and Communities

6 Clean Water and Sanitation, 8 Decent Work and Economic Growth 11 Sustainable Cities and Communities

3 Good Health and Wellbeing, 6 Clean Water and Sanitation

11 Sustainable Cities and Communities, 13 Climate Action

15 Life on Land

3 Good Health and Wellbeing, 6 Clean Water and Sanitation

8 Decent Work and Economic Growth, 11 Sustainable Cities and

Communities, 13 Climate Action, 15 Life on Land

\section{Scenarios}

As part of the Deakin University SDG research, six scenarios were created. These show six possible futures for Forrest depending on how successfully the SDGs were implemented. Shown below are the narratives (stories) for the six different scenarios. Many of the ideas provided by the community during the Deakin community engagements were incorporated into these narratives (although mostly only in the positive scenarios). It is important to realise that these are only potential outcomes and many other futures may arise.

\section{SUSTAINABILITY IN ALL ASPECTS (UTOPIA)}

The town shifts gradually to a more sustainable path. There has been significant take-up of renewable energy, particularly solar panels, and the town generates all its own energy through a local microgrid (SDG 7). The condition of the environment is improving over time thanks to changes in policy and management - for instance, there are strong regulations on land use to avoid environmental trade-offs (SDG 15). Domestic tourism is moderate and well managed to keep the environment pristine, focused on green- and eco-tourism, and niche agriculture such as mushrooms, plus examples of regenerative farming also encourage visitors (SDG 8). The region becomes known for smallscale sustainable farming, and Community Supported Agriculture models (where consumers pay in advance for regular deliveries of produce) are implemented to share the costs and risks of farming with the community (SDG 2). Niche agriculture and international tourism promote a moderate level of international trade at the local scale, although international tourism has trade-offs against carbon intensity, primarily through air travel (SDG 13). The town is susceptible to bushfire and drought but managed burning and sustainable water use mitigate the threat (SDG 6, 13, 15). Additionally, drought-resilient water infrastructure and a sewerage system are built which increases resilience to climate change impacts (SDG 6, 13). Forrest becomes an incubator for climate change resilience and technology research and this encourages the growth of the local economy beyond tourism (SDG 13). At a social level, medical services and excellent health care are available within the township (SDG 3). The population grows slowly through in-migration and an ageing population, and alternative housing options such as co-housing emerge to sustainably house new residents and increase the sense of community (SDG 11). Forrest is a desirable, safe place to live for families with young children and retirees, as poverty and inequality has been reduced/eliminated and equity is high (SDG 1, 10). The community values the Indigenous heritage of the land, recognises traditional owners and adopts traditional land management practices (SDG 10, 15). The community is small, socially engaged, and close-knit, and so have an advantage in being able to pull together to achieve implementation of the SDGs (SDG 17). 


\section{INCLUSIVE GROWTH ATTHE EXPENSE OF THE ENVIRONMENT}

On this pathway, there has been an economic boom, allowing investment in social institutions and the 'lifting up' of many disadvantaged peoples (SDG 1,10). This has occurred in concert with the exploitation of fossil fuel reserves and intensive management of the environment, resulting in an increased pace of climate change (SDG 13, 15). Australia has high fossil fuel reserves and has had minimal take-up of renewable energy, impairing achievement of climate action and sustainable consumption SDGs (SDG 7, 11, 13). In Forrest, results of environmental management include earthmoving to create firebreaks for bushfire prevention and fracking for fossil fuels (SDG 13, 15). These management techniques, combined with climate change, have a negative effect on biodiversity even though improvements are seen in other ways (such as increased bushfire resilience) (SDG 13, 15). Land use regulation leads to a slow decline in the rate

\section{PROSPERITY WITHOUT GROWTH}

The capitalist mantra of growth at all costs has been abandoned in this pathway (SDG 8). There is no drive to grow the town beyond its current capacity. Forrest has excellent health care (SDG 3), a new sewerage system (SDG 6), protection of local ecosystems (SDG 15) and enough jobs, funded by reinvestment of profits into the community (SDG 8). Alternative housing options such as co-housing emerge to house new residents, and policies to limit the use of housing for profit (for rental and tourism) increases available housing supply (SDG 11). Water scarcity is substantially reduced due to water reuse from the new sewerage system and improvements to water collection methods (SDG 6) and the community is resilient to disasters (SDG 13). Forrest is therefore a of native deforestation, replaced with timber plantations (SDG 15). A new sewerage system and drought resilient water infrastructure permits greater numbers of tourists and new residents, while desalinated water is trucked in when required (SDG 6, 8). Agriculture such as dairy and beef farming, and mushroom growing is highly managed and resource intensive; there is a rapid increase in productivity. The region becomes known for small-scale sustainable farming (SDG 2). This, as well as mountain biking, encourages domestic and international tourism to the region. International tourism has trade-offs against carbon intensity, principally from air travel emissions (SDG 8, 13). There are high levels of consumption, materialism, and meatrich diets (SDG 12). There is rapid technology development and Forrest becomes a development hub for new tech, allowing full and productive employment and growth in the local economy (SDG 8). The community

desirable place to live and raise families, although the fertility rate is below replacement and there is social pressure to limit children to one per couple (SDG 12). Economically, all forms of tourism decline as it has too high an impact on climate change (SDG 8), but in its place, Forrest becomes a development hub for climate change adaptation and resilience research, resulting in fulfilling employment and assisting with ecosystem management and disaster resilience (SDG 8, 13). There are renewable energy microgrids in the greater Otway region and electric vehicle chargers available in the town (SDG 7). There is clean and accessible public transport available to travel to local centres such as Colac and Geelong, but travelling long distances is more difficult, and the community values the indigenous heritage of the land and recognises traditional owners and traditional management practices for the local environment (SDG 10,15). Poverty and inequality are significantly reduced for all members of the community, so Forrest is a safe and desirable place to live, and the population of the town grows through migration, births, and an ageing population (SDG 1,2, 10). Medical services are available within the town, and excellent health care improves outcomes post-natally and for elderly people (SDG 3). New housing is built in rezoned land to house new residents (SDG 11). Social cohesion and engagement is high, meaning the community is able to pull together to achieve implementation of the SDGs (SDG 17). The acceleration of climate change due to forces outside of the local level of control limits the successful outcomes from SDG implementation (SDG 13).

becomes a little isolated (SDG 10, 11). The indigenous community assist in protection, restoration and management as stewards of the land and water, and all indigenous rights are recognised and have been enshrined in the constitution (SDG 6, 10 15). Ecosystem protection and a halt to deforestation sees improvements in CO2 capture (SDG $13,15)$. Sustainable agricultural practices and communal agricultural models allow the whole community to share the labour and output of farming (SDG 2). Seed sharing becomes widespread (SDG 2). The community are highly cohesive and engaged, and are focused on achieving the SDGs that do not emphasize economic growth for growth's sake (SDG 17). 


\section{ENVIRONMENTALLY FRIENDLY GROWTH IN A DIVIDED COMMUNITY}

The gap between the haves and have-nots has widened (SDG 10). Poverty and inequality are high and disadvantaged people are crowded out of the town due to rising housing costs (SDG 1, 10, 11). Access to health care is expensive and limited (SDG 3 ), while privileged people moving to Forrest limit the number of children they have as they see this as having a positive impact on sustainability (SDG 12). The local environment is a drawcard for migration into the town and tourism, and thus new and existing residents make efforts to preserve the environment for economic and their own benefits

\section{NO SUSTAINABILITY AGENDA}

This pathway is characterised by an insular perspective. Government policies change to focus on energy (SDG 7) and agricultural security (SDG 2) at the expense of education (SDG 4), health (SDG 3) and the environment (SDG 6, 13, 15). Inequality is high and the community has regressed back to the days of high economic disadvantage (SDG $1,10)$. Consumption is materials intensive and meat consumption is high and unsustainable, and only available to those who can afford it (SDG 12). Low investment and the abandonment of policy and management results in serious degradation of the environment (SDG 6, 15). Likewise, with minimal regulation for land use, deforestation continues, logging and large-scale
(SDG 6, 8, 15). Sustainable agriculture lessens the impact of agriculture on the environment and on climate (SDG 2). Consumption, like many things, is stratified: rich people have better access to sustainable resources while disadvantaged people are more likely to opt for cheaper, resource intensive products (SDG 12). There are plans for a new sewerage system, but there is division over the cost (SDG 6). Renewable energy and electric vehicles are available to those who can afford it, although the cost is prohibitive for many and resource efficiency is uneven across the community (SDG 7, 12). Forrest

agriculture intensifies (SDG 15), and sustainable agriculture practices decline (SDG 2). The effects of climate change have narrowed the window to carry out prescribed burning and increased the community's susceptibility to bushfire (SDG 13, 15). Water use and resources are not managed sustainably and there is no guard against drought (SDG 6). There has been minimal take-up of renewable energy such as solar panels, so unconventional fossil fuel resources (e.g. fracking) are exploited in order to provide energy security (SDG 7). The internet is not reliable, deterring people from starting local businesses, so the economy is neither diverse nor flourishing (SDG 8). There is some domestic tourism, but people avoid visiting in bushfire becomes a development hub for new technologies, including for climate adaptation and resilience - this encourages the growth of the local economy but prices people out of the housing market as prices rise due to demand (SDG 8, 11, 13). Community cohesion and participation is low and stratified: only privileged community members believe that SDG implementation is in the best interests of the community (SDG 17). There is a low chance of successful implementation of the SDGs as an integrated and holistic set of goals in Forrest.

season as the town is not safe or resilient (SDG 8, 13). Health services are not available close by, only in the major centres (Geelong, Melbourne), and they are difficult to access (SDG 3). This has an impact on post-natal health outcomes (SDG 5). Indigenous rights and recognition are no longer considered at all (SDG 10). Land is rezoned for new housing to house new residents (SDG 11), but Council are unwilling to consider sewerage for the township so any new housing developments must have septic systems (SDG 6). The community is small and close-knit; few community members are convinced that SDG implementation is in the best interests of the community, so there is a low chance of successful SDG implementation (SDG 17). 


\section{BUSINESS AS USUAL(BAU)}

This is a path in which not much changes from the status quo. The population grows slowly, through migration, births and an ageing population. Health care is excellent, although access to health services is somewhat limited within the town (SDG 3). Forrest is a safe place to live, and an attractive prospect for families with young children and 'treechanging' retirees (SDG 11). However, the escalation of house prices and lack of available rental properties are crowding people out of town; young people will generally move away from the town for university or work once coming of age, leaving a demographic gap in the 18-30 year old range (SDG 11, 12). There are pockets of disadvantage but the community support each other when they are in need (SDG 1, 10). Indigenous rights are paid lip service and little changes for indigenous recognition (SDG
10). Domestic tourism is moderate, focused on large-scale events and mountain biking, and investment in mountain bike trails and public amenities lowers the impact on the environment (SDG 8, 15). International tourism has trade-offs against carbon intensity (from air travel, SDG 13), but locally there are positive signs, such as investigation of a renewable energy microgrid (SDG 7). To diversify the economy, there has been an attempt to promote Forrest as a technology development hub, but it is hampered by poor internet access (SDG 8). Consumption is materials intensive, and diets contain unsustainable levels of meat (SDG 12). The environment continues to experience degradation, however regulations on land use lead to a slow decline in the rate of deforestation, which eventually ceases (SDG 6, 13, 15). Small-scale agriculture is locally sustainable (SDG
2), and while there is an increase in large-scale agricultural productivity, there is not a concurrent increase in employment (SDG 8). Managed burns reduce bushfire risk (SDG $13,15)$, and restrictions on water use protects against drought (SDG $6,13)$, however water supplies are vulnerable to sustained drought (SDG 6). The Forrest community take the initiative on climate resilience projects as they receive little support from Council or government (SDG 13). The town is unsewered; Barwon Water are investigating reticulated sewerage but it will come at a cost (SDG 6). The community is small and close-knit, but not all community members are convinced that the SDGs are in the best interests of the community, implying a moderate chance of successful holistic SDG implementation (SDG 17).

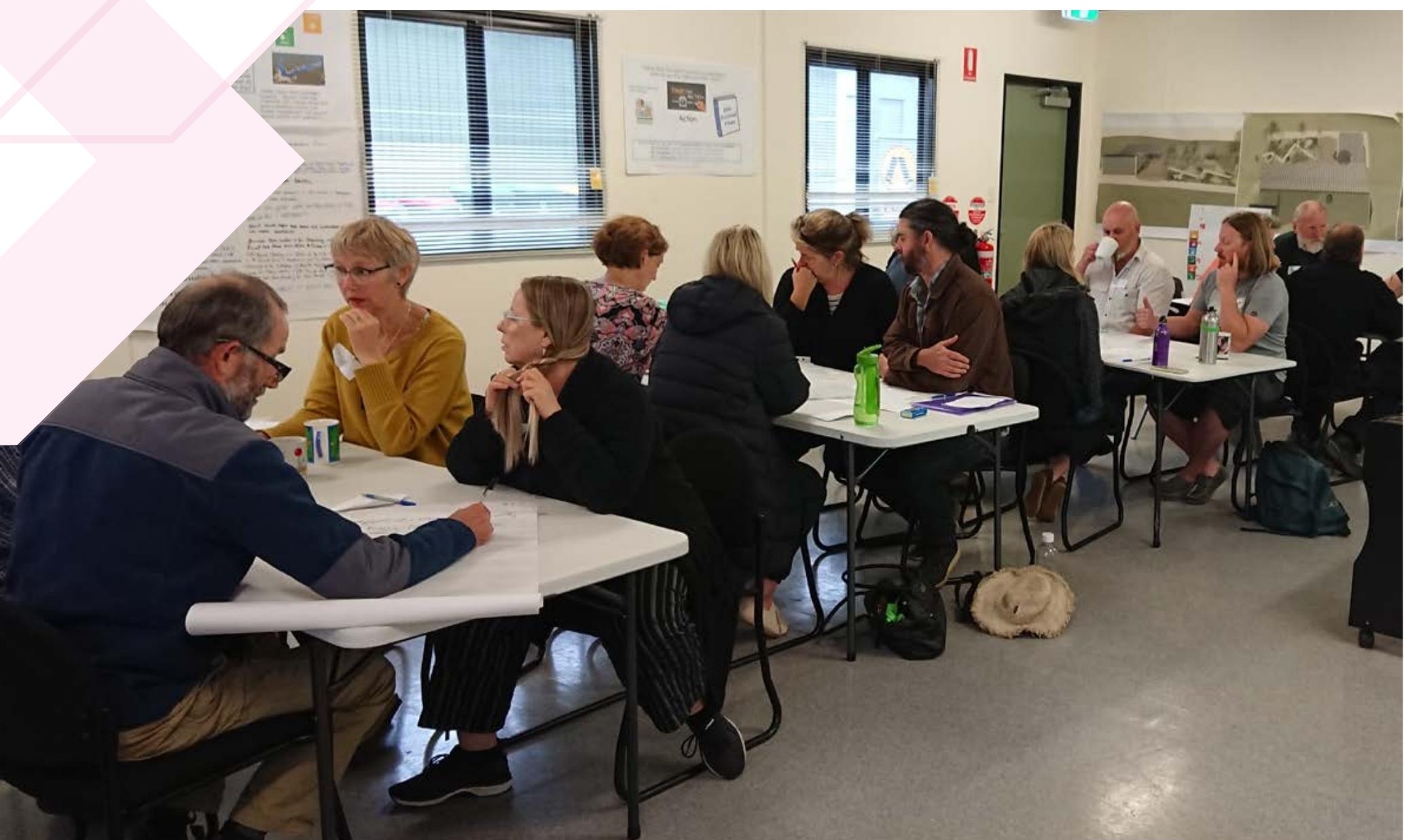




\section{Forrest Futures - Newsletters of the future}

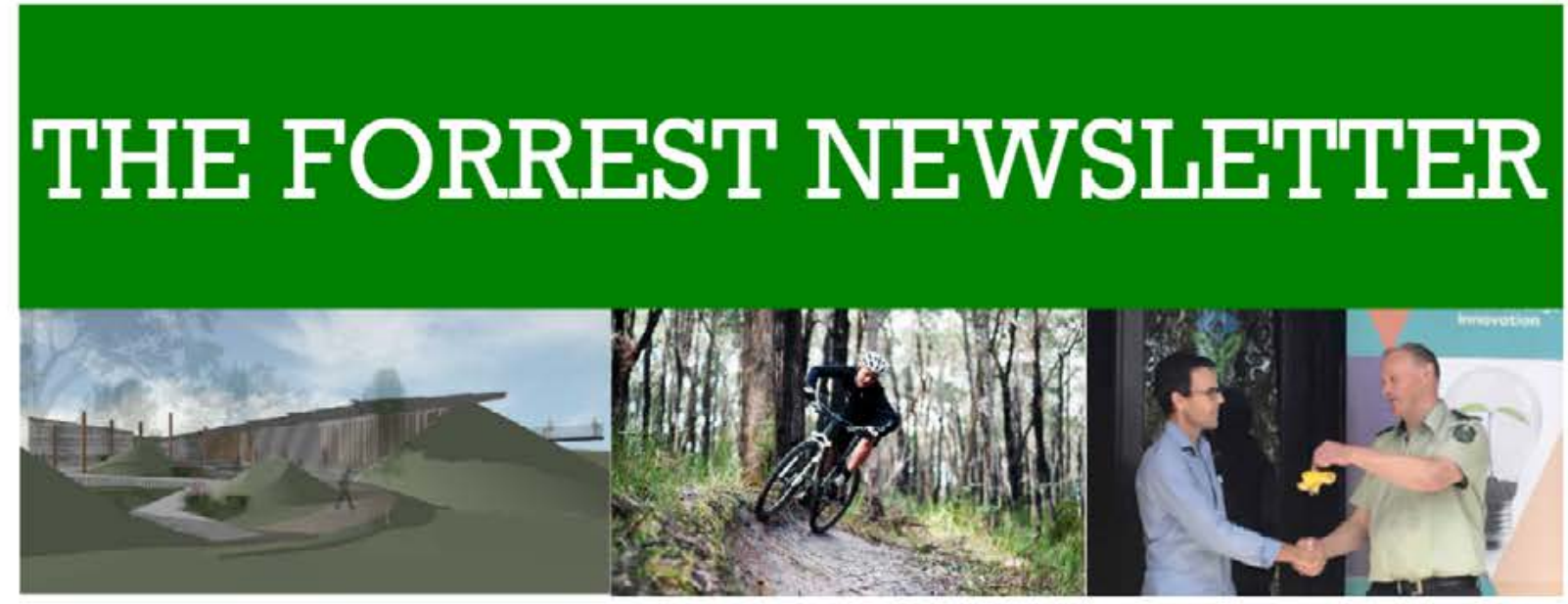

\section{FORREST FUTURES}

\section{YEARS SINCE STRATEGIC PLAN IMPLEMENTED}

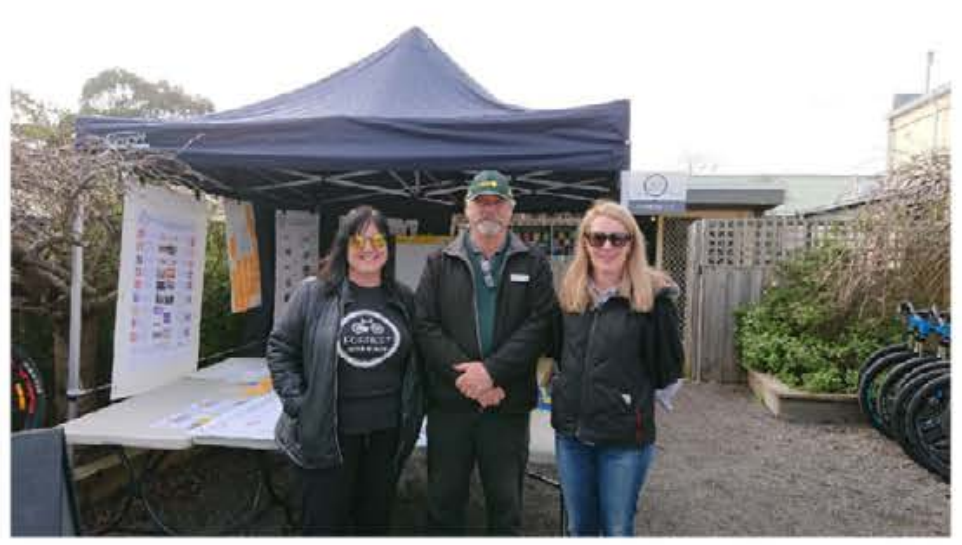

It has been ten years since the Forrest Futures II strategic plan was launched. There have been big changes in town on the road to becoming a more sustainable community.

On a walk around Forrest, we can see some of the changes. The Terminus Hotel has been overhauled to take into account its history and the environment. The Forrest Common and playground finally got some attention and is now beautifully landscaped. Alongside the river there are boutique shops and multi-use walking space.

People are happy and friendly, and there are many economically viable businesses supporting tourism and the environment. The place is buzzing with solar powered cars, powered by energy generated by the local microgrid. The hub is central to the tourist and community experience of our natural environment and there is a variety of tours available. Art and artisans are everywhere. Read on for more of the changes in town!

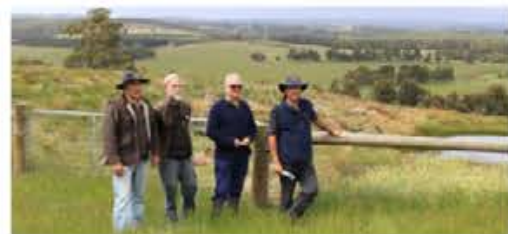

International visitors spend 1 week in Forrest

100 guests visited Forrest and were enthralled. They especially noted the general tidiness of the town, the streetscaping, and the edible landscape.

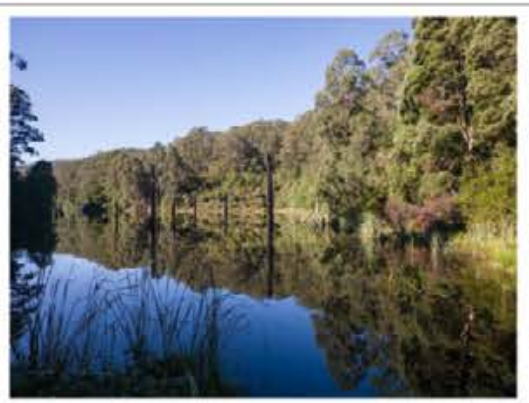

The town is now a leader in sustainable energy, food sharing and care of all citizens - from the very young to the elders.

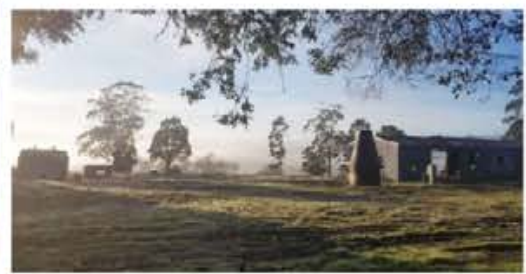

The new Forrest Brewery finally evicted the alpacas and opened the new site in 2025 - it took ten years, but Sharon and Matt finally got there. 


\section{THE FORREST NEWSLETTER}

-10 YEARS ON-
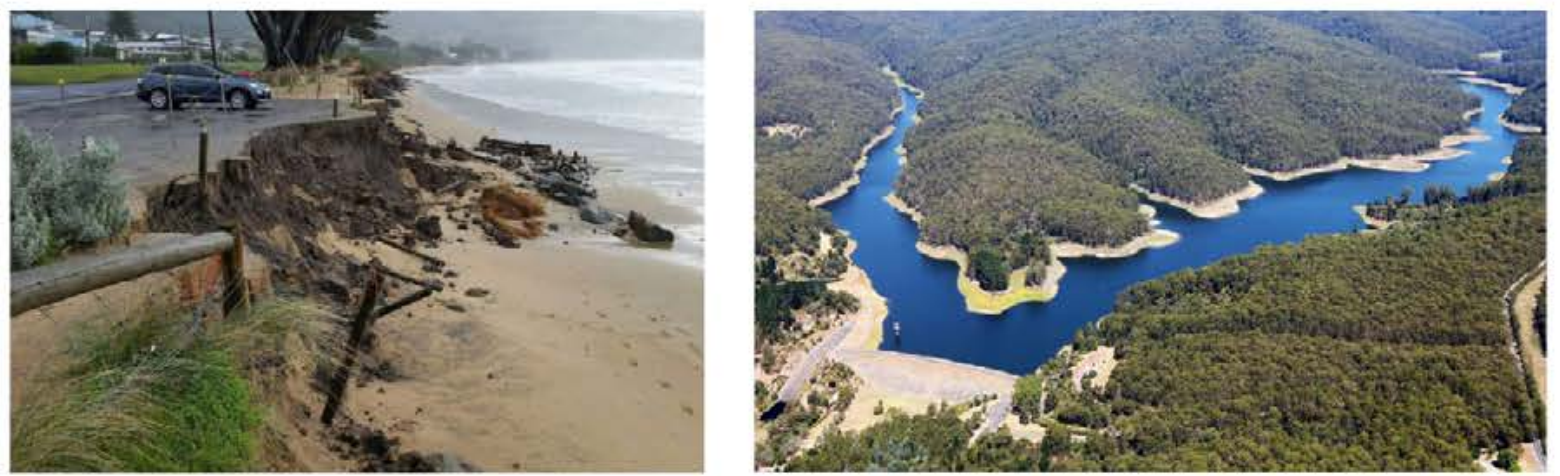

\section{CLOSED FOR 2 YRS SOLAR PV ARRAY OPENED}

\section{GREAT OCEAN ROAD}

Long term closure of the Great Ocean Road due to sea level rises and landslides which the State government can no longer afford to resolve. Forrest is now the main access road to Apollo Bay and the 12 Apostles.

\section{VAST ARRAY IN FORREST}

On Monday 23 Nov, 500 people attended the opening of a vast solar PV array on West Barwon Reservoir which will generate enough electricity to power 1000 homes.

The new microgrid provides solar power connectivity-including electric self-drive, community-owned cars. Elderly can now easily get to Colac for shopping and appointments.

\section{STRUCTURE PLAN REVIEW}

Plans announced by minister regarding the reopening of a Forrest to Birregurra light rail link. Mayor Andrew Evans cuts ribbon on light rail opening.

\section{FIRES}

2027 fires impacted the township and community of Forrest but Forrest Neighbourhood Safer Place and Gateway Centre provided refuge for CFA captain Bob Brooks and team. Community recovery was enabled through resilience of community.
Structure plan review results in changes to the 100 acre rule - small 10 acre allotments released to support a changing population. Multiple houses on LA2 blocks enable multi-generational living. All new developments require low-income housing and supported accommodation.

\section{FORREST HOPS}

Forrest Hop co-operative now rivals Yakaruer Valley Hops. Export of hop crops provide another source of employment and destination brand for Forrest.

\section{WASTE WATER}

Waste water resource brings new vision agribusiness to mountain town.$$
\text { HCL CENTRE }
$$

History and Cultural Learning Centre celebrates $5^{\text {th }}$ birthday. Local elders of early settlers and indigenous traditional owners work together to build comprehensive understanding of the Otways.

\section{CLIMATE CHANGE INNOVATION}

Forrest to commence innovative New Green Deal project which will see employment opportunities for job seekers to train as park rangers and firefighters.

\section{FORREST SCHOOL}

Bush kinder expands to whole community and everyone adopts "Gumboot Friday". 


\section{THE FORREST NEWSLETTER}

\section{- 10 YEARS ON-}

\section{THE}

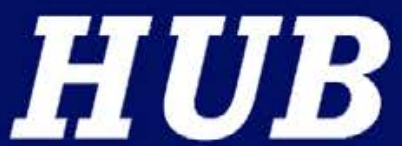

\section{WORKSHOPS THIS} MONTH:

$1^{\text {tt }}$ Saturday: How to microdose safely: Forrest Mushies

$2^{\text {nd }}$ Saturday: Vertical Food Walls

$3^{\text {rd }}$ Saturday: Microhydro electricity

$4^{\text {th }}$ Satuday: How eating beef can help save the planet

Every Sunday: Farmers and produce market selling local produce, wine, gin, cheese, mushies and other medicinals

\section{COMMUNITY}

\section{SPACE AT THE}

\section{HUB}

- Interactive displays

- Neighbourhood Safer Place

- Meeting rooms

- Cafe

- Tours and experiences

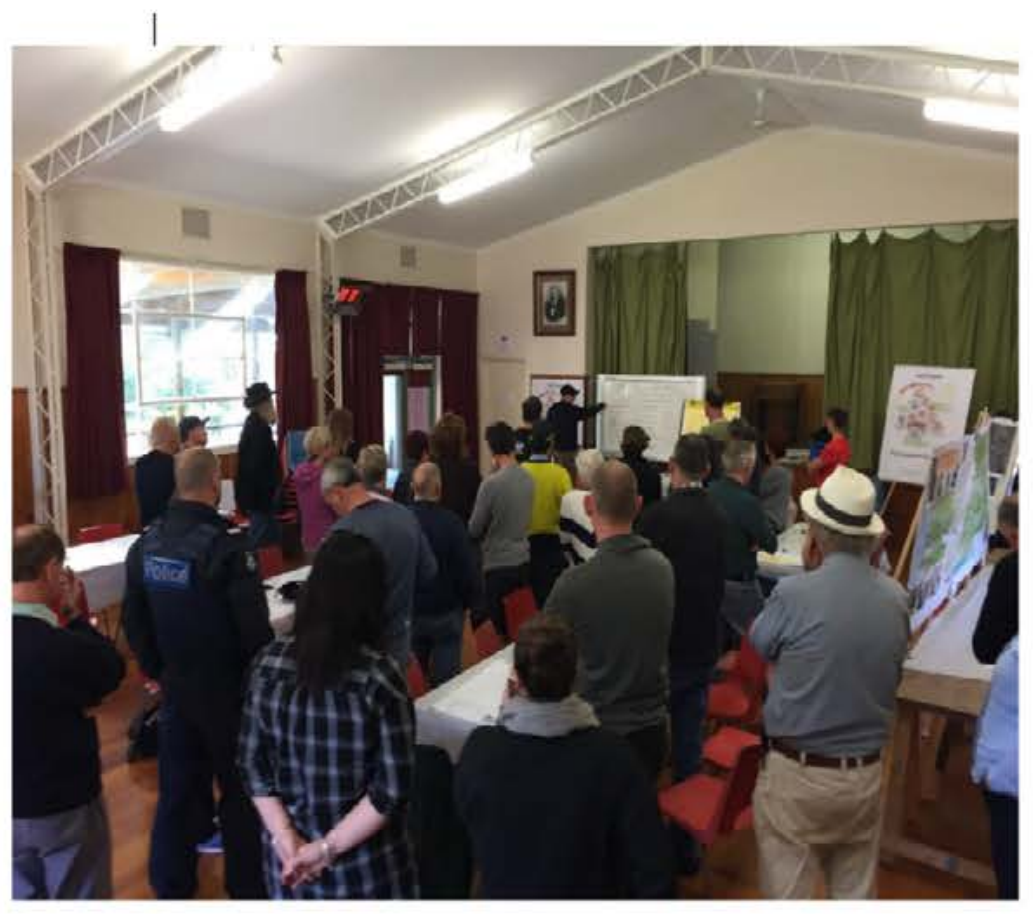

SINCE 2020

\section{FORREST'S ACHIEVEMENTS}

We have celebrated the accomplishment of $100 \%$ of Forrest's houses having solar panels, water tanks and full severage. In addition, the mayor cut the ribbon on our electric vehicle charging station.

The community centre continues to house indigenous land management programs with government

agencies and local people working together on

Otways land management and conservation.

New public art and sculpture that relates to the natural environment was commissioned and installed.

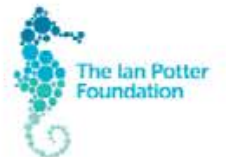

Forrest won most beautiful town of the Otways award. The Terminus renovation was a great success and the view from the verandah overlooks the new, sustainable houses that have been completed on the properties to the north.

Bumper harvests in the community garden mean the weekly share food market is heaving The gin distillery has been a major success.

Community gardens encourage elderly residents to remain in Forrest. Bev Frizon's $100^{\text {th }}$ birthday was celebrated at the Neighbourhood garden.

There was a major mountain bike event. 1,000 people came to town. All waste was managed through the town recycling hub.

Forrest joined the Otways Conservation Alliance.

Forrest is recognised as a leader in climate change technologies and environmental integration.

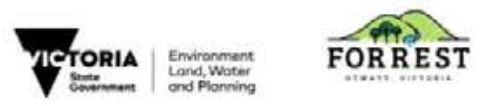




\section{Appendix \#4}

Table 4.1: Community feedback

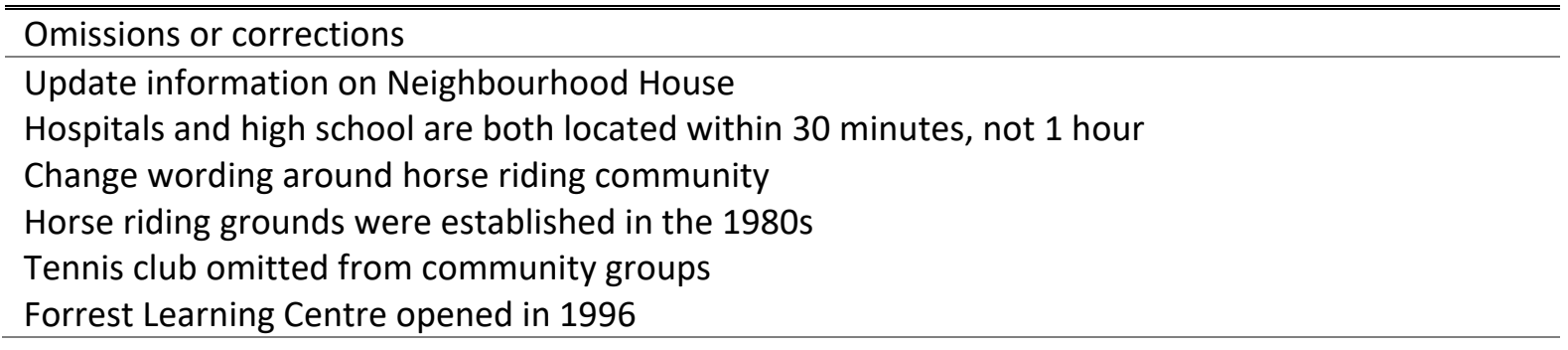

Content reframing

More of an emphasis on the healthy environment outside of the tourism context

The plan should be more socially oriented

Plan is for Forrest and District but there is little information regarding the District

Reorganise sections so that economy is not listed first

Community Advantage section only discusses tourism

A broader range of Human Capital should be explored (only 3 groups mentioned)

Projects should involve the community and achieve visible results

Include discussion of diversifying the economy to avoid having Forrest become an exclusively

tourist town

More recognition of Indigenous people and culture

Give more prominence to local voices

Include accountability for this plan, as well as the 2012 plan

Water authority feedback

\section{Executive Summary - page 7-Integrated Water Management Plan Incorporating New Wastewater Infrastructure}

Barwon Water is committed to an ongoing partnership with the Forrest community and Colac Otway Shire as we investigate opportunities for wastewater improvements in Forrest. Whilst we are dedicated to working towards a solution together, we are realistic about the timeframes involved in the investigation and funding of a proposed wastewater scheme. This process may take years and has not stalled as stated in the draft Plan. We ask the community to continue to work together with us and Colac Otway Shire on this project in a coordinated way.

The purpose of the current economic analysis, which is underway, is to identify the appropriate funding model to deliver the preferred wastewater option. We suggest that the preparation of an integrated water management (IWM) plan for Forrest maybe be a long-term goal for the community to consider, if it wishes. Further we suggest that to deliver an IWM plan for Forrest at this point, which incorporates wastewater, would complicate and dilute the focus on the pressing issue, being wastewater, not to mention greatly extend the time taken to deliver needed wastewater improvements. 


\section{Response}

We have replaced the text describing the project as stalled with "[Barwon Water] is currently undertaking an economic analysis to identify an appropriate funding model." We have also clarified the distinction between the wastewater strategy and an Integrated Water Management Plan and modified the final sentence to read "However, an integrated water management plan is relatively new idea and incorporating it within the wastewater strategy would delay the wastewater project. Wastewater infrastructure is an urgent priority."

\section{Community Ideas for Town Improvement Towards 2030 - page 12}

We are very supportive of the community being engaged and taking ownership by suggesting ideas which will potentially improve the town and district.

We note one idea put forward around potentially opening up access to the West Barwon Reservoir for non-motorised recreation such as canoes and kayaks. While this idea may appear straightforward on the face of it, it may be very difficult to actually achieve. There is a range of obstacles or issues which would need to be overcome first such as potential risks to drinking water quality, operational and capital expenses (both on site and in the water treatment process) and government policy around protection of the catchment.

\section{Response}

We acknowledge that recreation on West Barwon Reservoir would be difficult to achieve, but we believe that this presents a recreational opportunity that we would like Barwon Water to support. This idea was not included in the Plan as an idle suggestion - co-author Sharon Bradshaw has previously presented these ideas to a Barwon Water board meeting.

\section{Topography and Landscape - page 23 - Boundary Creek}

The draft text in this section is largely accurate, however there is one sentence we would suggest is reviewed and reworded to improve accuracy, being:

["Ecological impacts of this have included loss and/or reduction of fish, crustacean and mammal species in the Barwon River and its creeks; fish kills along the Barwon River; bushfires in the peat wetlands; and habitat erosion caused by toxic flows."]

This is a broad statement not supported by scientific evidence. Based on the studies undertaken to date, ongoing impacts from Big Swamp are confined to the downstream reach of Boundary Creek and the Barwon River immediately downstream of Boundary Creek. It is not impacting the whole of the Barwon River and its creeks as inferred by the current wording.

We note mention in this section that the Remediation and Environmental Protection Plan will run until 2023. To clarify this, this Plan does not technically have an end date but rather we anticipate seeing successful outcomes from remediation within 10 years of implementation. The majority of the actions will be implemented by 2023 , however ongoing monitoring will continue well beyond 2023.

\section{Response}

We have modified the sentence identified to read "Ecological impacts of this have included loss and/or reduction of fish, crustacean and mammal species in the Barwon River and its creeks, and fish kills along the Barwon River; although sampling in 2020 indicated that the river has recovered from the 2016 fish kill event." We have also modified the last sentence of this section discussing the time 
frame of the remediation project to: "This plan will run until 2023, and monitoring will continue beyond this time. Improvements are anticipated within 10 years of the commencement of remediation".

\section{Recent Projects in Forrest and District - page 40 - Forrest Wastewater Investigation} We suggest you might consider adding "... and Economic Assessment" to the title of this section.

To confirm, so far the investment in this project has been in the order of $\$ 200,000$ and the current estimate of the capital cost is $\$ 10.1$ million. We would prefer that the Plan didn't use the work 'ask' in reference to 'total infrastructure ask'.

\section{Response}

As suggested, we have changed the heading to add "...and Economic Assessment" and changed the subheading from "total infrastructure ask" to "total infrastructure estimate."

\section{Drivers for Change - page 53 - Wastewater}

We suggest that you consider re-wording this paragraph in relation to any perceived limitations on additional development in town resulting from ageing septic systems. While we understand the intention of the point being made, this is not actually the case, as development could go ahead provided it complies with Council's wastewater management guidelines.

\section{Response}

With respect to limitations on development in Forrest, we submit that there are very few developments which would be able to meet Council's wastewater management guidelines due to failing septic systems at the current time. [Text here detailing which properties cannot currently be developed.]

We stand by our statement that insufficient wastewater management in Forrest is a significant limiting factor on housing and economic development. Further to this, we would like to reemphasise to Barwon Water the need for urgency and speed in resolving the wastewater issue, as many residents are sceptical of a positive outcome. 


\section{Appendix \#5}

Table 5.1: the list of community objectives and community goals which the objective addresses

\begin{tabular}{|c|c|}
\hline Objectives & Goals the objective addresses \\
\hline & Five goals \\
\hline $\begin{array}{l}\text { Forrest Gateway to the Otways Centre } \\
\text { (incorporating a bushfire place of last resort) }\end{array}$ & $\begin{array}{l}\text { Bushfire Safe, Economy, Infrastructure, } \\
\text { Cared-for Community, Secure Future }\end{array}$ \\
\hline $\begin{array}{l}\text { Change town planning character overlay (post- } \\
\text { bushfire) }\end{array}$ & $\begin{array}{l}\text { Bushfire Safe, Economy, Infrastructure, } \\
\text { Cared-for Community, Secure Future }\end{array}$ \\
\hline $\begin{array}{l}\text { Integrated water management plan (water supply, } \\
\text { tanks, reuse and stormwater) }\end{array}$ & $\begin{array}{l}\text { Bushfire Safe, Economy, Infrastructure, } \\
\text { Cared-for Community, Secure Future }\end{array}$ \\
\hline $\begin{array}{l}\text { Improve stability of power supply (outages occur } \\
\text { regularly) }\end{array}$ & $\begin{array}{l}\text { Bushfire Safe, Economy, Infrastructure, } \\
\text { Cared-for Community, Secure Future }\end{array}$ \\
\hline \multirow[t]{2}{*}{$\begin{array}{l}\text { Improve internet access (mobile and fixed) and } \\
\text { communications infrastructure generally }\end{array}$} & $\begin{array}{l}\text { Bushfire Safe, Economy, Infrastructure, } \\
\text { Cared-for Community, Secure Future }\end{array}$ \\
\hline & Four goals \\
\hline $\begin{array}{l}\text { Housing options for local workers, including } \\
\text { encouraging more permanent housing at caravan } \\
\text { park }\end{array}$ & $\begin{array}{l}\text { Economy, Infrastructure, Cared-for } \\
\text { Community, Secure Future }\end{array}$ \\
\hline $\begin{array}{l}\text { Options for farms to build second dwellings (change } \\
\text { to zoning laws) }\end{array}$ & $\begin{array}{l}\text { Economy, Infrastructure, Cared-for } \\
\text { Community, Secure Future }\end{array}$ \\
\hline More permanent housing options & $\begin{array}{l}\text { Economy, Infrastructure, Cared-for } \\
\text { Community, Secure Future }\end{array}$ \\
\hline $\begin{array}{l}\text { Enabling housing for long-term residents rather } \\
\text { than B\&Bs }\end{array}$ & $\begin{array}{l}\text { Economy, Infrastructure, Cared-for } \\
\text { Community, Secure Future }\end{array}$ \\
\hline Increased options for short-term accommodation & $\begin{array}{l}\text { Economy, Infrastructure, Cared-for } \\
\text { Community, Secure Future }\end{array}$ \\
\hline $\begin{array}{l}\text { Upgrade facilities at Mountain Bike Trail hub for } \\
\text { tourist and community use }\end{array}$ & $\begin{array}{l}\text { Economy, Infrastructure, Cared-for } \\
\text { Community, Secure Future }\end{array}$ \\
\hline $\begin{array}{l}\text { Better access to public transport (e.g. use the rail } \\
\text { trail to link to Birregurra or improve bus service) }\end{array}$ & $\begin{array}{l}\text { Economy, Infrastructure, Cared-for } \\
\text { Community, Secure Future }\end{array}$ \\
\hline $\begin{array}{l}\text { Build a new caravan park at the Rec Reserve/use it } \\
\text { as camping overflow at times of high tourist } \\
\text { congestion }\end{array}$ & $\begin{array}{l}\text { Economy, Infrastructure, Cared-for } \\
\text { Community, Secure Future }\end{array}$ \\
\hline $\begin{array}{l}\text { Access for non-powered boats including canoes and } \\
\text { kayaks on Barwon Reservoir, either open access or } \\
\text { permitted access for annual triathlon }\end{array}$ & $\begin{array}{l}\text { Economy, Infrastructure, Cared-for } \\
\text { Community, Secure Future }\end{array}$ \\
\hline \multirow[t]{2}{*}{$\begin{array}{l}\text { Epic Mountain Bike Trail around the perimeter of } \\
\text { the Barwon Reservoir }\end{array}$} & $\begin{array}{l}\text { Economy, Infrastructure, Cared-for } \\
\text { Community, Secure Future }\end{array}$ \\
\hline & Three goals \\
\hline Roundabout at Brewery corner \& proper crossing & $\begin{array}{l}\text { Economy, Infrastructure, Cared-for } \\
\text { Community }\end{array}$ \\
\hline $\begin{array}{l}\text { Creative in-town wayfinding signage designed with } \\
\text { local art groups }\end{array}$ & $\begin{array}{l}\text { Economy, Infrastructure, Cared-for } \\
\text { Community }\end{array}$ \\
\hline
\end{tabular}




\begin{tabular}{|c|c|}
\hline Objectives & Goals the objective addresses \\
\hline Art gallery and studio (perhaps at old CFA building) & $\begin{array}{l}\text { Economy, Infrastructure, Cared-for } \\
\text { Community }\end{array}$ \\
\hline $\begin{array}{l}\text { Upgrade hall to remove asbestos and improve } \\
\text { facility for performances }\end{array}$ & $\begin{array}{l}\text { Economy, Infrastructure, Cared-for } \\
\text { Community }\end{array}$ \\
\hline Upgrade heating/air conditioning at the hall & $\begin{array}{l}\text { Economy, Infrastructure, Cared-for } \\
\text { Community }\end{array}$ \\
\hline $\begin{array}{l}\text { Connect Barwon Downs and Forrest with a } \\
\text { walking/horseriding/ bike track (not necessarily rail } \\
\text { trail, possibly along channel) }\end{array}$ & $\begin{array}{l}\text { Economy, Infrastructure, Cared-for } \\
\text { Community }\end{array}$ \\
\hline $\begin{array}{l}\text { Continue Rail Trail to Barwon Downs and then } \\
\text { Birregurra }\end{array}$ & $\begin{array}{l}\text { Economy, Infrastructure, Cared-for } \\
\text { Community }\end{array}$ \\
\hline Public art on the water-tower & $\begin{array}{l}\text { Economy, Cared-for Community, Secure } \\
\text { Future }\end{array}$ \\
\hline Street art on reservoir wall & $\begin{array}{l}\text { Economy, Cared-for Community, Secure } \\
\text { Future }\end{array}$ \\
\hline Health and wellbeing precinct & $\begin{array}{l}\text { Economy, Cared-for Community, Secure } \\
\text { Future }\end{array}$ \\
\hline Arts trail \& sculpture walk along Barwon River & $\begin{array}{l}\text { Economy, Cared-for Community, Secure } \\
\text { Future }\end{array}$ \\
\hline $\begin{array}{l}\text { Investigate alternative crops to encourage new } \\
\text { businesses }\end{array}$ & $\begin{array}{l}\text { Economy, Cared-for Community, Secure } \\
\text { Future }\end{array}$ \\
\hline $\begin{array}{l}\text { Stock the Barwon Reservoir with estuary perch, a } \\
\text { native fish species }\end{array}$ & $\begin{array}{l}\text { Economy, Cared-for Community, Secure } \\
\text { Future }\end{array}$ \\
\hline $\begin{array}{l}\text { All-abilities infrastructure access to the reservoir for } \\
\text { fishing }\end{array}$ & $\begin{array}{l}\text { Economy, Infrastructure, Cared-for } \\
\text { Community }\end{array}$ \\
\hline $\begin{array}{l}\text { Swimming hole, swimming platform on the river's } \\
\text { edge, downstream from the catchment }\end{array}$ & $\begin{array}{l}\text { Economy, Infrastructure, Cared-for } \\
\text { Community }\end{array}$ \\
\hline $\begin{array}{l}\text { Recognition and preservation of original Forrest } \\
\text { Station site }\end{array}$ & $\begin{array}{l}\text { Economy, Infrastructure, Cared-for } \\
\text { Community }\end{array}$ \\
\hline More action on wastewater & Economy, Infrastructure, Secure Future \\
\hline Wastewater treatment (for reuse e.g. crops) & Economy, Infrastructure, Secure Future \\
\hline Waste to energy & Economy, Infrastructure, Secure Future \\
\hline $\begin{array}{l}\text { Weed eradication program (e.g. holly and } \\
\text { blackberry removal between Hennigan Cres \& } \\
\text { reservoir); set up Forrest LandCare to do this in } \\
\text { partnership with DELWP }\end{array}$ & $\begin{array}{l}\text { Bushfire Safe, Economy, Cared-for } \\
\text { Community }\end{array}$ \\
\hline $\begin{array}{l}\text { Caravan park that retains its affordability and } \\
\text { community connectedness }\end{array}$ & $\begin{array}{l}\text { Infrastructure, Cared-for Community, } \\
\text { Secure Future }\end{array}$ \\
\hline $\begin{array}{l}\text { Roof-top solar program for community observing } \\
\text { social equity }\end{array}$ & $\begin{array}{l}\text { Infrastructure, Cared-for Community, } \\
\text { Secure Future }\end{array}$ \\
\hline $\begin{array}{l}\text { Fresh inspection of buildings and sites for heritage } \\
\text { listing }\end{array}$ & $\begin{array}{l}\text { Infrastructure, Cared-for Community, } \\
\text { Secure Future }\end{array}$ \\
\hline $\begin{array}{l}\text { Retain community involvement/management of the } \\
\text { Forrest Common and caravan park sites }\end{array}$ & $\begin{array}{l}\text { Infrastructure, Cared-for Community, } \\
\text { Secure Future }\end{array}$ \\
\hline $\begin{array}{l}\text { Expand the Common to full } 5 \text { acres/Develop Forrest } \\
\text { Common in line with Master Plan }\end{array}$ & $\begin{array}{l}\text { Infrastructure, Cared-for Community, } \\
\text { Secure Future }\end{array}$ \\
\hline
\end{tabular}




\begin{tabular}{|c|c|}
\hline Objectives & Goals the objective addresses \\
\hline & Two goals \\
\hline Bushfire place of last resort & Bushfire Safe, Infrastructure \\
\hline Second CFA truck & Bushfire Safe, Cared-for Community \\
\hline Prohibit camping on Forrest Common & Bushfire Safe, Cared-for Community \\
\hline Greater access to tennis courts & Economy, Cared-for Community \\
\hline Citizen science projects/school education & Economy, Cared-for Community \\
\hline Create a Forrest History Centre & Economy, Cared-for Community \\
\hline $\begin{array}{l}\text { Coordinated plan to promote Forrest as a foodie } \\
\text { destination }\end{array}$ & Economy, Secure Future \\
\hline Solar farm & Infrastructure, Secure Future \\
\hline Public toilet improvements & Infrastructure, Cared-for Community \\
\hline $\begin{array}{l}\text { Better road signage on Turner Dve }(40 \mathrm{~km} / \mathrm{hr}) \text {, traffic } \\
\text { calming measures (e.g. speed humps) }\end{array}$ & Infrastructure, Cared-for Community \\
\hline $\begin{array}{l}\text { Footpath on eastern side of road from town to } \\
\text { Barwon Reservoir (trail on western side of road plus } \\
\text { fire break could be repurposed to avoid destroying } \\
\text { bushland) }\end{array}$ & Infrastructure, Cared-for Community \\
\hline Address dangerous crossing at Grant St and Tip Rd & Infrastructure, Cared-for Community \\
\hline $\begin{array}{l}\text { Community gardens (possibly at school or caravan } \\
\text { park) }\end{array}$ & Cared-for Community, Secure Future \\
\hline $\begin{array}{l}\text { Link the school with the arts proposals (listed } \\
\text { above) }\end{array}$ & Cared-for Community, Secure Future \\
\hline \multirow[t]{2}{*}{ Energy microgrid(s) } & Cared-for Community, Secure Future \\
\hline & One goal \\
\hline Remove native trees from roadsides & Bushfire Safe \\
\hline Service road carparking & Economy \\
\hline Bus parking & Economy \\
\hline $\begin{array}{l}\text { Town beautification (e.g. tree planting on } \\
\text { Henry/Station Sts) }\end{array}$ & Cared-for Community \\
\hline
\end{tabular}

The list of community priorities

To help achieve the five goals, a number of priorities have been identified by the community. Some are the responsibility of government and council, public or private enterprises and organisations, and others may be priorities the community can take on. Many priorities are in progress and completion could pave the way for further ideas. Investments and project decisions should be made in line with the goals, values and priorities and with respect to the outcomes of extensive consultations that have informed this Plan. The impact of the Plan and meeting these goals will reach far beyond the population of Forrest \& District.

Gateway to the Otways Centre: The Gateway to the Otways Centre is a community-led initiative for driving climate and economic adaptation, resilience and recovery, while celebrating the unique and accessible beauty of the Otway Ranges. The project involves constructing a best-practice, fire- 
adapted building which will have everyday use as a community and visitor hub, a research and learning centre and a co-located CFA fire station. The design enables the Centre to operate as a Bushfire Place of Last Resort and will help achieve all five community goals.

Integrated Water Management Plan incorporating new wastewater infrastructure: The lack of suitable wastewater facilities in Forrest is an impediment to community development and poses a public health risk. Installing new wastewater infrastructure will advance many other improvements, such as residential development and health and wellbeing. Developing a fully integrated water management plan will set up the community for a sustainable future and help achieve all five community goals. Wastewater infrastructure is an urgent priority.

Mountain Bike Trails Design Project: Upgrading the mountain bike trail facilities and trail network will help achieve four community goals. Upgraded trails will also benefit horse-riders and walkers. This project has been through extensive community consultation, and with funding, can be realised quickly.

Revitalised Forrest Common (and Forrest Caravan Park) precinct: The Forrest Common located on Station Street is a 1.5ha township parkland that is well used by the community and visitors and includes a playground, tennis courts, car park, picnic and BBQ facility, and expansive lawn area. A Master Plan developed by the community and Colac Otway Shire in 2019 to revitalise this precinct has been endorsed and is awaiting funding. The Forrest Caravan Park is a leased area adjoining this precinct and is due for lease renewal in 2021. Addressing these will help achieve four community goals.

Improve communications infrastructure: Many residents noted frustrations with poor internet and mobile service. Not only are these safety concerns for residents - bushfire safety information is increasingly moving online, and the defunding of the $A B C$ puts their crucial bushfire services at risk. It is also an impediment to local business growth and affects education opportunities for youth and the whole community. This will help with all five goals.

Changes to zoning laws to allow residential development on agricultural land adjacent to township boundary: The lack of housing for residents is a central problem in the community. Changes to zoning laws is a step toward fixing this problem. Development adjacent to and within township boundaries will support the school and local businesses and provide access to services where a bushfire place of last resort can be provided and the CFA and Police are present. This will facilitate development of housing both for locals and tourist accommodation and will help with four community goals.

Regular public transport links: A once-weekly bus to Birregurra, Colac and Apollo Bay is a clear lack of accessibility. More frequent bus services to local centres will provide mobility for local residents and reduce reliance on private cars, improving health and wellbeing. This will help with four community goals.

Community garden: An integrated community garden with the Forrest Learning Centre will help with two community goals, and will be easily achievable as the garden at the school already exists. Second CFA truck: An appropriately resourced volunteer firefighting brigade fulfils two community goals and will go a long way toward assisting with bushfire safety, and is a 'quick win' for which there has been strong community support and fundraising. 